Supporting Information for:

\title{
An $S_{10}$-symmetric 5-fold Interlocked [2]Catenane
}

Tanya K. Ronson, ${ }^{\dagger}$ Yujia Wang, ${ }^{\ddagger}$ Kim Baldridge, ${ }^{*, \ddagger}$ Jay S. Siegel ${ }^{*, \ddagger}$ and Jonathan R. Nitschke $e^{*, \dagger}$ †Department of Chemistry, University of Cambridge, Lensfield Road, Cambridge, CB2 $1 E W$, United Kingdom.

$\ddagger$ Health Sciences Platform, Tianjin University, 92 Weijin Road, Nankai District, Tianjin300072, China.

\section{Table of Contents}

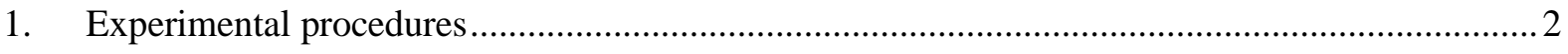

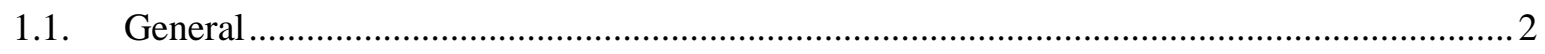

1.2. Synthesis and characterization of sym-pentakis(4-aminothiophenyl)corannulene (A) .........2

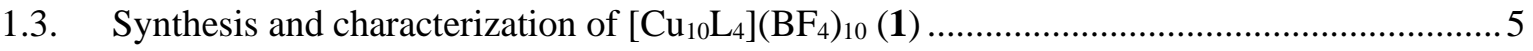

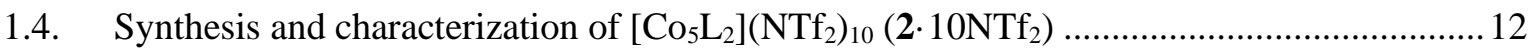

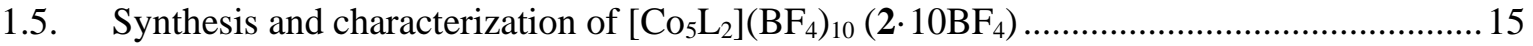

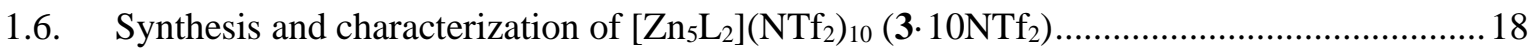

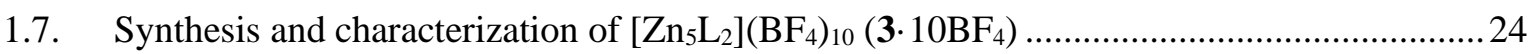

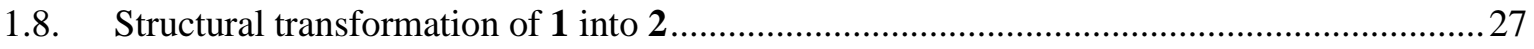

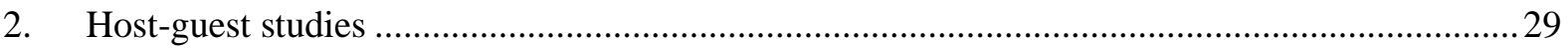

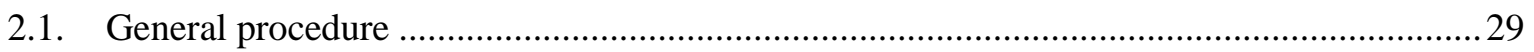

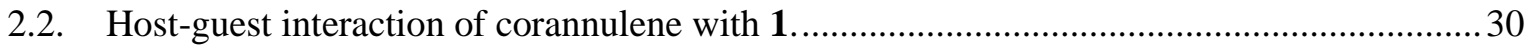

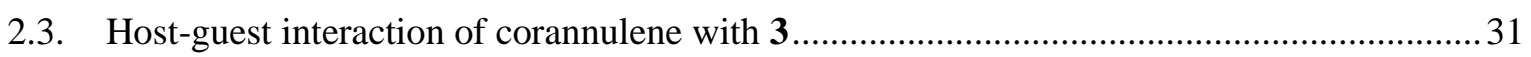

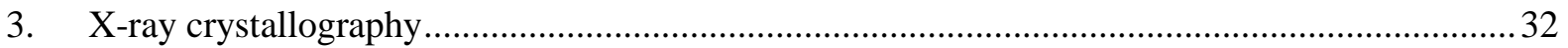

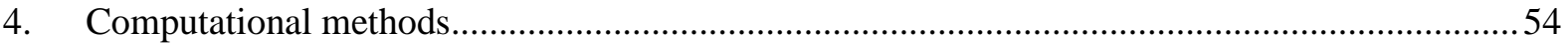

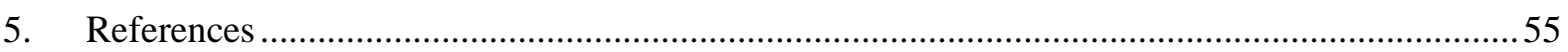




\section{Experimental procedures}

\subsection{General}

Unless otherwise specified, all starting materials were purchased from commercial sources and used as supplied. Cobalt(II) bis(trifluoromethanesulfonyl)imide ${ }^{1}$ and sym-pentachlorocorannulene ${ }^{2}$ were prepared following literature procedures. NMR spectra were recorded using $400 \mathrm{MHz}$ Avance III HD Smart Probe (routine ${ }^{1} \mathrm{H}$ NMR, DOSY) and DCH $500 \mathrm{MHz}$ dual cryoprobe (high-resolution ${ }^{13} \mathrm{C}$ and 2D experiments) NMR spectrometers. Chemical shifts $(\delta)$ for ${ }^{1} \mathrm{H}$ NMR spectra are reported in parts per million (ppm) and are reported relative to the solvent residual peak. DOSY experiments were performed on a Bruker DRX-400 spectrometer. Maximum gradient strength was $6.57 \mathrm{G} / \mathrm{cmA}$. The standard Bruker pulse program, ledbpgp2s, employing a stimulated echo and longitudinal eddy-current delay (LED) using bipolar gradient pulses for diffusion using 2 spoil gradients was utilized. Rectangular gradients were used with a total duration of $1.5 \mathrm{~ms}$. Gradient recovery delays were $1200 \mu \mathrm{s}$. Diffusion times were $50 \mathrm{~ms}$. Individual rows of the S4 quasi-2D diffusion databases were phased and baseline corrected. Low-resolution electrospray ionization mass spectra (ESI-MS) were obtained on a Micromass Quattro LC infused from a Harvard Syringe Pump at a rate of $10 \mu \mathrm{L}$ per minute. Highresolution ESI mass spectra were obtained by the EPSRC UK National Mass Spectrometry Facility at Swansea University using a Thermofisher LTQ Orbitrap XL.

\subsection{Synthesis and characterization of sym-pentakis(4-aminothiophenyl)corannulene} (A)

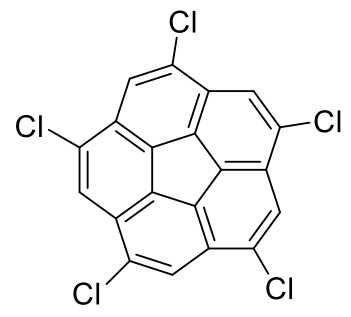

7.5

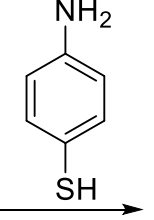

$\mathrm{NaH}, \mathrm{DMI}, 60^{\circ} \mathrm{C}$

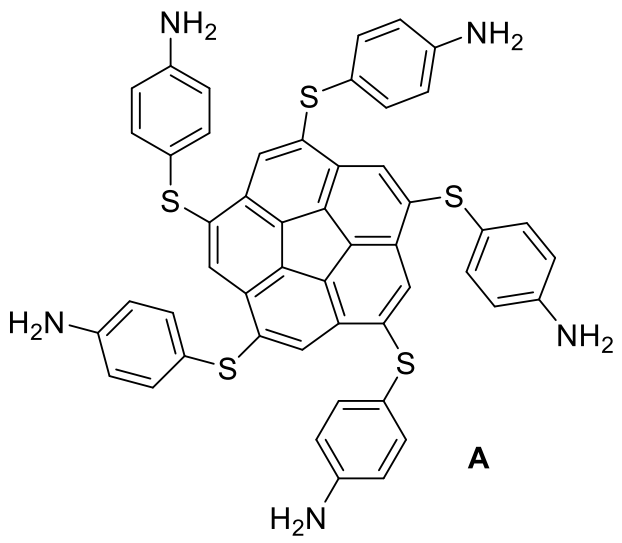

Scheme S1: Synthesis of subcomponent sym-pentakis(4-aminothiophenyl)corannulene (A).

To a flame-dried and degassed round bottom flask, 4-aminothiophenol (225 mg, $1.8 \mathrm{mmol}$ ), sodium hydride (58 mg, $1.45 \mathrm{mmol}$ ) and 1,3-dimethyl-2-imidazolidinone (DMI) (10 mL) were added. The 
mixture was stirred at room temperature for $15 \mathrm{~min}$. The yellow suspension changed to a clear yellow solution. sym-Pentachlorocorannulene $(100 \mathrm{mg}, 0.24 \mathrm{mmol})$ was added and the mixture was warmed up to $60{ }^{\circ} \mathrm{C}$ for $24 \mathrm{~h}$. After cooling down to room temperature, the mixture was extracted three times with EtOAc and water, dried over $\mathrm{MgSO}_{4}$ and the solvent was evaporated under reduced pressure. The crude orange-red oil was redissolved in DCM (ca. $10 \mathrm{~mL}$ ) and hexane was added (ca. $300 \mathrm{~mL}$ ) to slowly precipitate out the product. After filtration the desired compound could be obtained as an orange solid (95 mg, $0.11 \mathrm{mmol})$ in $46 \%$ yield. ${ }^{1} \mathrm{H}$ NMR $\left(500 \mathrm{MHz}, 298 \mathrm{~K}, \mathrm{CDCl}_{3}\right): \delta=7.63\left(\mathrm{~s}, 5 \mathrm{H}, H_{l}\right), 7.22(\mathrm{~d}, J$ $\left.=11 \mathrm{~Hz}, 10 \mathrm{H}, H_{2}\right), 6.65\left(\mathrm{~d}, J=11 \mathrm{~Hz}, 10 \mathrm{H}, H_{3}\right), 3.80\left(\mathrm{br} \mathrm{s}, 10 \mathrm{H}, H_{4}\right) \cdot{ }^{13} \mathrm{C} \mathrm{NMR}(126 \mathrm{MHz}, 298 \mathrm{~K}$, $\mathrm{CDCl}_{3}$ ): $\delta=146.8,138.4,135.0,135.0,131.0,125.0,121.5,116.2$. IR (neat, $\mathrm{cm}^{-1}$ ): $3674.7 \mathrm{~m}, 3360.4 w$, $2987.2 w, 2971.8 s, 2901.4 s, 1618.0 w, 1594.8 w, 1493.6 m, 1451.2 w, 1406.8 m, 1394.3 m, 1382.7 m$, $1250.6 m, 1241.9 m, 1230.4 m, 1175.4 w, 1075.1 s, 1065.5 s, 1055.8 s, 891.9 w, 879.4 s, 869.7 w, 822.5 w$. HRMS (MALDI) found: $865.1491[\mathrm{M}]^{+} ; \mathrm{C}_{50} \mathrm{H}_{35} \mathrm{~N}_{5} \mathrm{~S}_{5}$ requires: 865.1496. M.p.: 125.6-128.1 ${ }^{\circ} \mathrm{C}$.

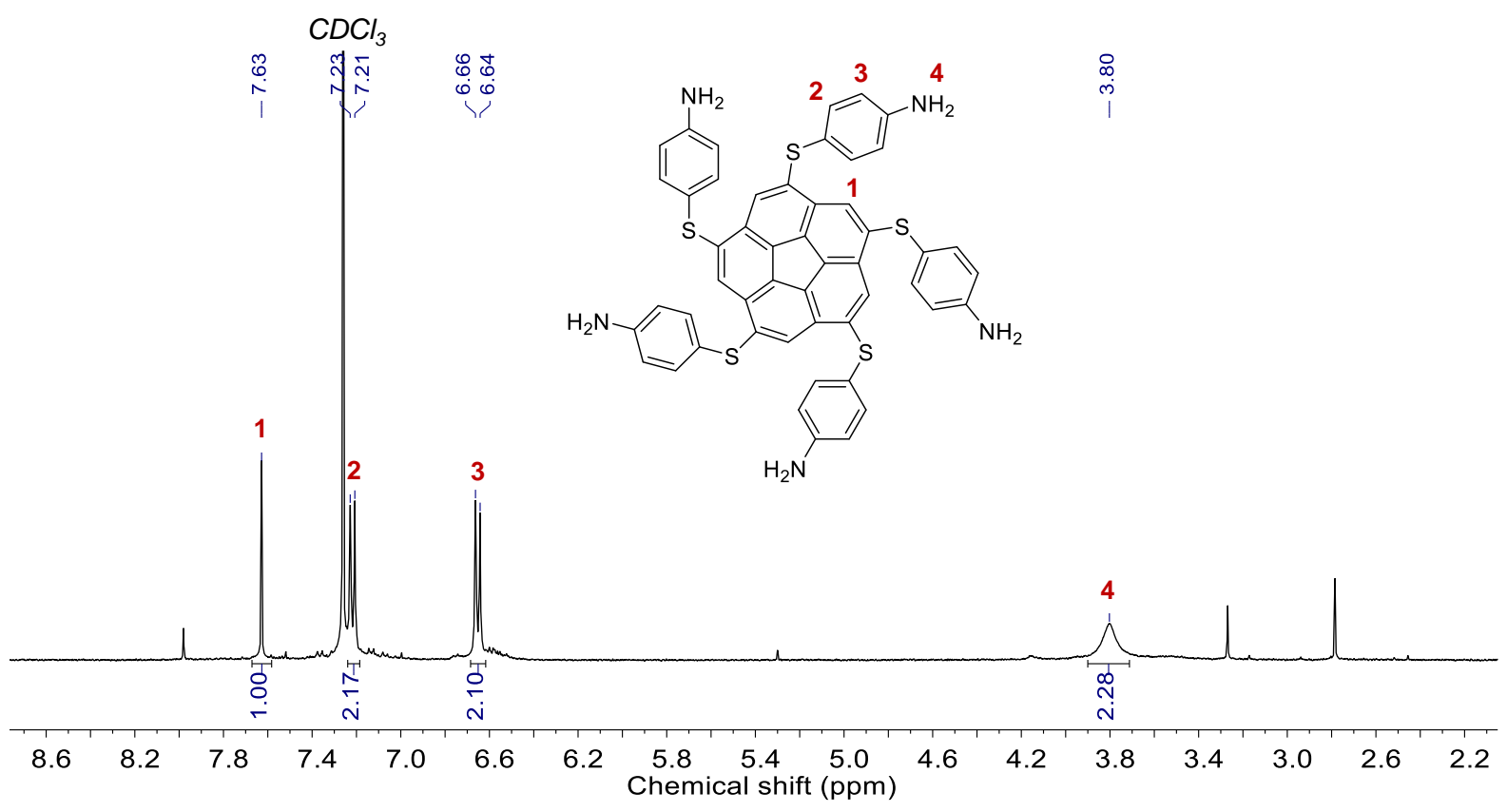

Figure S1: ${ }^{1} \mathrm{H}$ NMR $\left(500 \mathrm{MHz}, 298 \mathrm{~K}, \mathrm{CD}_{3} \mathrm{CN}\right)$ of subcomponent $\mathbf{A}$ showing the peak assignment. 


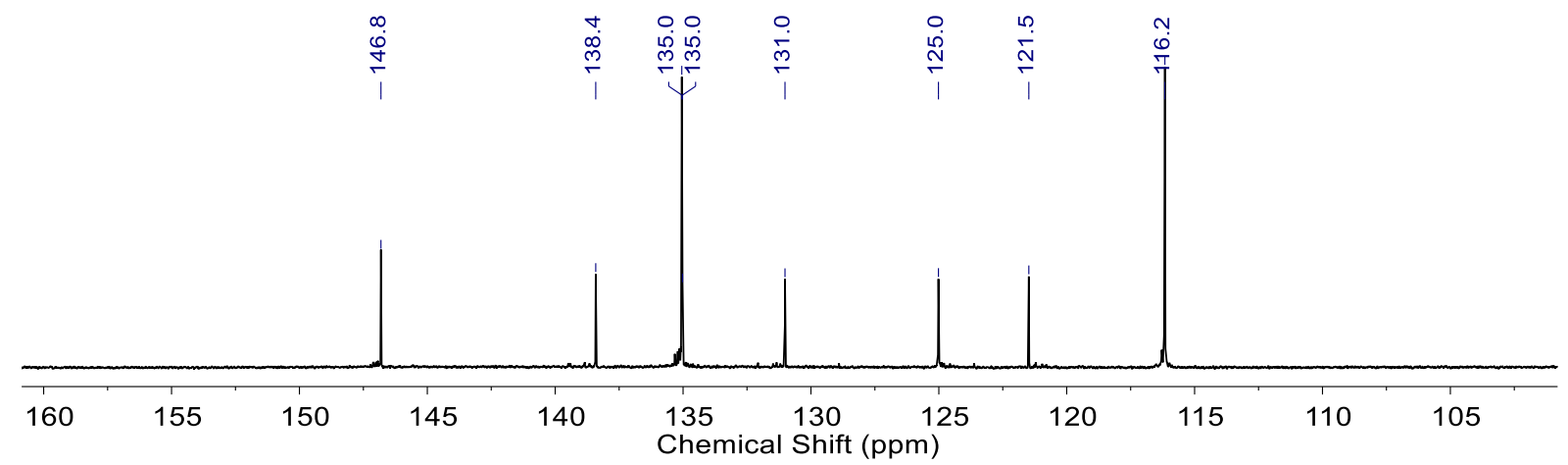

Figure S2: Aromatic region of the ${ }^{13} \mathrm{C}$ NMR spectrum $\left(126 \mathrm{MHz}, 298 \mathrm{~K}, \mathrm{CD}_{3} \mathrm{CN}\right)$ of subcomponent A. 


\subsection{Synthesis and characterization of $\left[\mathrm{Cu}_{10} \mathrm{~L}_{4}\right]\left(\mathrm{BF}_{4}\right)_{10}(1)$}

To a Teflon-capped J-Young NMR tube was added sym-pentakis(4-aminothiophenyl)corannulene (3.0 $\mathrm{mg}, 3.5 \mu \mathrm{mol}, 4$ equiv.), 2-formyl-6-methylpyridine (2.5 mg, $21 \mu \mathrm{mol}, 24$ equiv.) and tetrakis(acetonitrile)copper(I) tetrafluoroborate $(3.3 \mathrm{mg}, 10.5 \mu \mathrm{mol}, 12$ equiv.) as stock solutions of known concentration in $\mathrm{CD}_{3} \mathrm{CN}$ (total volume $0.6 \mathrm{~mL}$ ). The solution was degassed by three evacuation/nitrogen fill cycles and then sonicated for $5 \mathrm{~min}$. The NMR tube was then rotated at room temperature for $24 \mathrm{hr}$ and the formation of $\mathbf{1} \cdot 10 \mathrm{BF}_{4}$ was confirmed by ${ }^{1} \mathrm{H}$ NMR. The solution was then filtered and diethyl ether (ca. $5 \mathrm{~mL}$ ) was added. The dark brown solid was isolated through centrifugation and washed a further two times with diethyl ether to give $\mathbf{1} \cdot 10 \mathrm{BF}_{4}$ as a brown powder in approximately quantitative yield. ${ }^{1} \mathrm{H}$ NMR $\left(500 \mathrm{MHz} ; 298 \mathrm{~K} ; \mathrm{CD}_{3} \mathrm{CN}\right): \delta 9.31\left(\mathrm{~s}, 10 \mathrm{H}, H_{4^{\prime}}\right), 8.41(\mathrm{~d}, J$ $\left.=7.7 \mathrm{~Hz}, 10 \mathrm{H}, H_{6}\right), 8.35\left(\mathrm{~s}, 10 \mathrm{H}, H_{l^{\prime}}\right), 8.20\left(\mathrm{~d}, J=7.7 \mathrm{~Hz}, 10 \mathrm{H}, H_{5^{\prime}}\right), 8.09\left(\mathrm{~d}, J=8.4 \mathrm{~Hz}, 20 \mathrm{H}, H_{2^{\prime}}\right)$, $7.83\left(\mathrm{~d}, J=7.7 \mathrm{~Hz}, 10 \mathrm{H}, H_{5}\right), 7.79\left(\mathrm{~d}, J=7.6 \mathrm{~Hz}, 10 \mathrm{H}, H_{7}\right), 7.75\left(\mathrm{t}, J=7.7 \mathrm{~Hz}, 10 \mathrm{H}, H_{6^{\prime}}\right), 7.56(\mathrm{~d}, J=$ $\left.7.7 \mathrm{~Hz}, 10 \mathrm{H}, H_{7^{\prime}}\right), 7.29\left(\mathrm{~d}, J=8.4 \mathrm{~Hz}, 20 \mathrm{H}, H_{3^{\prime}}\right), 7.17\left(\mathrm{~s}, 10 \mathrm{H}, H_{4}\right), 7.13\left(\mathrm{~s}, 10 \mathrm{H}, H_{l}\right), 6.61(\mathrm{~d}, J=8.1$ $\mathrm{Hz}, 20 \mathrm{H}), 6.46(\mathrm{~d}, J=8.1 \mathrm{~Hz}, 20 \mathrm{H}), 3.01\left(\mathrm{~s}, 30 \mathrm{H}, H_{8^{\prime}}\right), 2.26\left(\mathrm{~s}, 30 \mathrm{H}, H_{8}\right) .{ }^{13} \mathrm{C}$ NMR $(126 \mathrm{MHz}, 298 \mathrm{~K}$, $\mathrm{CD}_{3} \mathrm{CN}$ ): $\delta=161.0$ (imine), 160.2, 159.2, 158.9 (imine), 151.2, 148.7, 148.3, 145.8, 140.4, 139.5, 139.3, 138.0, 137.3, 137.0, 135.1, 134.9, 134.8, 134.6, 134.2, 132.8, 131.8, 130.8 (two overlapping signals), 128.1, 127.3 (two overlapping signals), 123.9, 121.7, 27.0, 25.3. ESI-MS: $m / z=917.4\left[1\left(\mathrm{BF}_{4}^{-}\right)_{3}\right]^{7+}$,

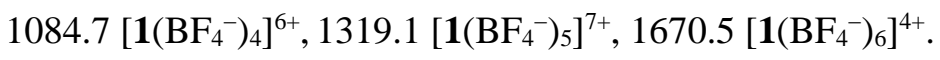

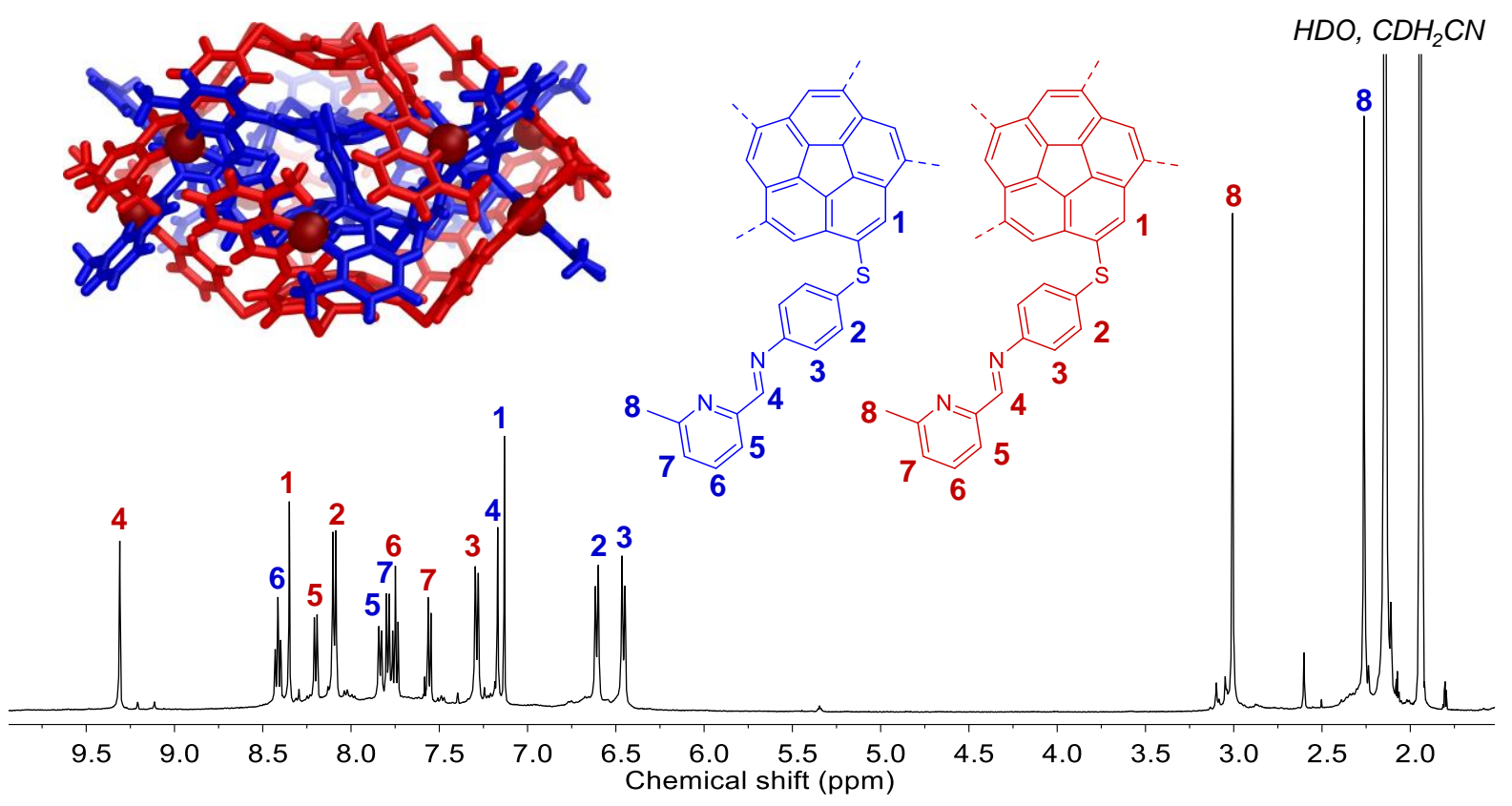

Figure S3: ${ }^{1} \mathrm{H}$ NMR spectrum $\left(500 \mathrm{MHz}, 298 \mathrm{~K}, \mathrm{CD}_{3} \mathrm{CN}\right)$ of $\mathbf{1} \cdot 10 \mathrm{BF}_{4}$. The interior and exterior ligands are coloured blue and red respectively. 


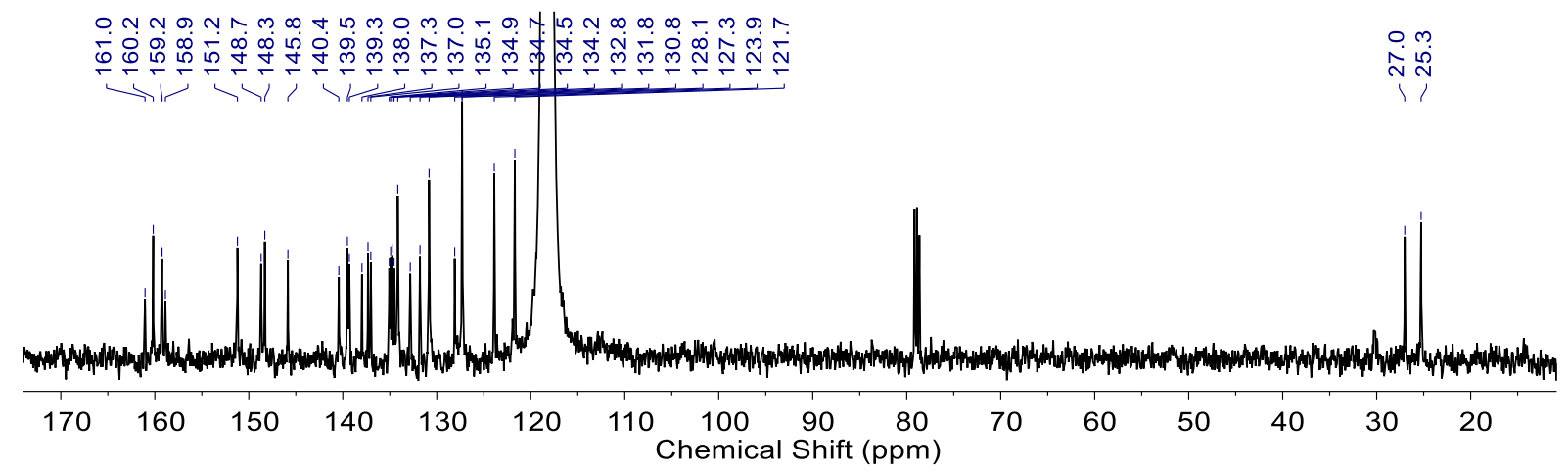

Figure S4: ${ }^{13} \mathrm{C}$ NMR spectrum $\left(126 \mathrm{MHz}, 298 \mathrm{~K}, \mathrm{CD}_{3} \mathrm{CN}\right)$ of $\mathbf{1} \cdot 10 \mathrm{BF}_{4}$.

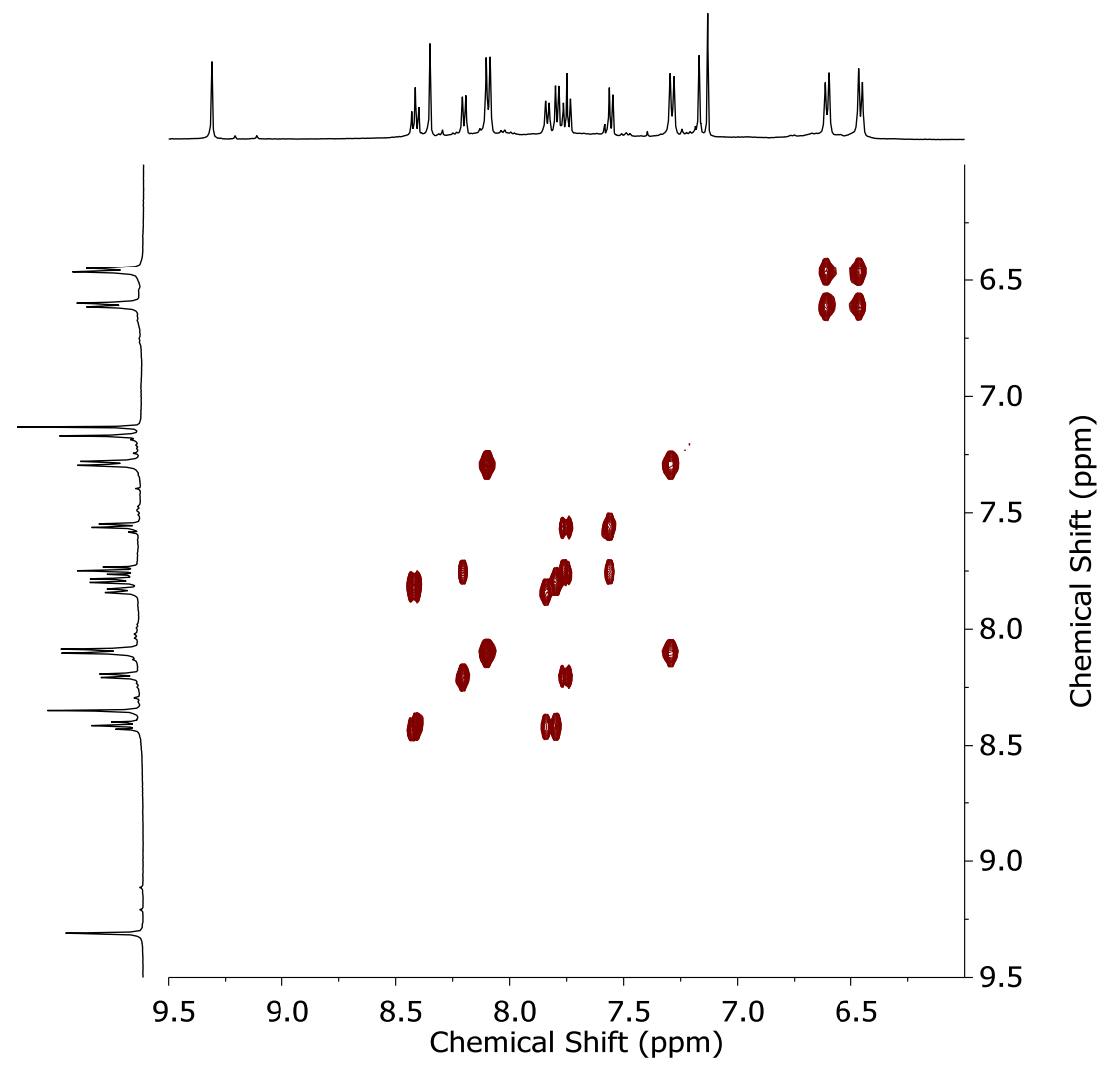

Figure S5: Aromatic region of the ${ }^{1} \mathrm{H}-{ }^{1} \mathrm{H}$ COSY spectrum $\left(500 \mathrm{MHz}, 298 \mathrm{~K}, \mathrm{CD}_{3} \mathrm{CN}\right)$ of $\mathbf{1} \cdot 10 \mathrm{BF}_{4}$. 


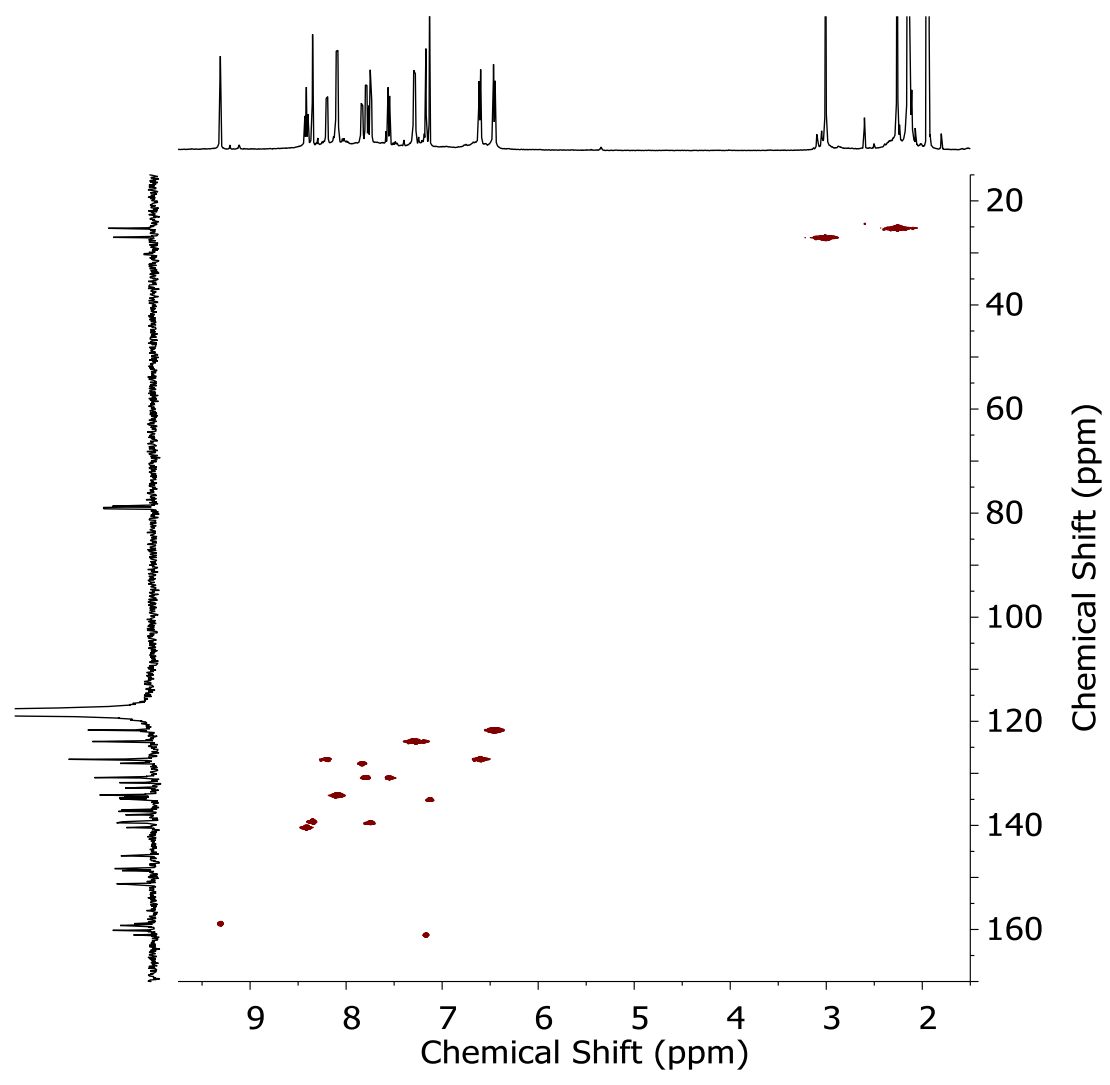

Figure S6: ${ }^{1} \mathrm{H}^{13}{ }^{13} \mathrm{C}$ HSQC spectrum $\left(500 \mathrm{MHz}, 298 \mathrm{~K}, \mathrm{CD}_{3} \mathrm{CN}\right)$ of $\mathbf{1} \cdot 10 \mathrm{BF}_{4}$.

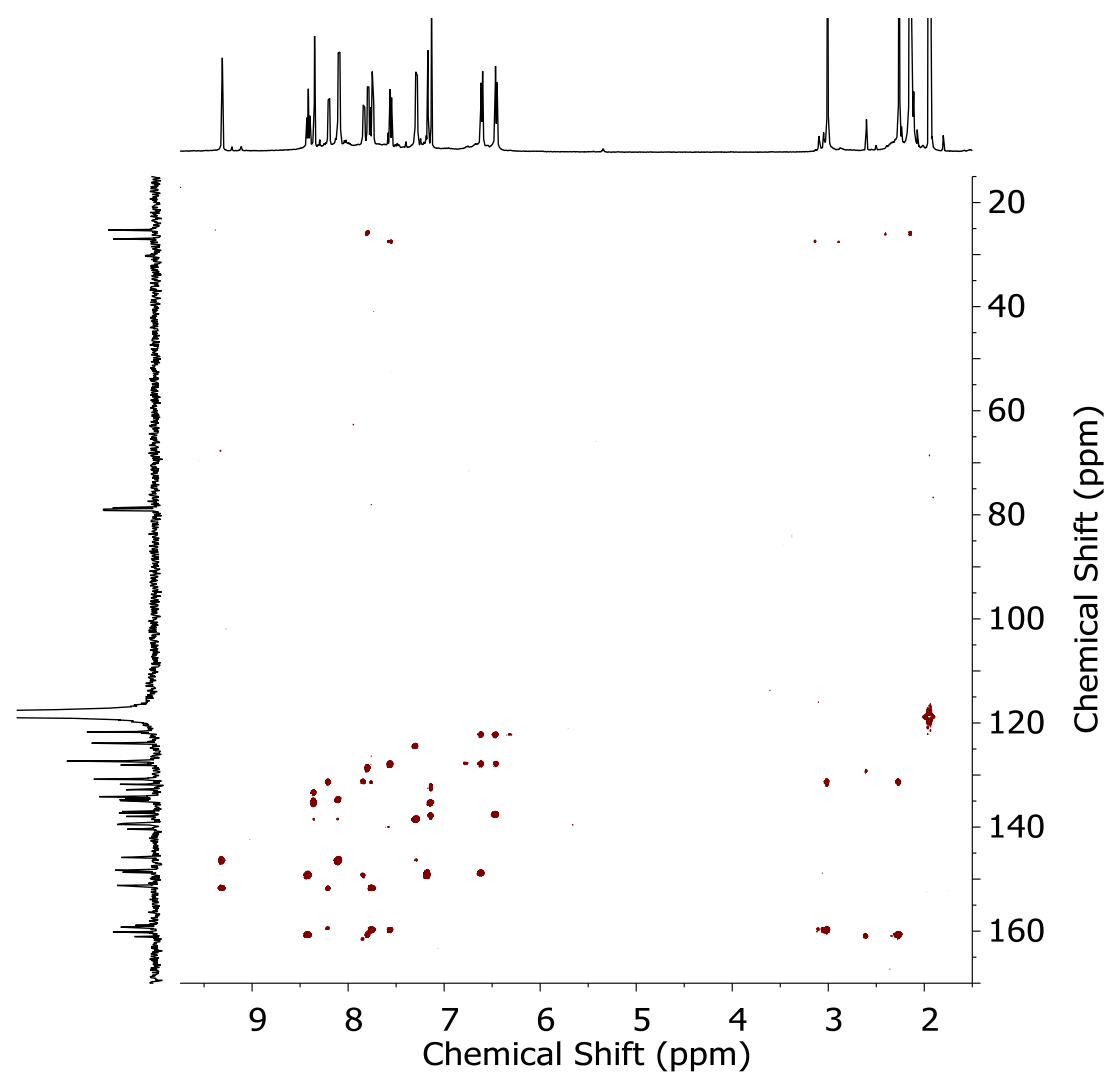

Figure S7: ${ }^{1} \mathrm{H}_{-}{ }^{13} \mathrm{C}$ HMBC spectrum $\left(500 \mathrm{MHz}, 298 \mathrm{~K}, \mathrm{CD}_{3} \mathrm{CN}\right)$ of $\mathbf{1} \cdot 10 \mathrm{BF}_{4}$. 


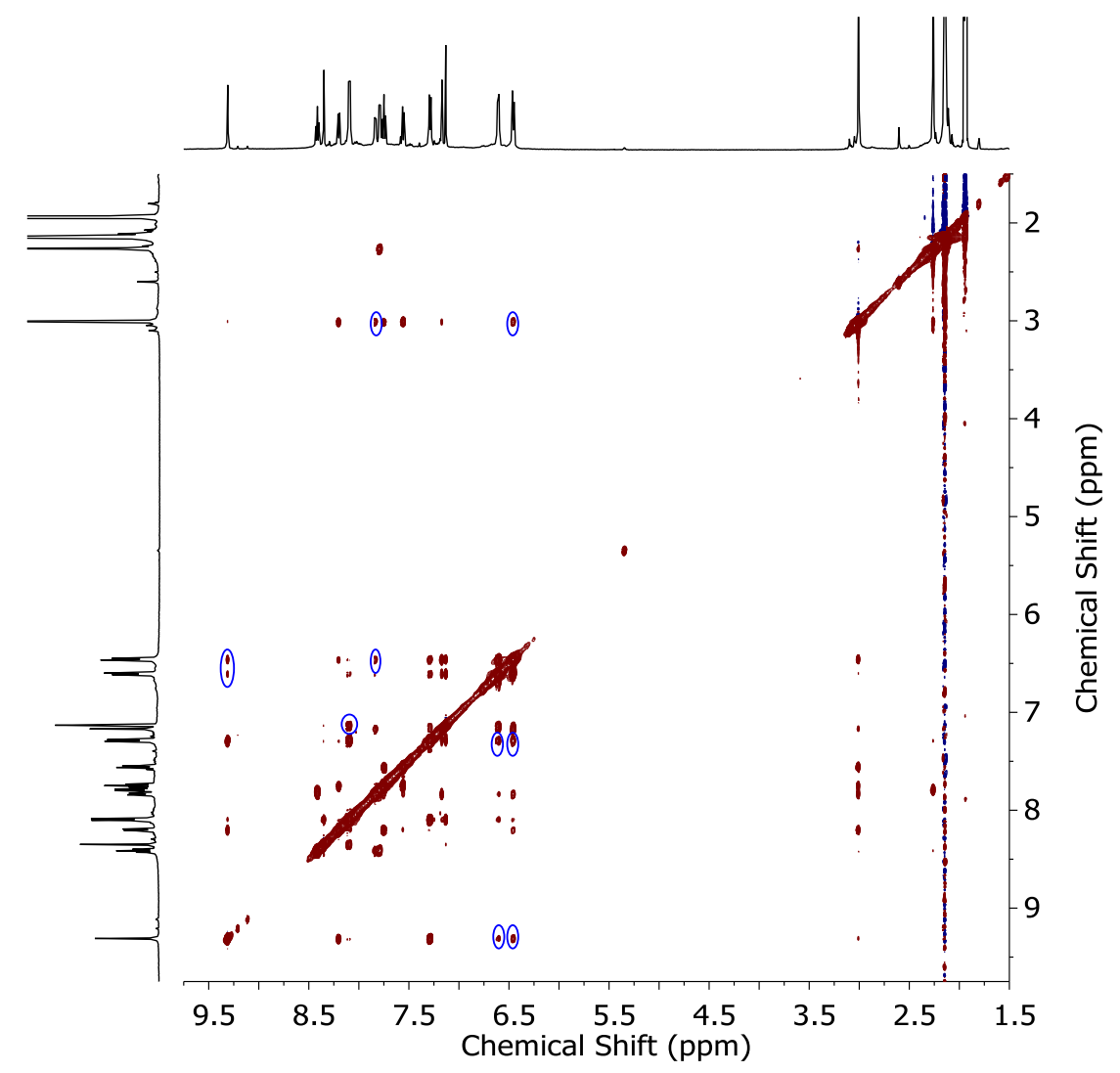

Figure S8: ${ }^{1} \mathrm{H}-{ }^{1} \mathrm{H}$ NOESY spectrum $\left(500 \mathrm{MHz}, 298 \mathrm{~K}, \mathrm{CD}_{3} \mathrm{CN}\right)$ of 1·10BF 4 . NOE crosspeaks between protons of the exo- and endo- ligand are highlighted by blue circles.

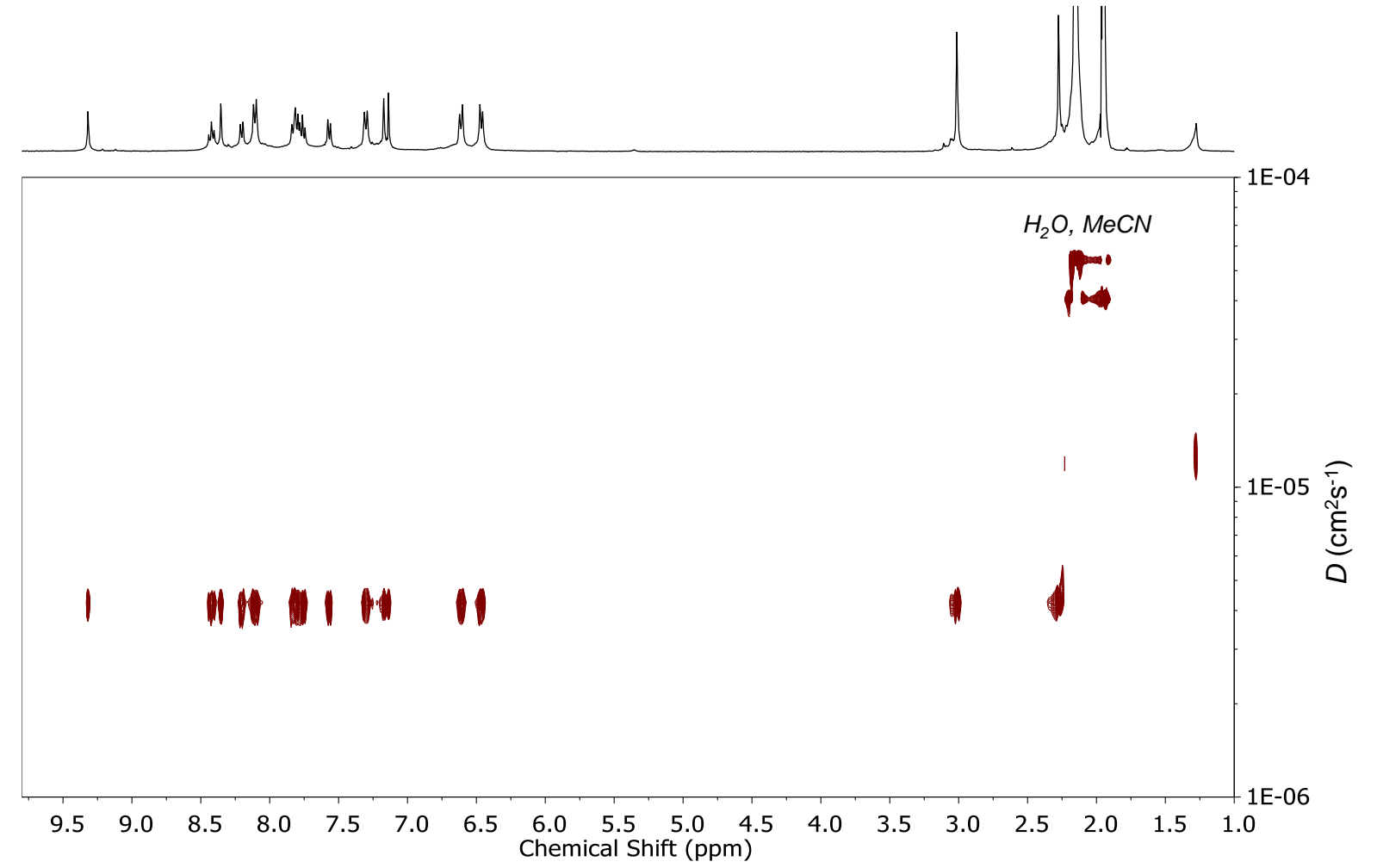

Figure S9: ${ }^{1} \mathrm{H}$ DOSY spectrum $\left(400 \mathrm{MHz}, 298 \mathrm{~K}, \mathrm{CD}_{3} \mathrm{CN}\right)$ of $\mathbf{1} \cdot 10 \mathrm{BF}_{4}$. The diffusion coefficient for $\mathbf{1}$ in $\mathrm{CD}_{3} \mathrm{CN}$ was measured to be $4.26 \times 10^{-6} \mathrm{~cm}^{2} \mathrm{~s}^{-1}$. 


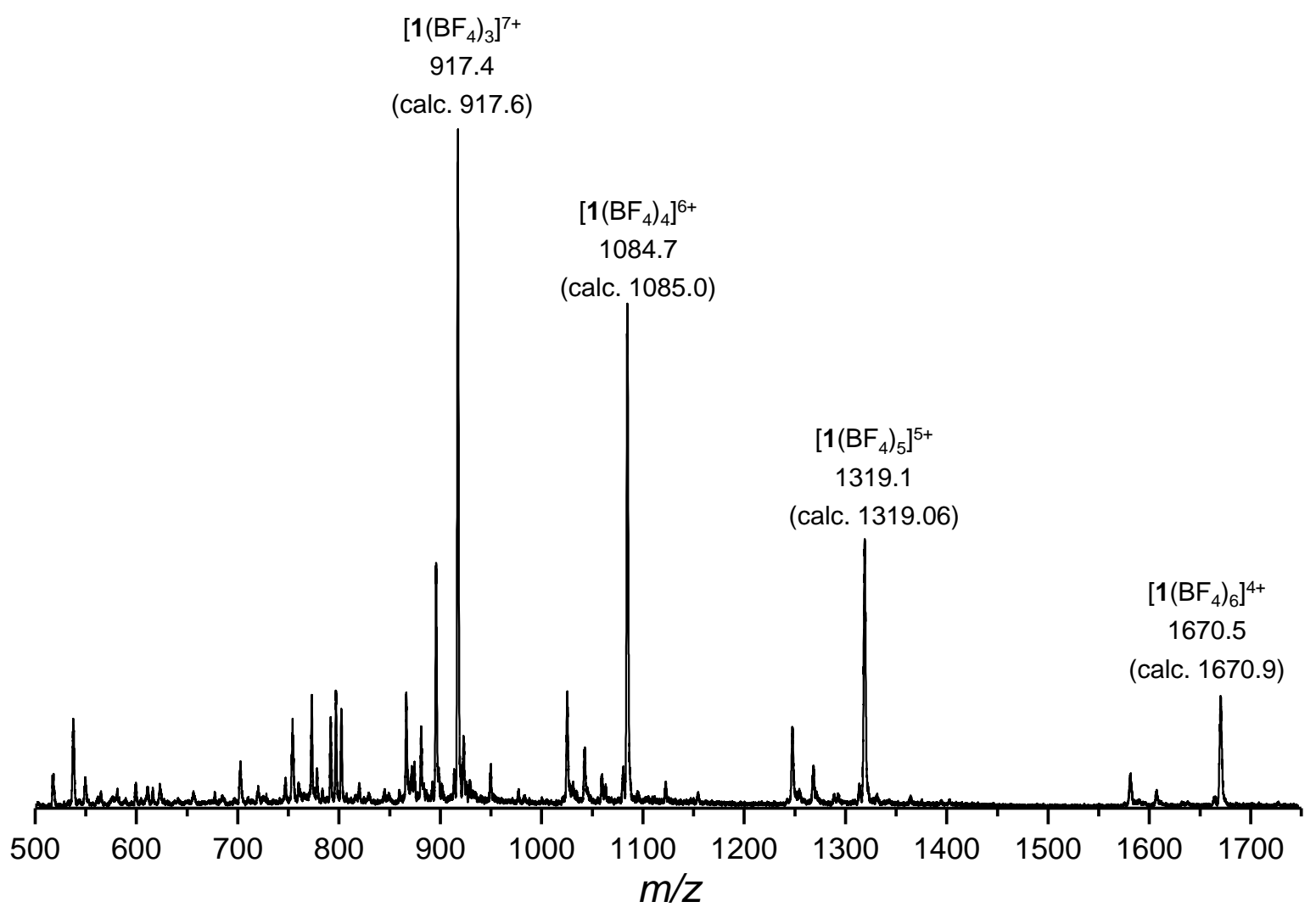

Figure S10: Low-resolution ESI-mass spectrum of 1-10BF 4 . 
a)

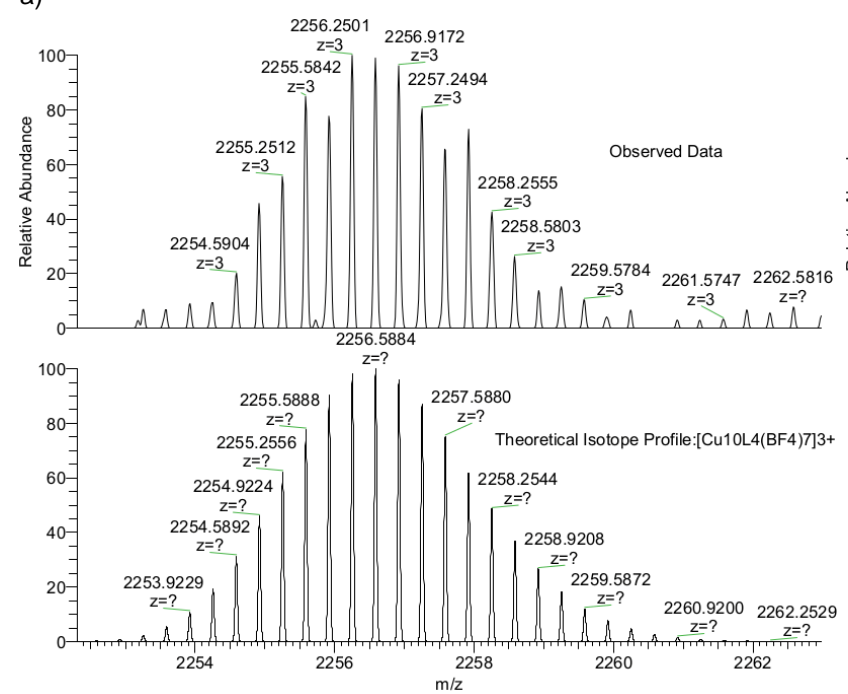

b)

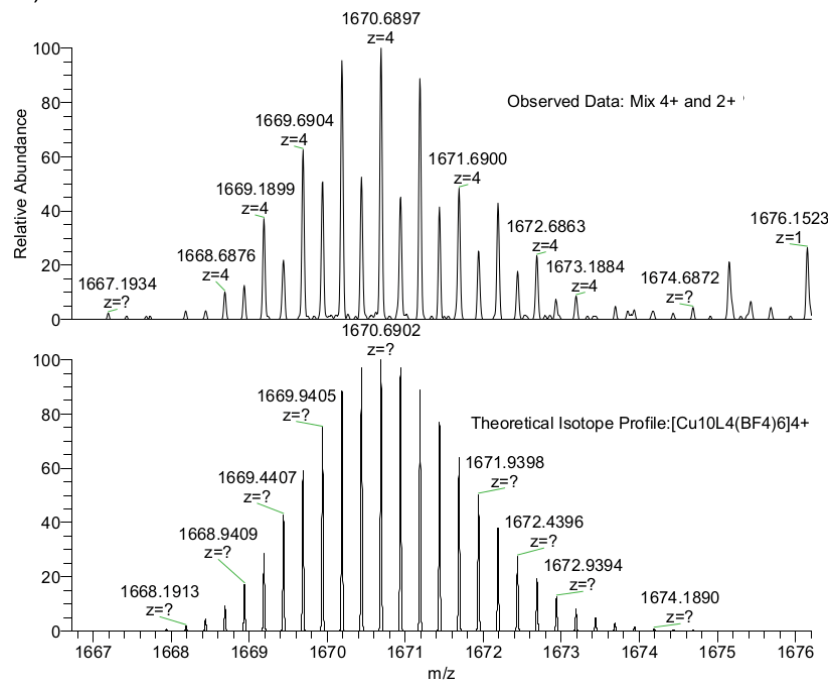

c)

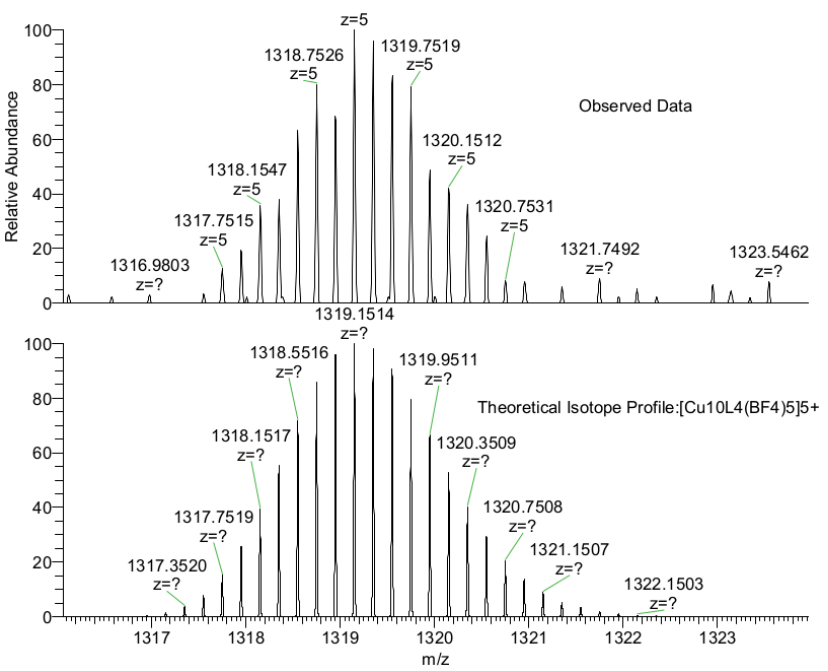

d)

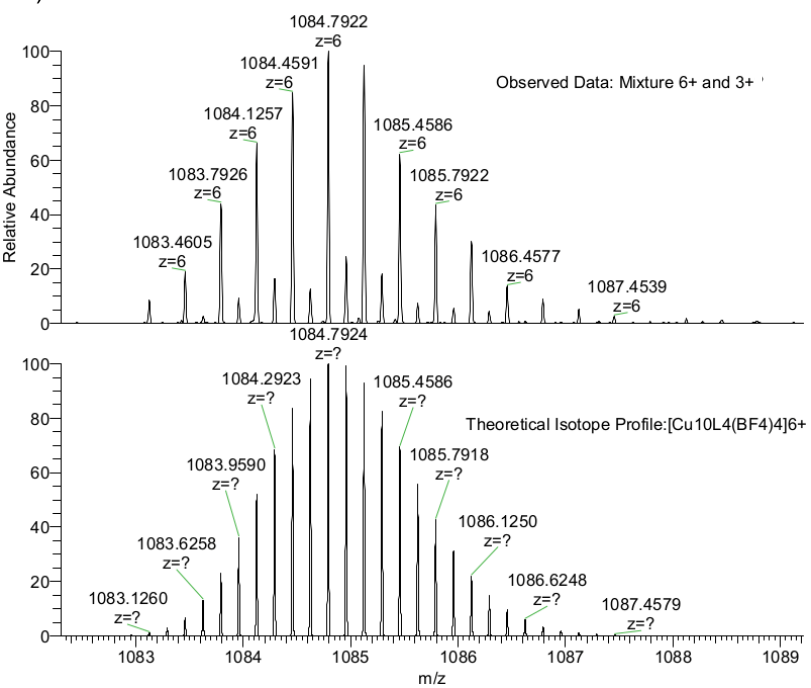

Figure S11: High-resolution ESI-mass spectrometry analysis of $\mathbf{1} \cdot 10 \mathrm{BF}_{4}$ showing the (a) +3 peak (b) +4 peak (c) +5 peak and (d) +6 peak. The fragmentation patterns observed for the +4 and the +6 peaks are attributed to homolytic fragmentation of the $\left[\mathrm{Cu}_{10} \mathrm{~L}_{4}\right]^{10+}$ assembly under the MS conditions. The ionisation conditions of the instrument used to record the high-resolution ESI-MS are harsher than those used to record the low-resolution ESI-MS in Figure S10, as evidenced by much higher levels of fragmentation overall and the observation of strong peaks for low charged +1 and +2 fragments. No other spectroscopic evidence suggested the formation of $\left[\mathrm{Cu}_{5} \mathrm{~L}_{2}\right]^{5+}$ single cages in solution. 


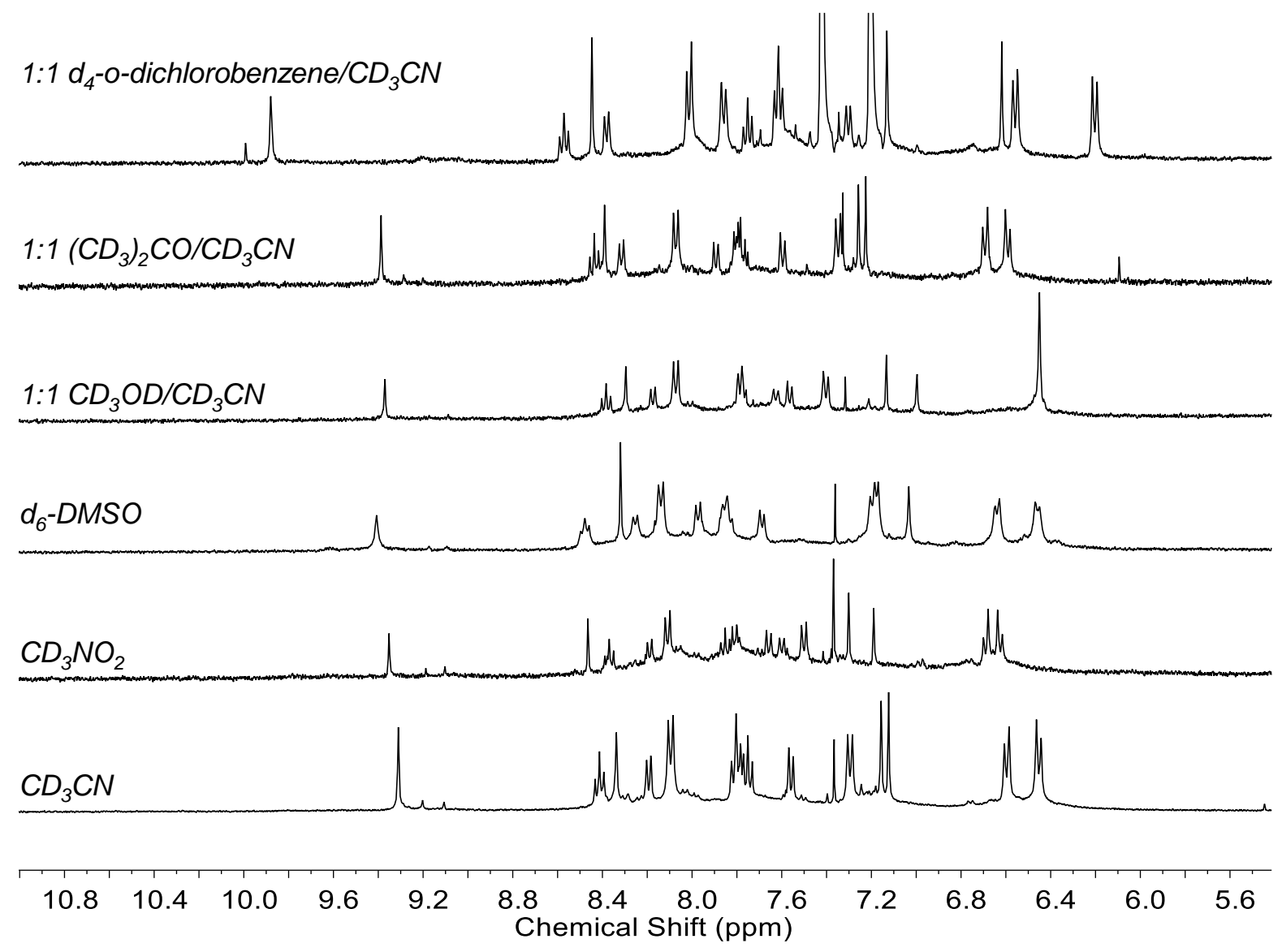

Figure S12: Partial ${ }^{1} \mathrm{H}$ NMR spectra $\left(400 \mathrm{MHz}, 298 \mathrm{~K}, \mathrm{CD}_{3} \mathrm{CN}\right)$ of $1 \cdot 10 \mathrm{BF}_{4}$ in different solvents showing the persistence of the catenated cage structure. 


\subsection{Synthesis and characterization of $\left[\operatorname{Cos}_{2} \mathrm{~L}_{2}\right]\left(\mathrm{NTf}_{2}\right)_{10}\left(2 \cdot 10 \mathrm{NTf} \mathrm{f}_{2}\right)$}

To a small test tube was added 2-formyl-1,10-phenanthroline (4.8 mg, $23 \mu \mathrm{mol}, 10$ equiv.), cobalt(II) bis(trifluoromethanesulfonyl)imide ( $8.2 \mathrm{mg}, 11.5 \mu \mathrm{mol}, 5$ equiv.) and $\mathrm{CD}_{3} \mathrm{CN}(0.5 \mathrm{~mL})$ and the mixture was stirred at room temperature for $5 \mathrm{~min}$. Sym-pentakis(4-aminothiophenyl)corannulene (4.0 mg, 4.6 $\mu$ mol, 2 equiv.) was then added as a solution in $\mathrm{CD}_{3} \mathrm{CN}(0.4 \mathrm{~mL})$ and the mixture was degassed by bubbling with nitrogen for $15 \mathrm{~min}$ and then stirred at $353 \mathrm{~K}$ for 2 days. Formation of $\mathbf{2} \cdot 10 \mathrm{NTf}_{2}$ was confirmed by ${ }^{1} \mathrm{H}$ NMR. The solution was then filtered and diethyl ether (ca. $5 \mathrm{~mL}$ ) was added. The dark orange solid was isolated through centrifugation and washed a further two times with diethyl ether to give $2 \cdot 10 \mathrm{NTf}_{2}$ as a dark orange powder. Yield $14.8 \mathrm{mg}, 95 \% .{ }^{1} \mathrm{H} \mathrm{NMR}\left(400 \mathrm{MHz} ; 298 \mathrm{~K} ; \mathrm{CD}_{3} \mathrm{CN}\right)$ : $\delta$ 259.4, 187.8, 106.4, 49.1, 34.7, 27.2, 19.6, 3.2, 0.7, -12.5, -65.9. ESI-MS: $m / z=392.9[2]^{10+}, 467.8$ $\left[2\left(\mathrm{NTf}_{2}^{-}\right)\right]^{9+}, 561.2\left[2\left(\mathrm{NTf}_{2}^{-}\right)_{2}\right]^{8+}, 681.3\left[2\left(\mathrm{NTf}_{2}^{-}\right)_{3}\right]^{7+}, 841.6\left[2\left(\mathrm{NTf}_{2}^{-}\right)_{4}\right]^{6+}, 1065.9\left[2\left(\mathrm{NTf}_{2}^{-}\right)_{5}\right]^{5+}, 1402.3$ $\left[2\left(\mathrm{NTf}_{2}^{-}\right)_{6}\right]^{4+}$.

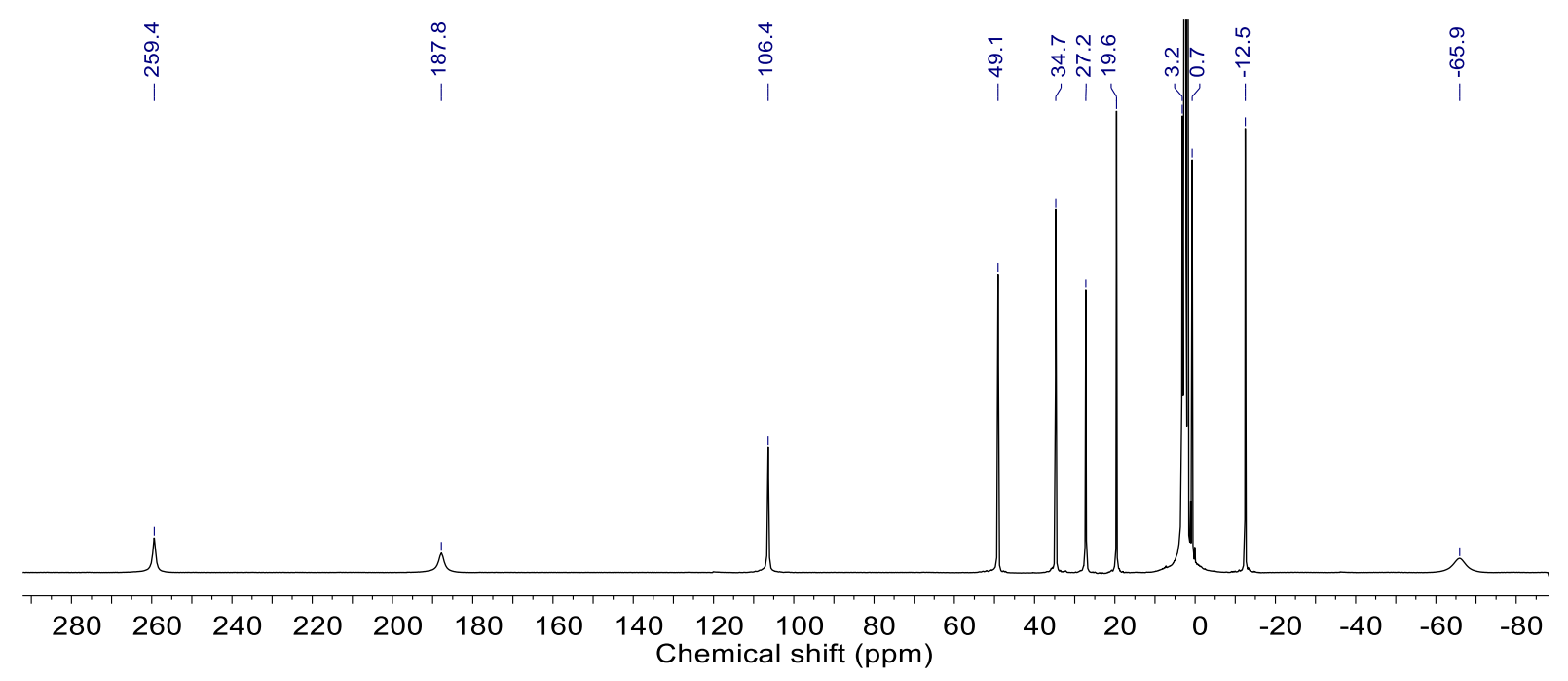

Figure S13: ${ }^{1} \mathrm{H}$ NMR spectrum $\left(400 \mathrm{MHz}, 298 \mathrm{~K}, \mathrm{CD}_{3} \mathrm{CN}\right)$ of $\mathbf{2} \cdot 10 \mathrm{NTf}_{2}$. 


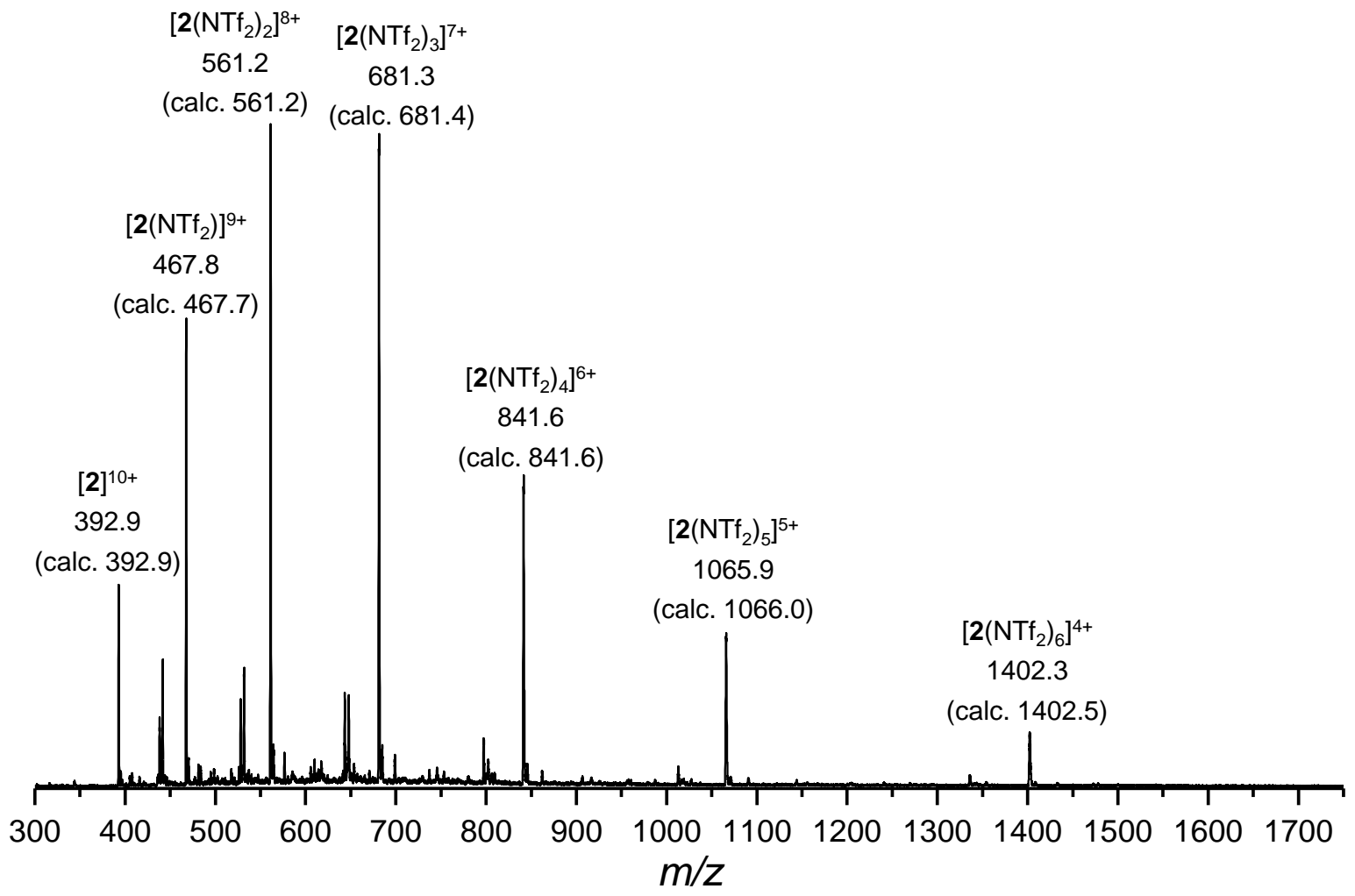

Figure S14: Low-resolution ESI-mass spectrum of 2 $10 \mathrm{NTf}_{2}$. 

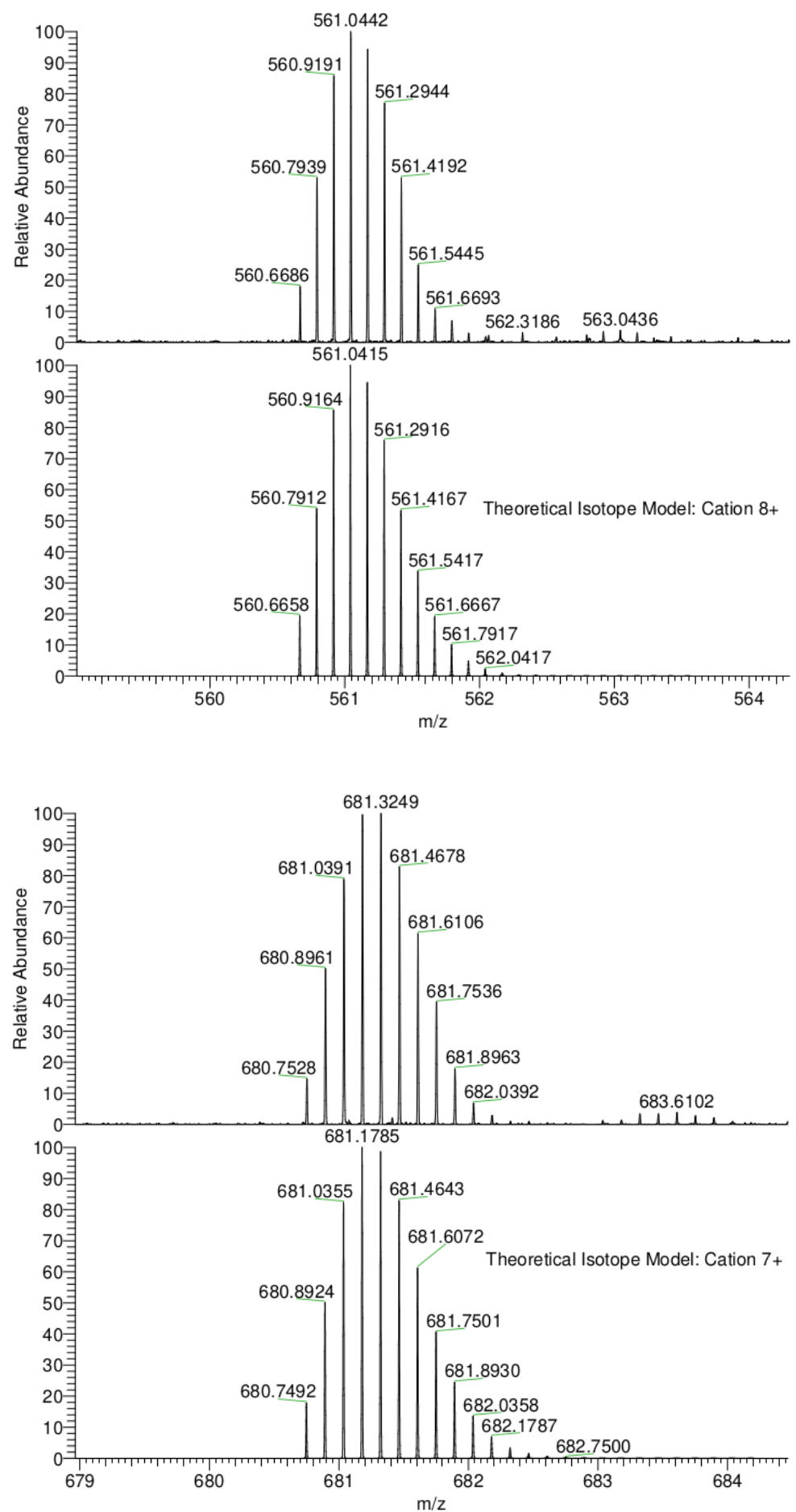

Figure S15: High-resolution ESI-mass spectrometry analysis of $2 \cdot 10 \mathrm{NTf}_{2}$ showing the +8 and +7 peaks. 


\subsection{Synthesis and characterization of $\left[\mathrm{Cos}_{2}\right]\left(\mathrm{BF}_{4}\right)_{10}\left(2 \cdot 10 \mathrm{BF}_{4}\right)$}

To a small test tube was added 2-formyl-1,10-phenanthroline (3.0 mg, $14.4 \mu \mathrm{mol}, 10$ equiv.), cobalt tetrafluoroborate hexahydrate $(2.5 \mathrm{mg}, 7.4 \mu \mathrm{mol}, 5$ equiv. $)$ and $\mathrm{CD}_{3} \mathrm{CN}(0.4 \mathrm{~mL})$ and the mixture was stirred at room temperature for $5 \mathrm{~min}$. Sym-pentakis(4-aminothiophenyl)corannulene $(2.5 \mathrm{mg}, 2.9$ $\mu$ mol, 2 equiv.) was then added as a solution in $\mathrm{CD}_{3} \mathrm{CN}(0.25 \mathrm{~mL})$ and the mixture was degassed by bubbling with nitrogen for $15 \mathrm{~min}$ and then stirred at $353 \mathrm{~K}$ for 2 days. Formation of $\mathbf{2} \cdot 10 \mathrm{BF}_{4}$ was confirmed by ${ }^{1} \mathrm{H}$ NMR. The solution was then filtered and diethyl ether (ca. $5 \mathrm{~mL}$ ) was added. The light orange solid was isolated through centrifugation and washed a further two times with diethyl ether to give $2 \cdot 10 \mathrm{BF}_{4}$ as a light orange powder. Yield $4.2 \mathrm{mg}, 60 \%$. The ${ }^{1} \mathrm{H}$ NMR data of the product closely matched those of the triflimide salt. ${ }^{1} \mathrm{H}$ NMR (400 MHz; $\left.298 \mathrm{~K} ; \mathrm{CD}_{3} \mathrm{CN}\right): \delta 259.3,187.8,106.4,49.1$, 34.7, 27.2, 19.6, 3.2, 0.7, -12.5, -65.9. ESI-MS: $m / z=392.9[2]^{10+}, 446.2\left[2\left(\mathrm{BF}_{4}^{-}\right)\right]^{9+}, 512.8\left[2\left(\mathrm{BF}_{4}^{-}\right)_{2}\right]^{8+}$, $598.4\left[2\left(\mathrm{BF}_{4}^{-}\right)_{3}\right]^{7+}, 712.7\left[2\left(\mathrm{BF}_{4}^{-}\right)_{4}\right]^{6+}, 872.6\left[2\left(\mathrm{BF}_{4}^{-}\right)_{5}\right]^{5+}, 1112.5\left[2\left(\mathrm{BF}_{4}^{-}\right)_{6}\right]^{4+}, 1512.1\left[2\left(\mathrm{BF}_{4}^{-}\right)_{7}\right]^{3+}$.

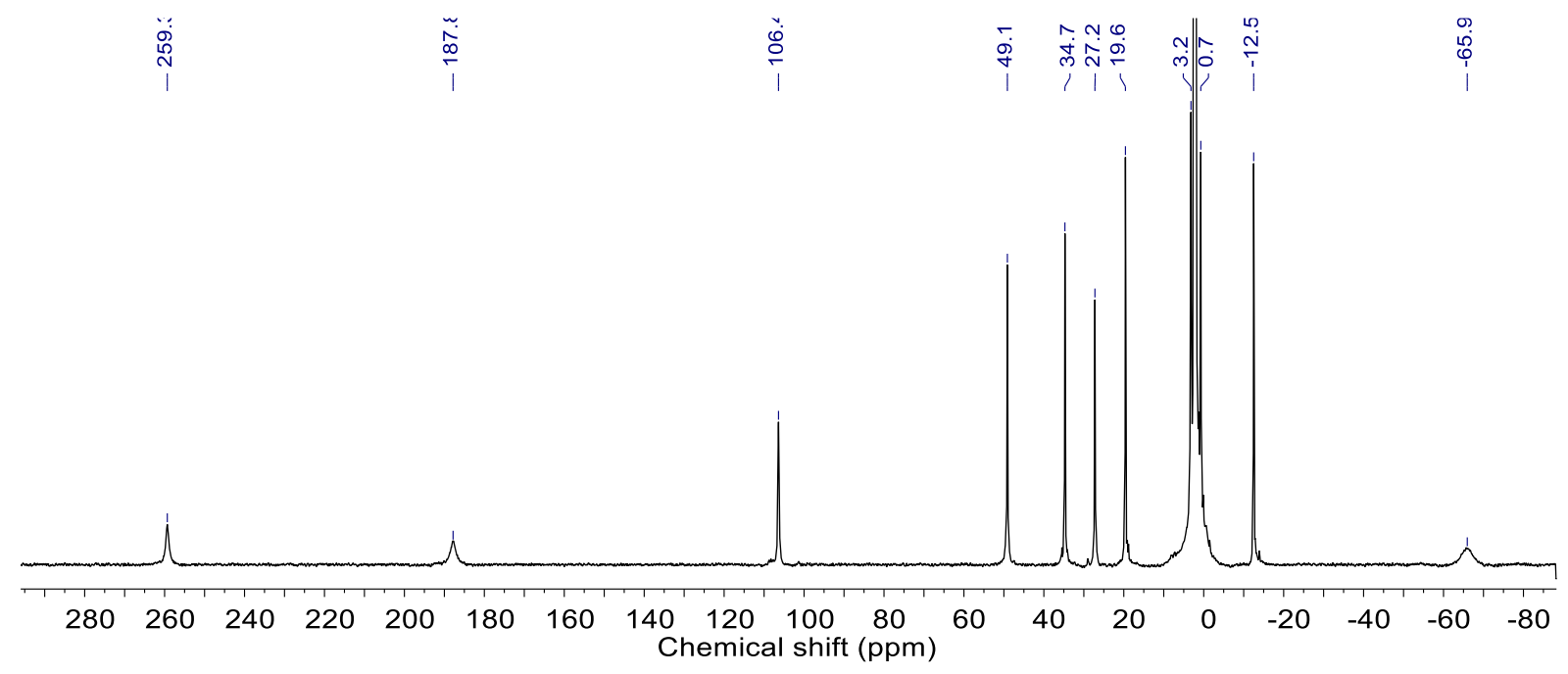

Figure S16: ${ }^{1} \mathrm{H}$ NMR spectrum $\left(400 \mathrm{MHz}, 298 \mathrm{~K}, \mathrm{CD}_{3} \mathrm{CN}\right)$ of $\mathbf{2} \cdot 10 \mathrm{BF}_{4}$. 


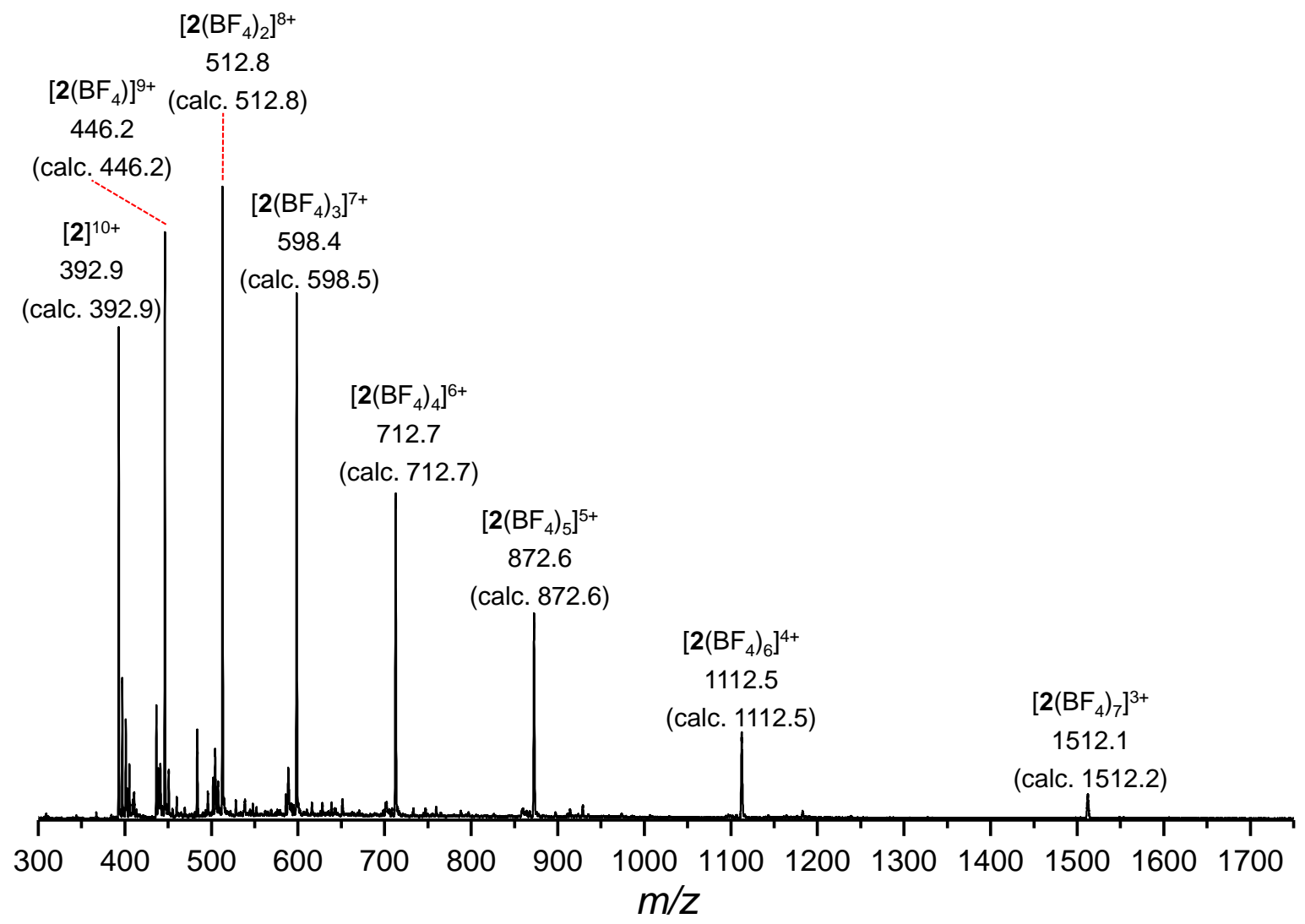

Figure S17: Low-resolution ESI-mass spectrum of 2 $10 \mathrm{BF}_{4}$. 

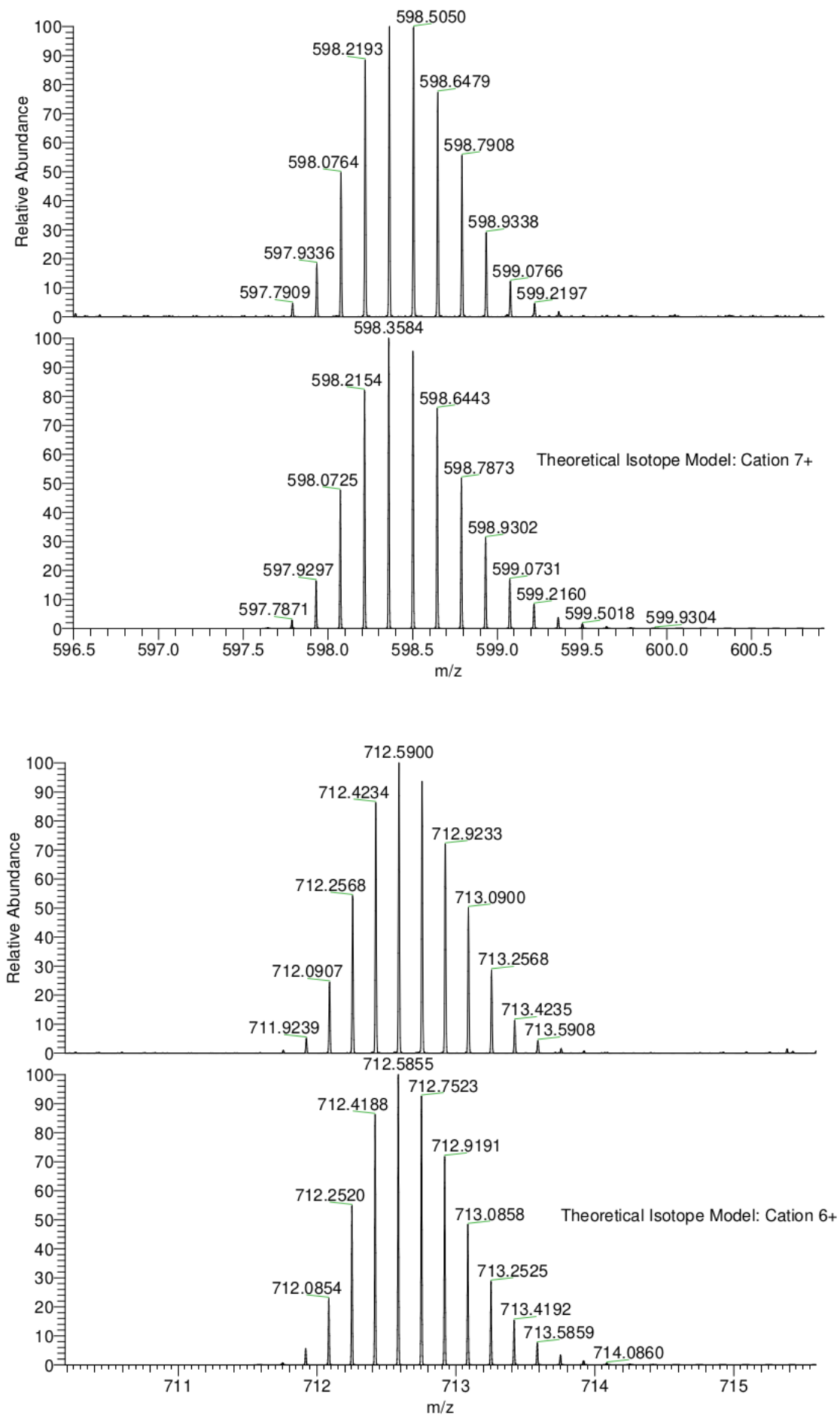

Figure S18: High-resolution ESI-mass spectrometry analysis of $2 \cdot 10 \mathrm{BF}_{4}$ showing the +7 and +6 peaks. 


\subsection{Synthesis and characterization of $\left[\mathrm{Zn}_{5} \mathrm{~L}_{2}\right]\left(\mathrm{NTf}_{2}\right)_{10}\left(3 \cdot 10 \mathrm{NTf}_{2}\right)$}

To a small test tube was added 2-formyl-1,10-phenanthroline (4.8 mg, $23 \mu \mathrm{mol}, 10$ equiv.), zinc(II) bis(trifluoromethanesulfonyl)imide ( $7.2 \mathrm{mg}, 11.5 \mu \mathrm{mol}, 5$ equiv.) and $\mathrm{CD}_{3} \mathrm{CN}(0.5 \mathrm{~mL})$ and the mixture was stirred at room temperature for $5 \mathrm{~min}$. Sym-pentakis(4-aminothiophenyl)corannulene (4.0 mg, 4.6 $\mu$ mol, 2 equiv.) was then added as a solution in $\mathrm{CD}_{3} \mathrm{CN}(0.4 \mathrm{~mL})$ and the mixture was degassed by bubbling with nitrogen for $15 \mathrm{~min}$ and then stirred at $353 \mathrm{~K}$ for 2 days. Formation of $\mathbf{3} \cdot 10 \mathrm{NTf}_{2}$ was confirmed by ${ }^{1} \mathrm{H}$ NMR. The solution was then filtered and diethyl ether (ca. $5 \mathrm{~mL}$ ) was added. The light orange solid was isolated through centrifugation and washed a further two times with diethyl ether to give 3. $10 \mathrm{NTf}_{2}$ as a light orange powder. Yield $13.5 \mathrm{mg}, 87 \% .{ }^{1} \mathrm{H} \mathrm{NMR}\left(500 \mathrm{MHz} ; 298 \mathrm{~K} ; \mathrm{CD}_{3} \mathrm{CN}\right)$ : $\delta$ $9.24\left(\mathrm{~d}, J=8.4 \mathrm{~Hz}, 10 \mathrm{H}, H_{6}\right), 8.68\left(\mathrm{~s}, 10 \mathrm{H}, H_{4}\right), 8.61\left(\mathrm{~d}, J=8.4 \mathrm{~Hz}, 10 \mathrm{H}, H_{5}\right), 8.56$ (dd, $J=8.1,1.5 \mathrm{~Hz}$, $\left.10 \mathrm{H}, H_{9}\right), 8.38\left(\mathrm{~d}, J=9.3 \mathrm{~Hz}, 10 \mathrm{H}, H_{7}\right), 8.27\left(\mathrm{~d}, J=9.3 \mathrm{~Hz}, 10 \mathrm{H}, H_{8}\right), 8.15\left(\mathrm{~s}, 10 \mathrm{H}, H_{l}\right), 7.55(\mathrm{dd}, J=$ $\left.4.8,1.5 \mathrm{~Hz}, 10 \mathrm{H}, H_{l 1}\right), 7.49\left(\mathrm{dd}, J=8.0,4.8 \mathrm{~Hz}, 10 \mathrm{H}, H_{10}\right), 7.07\left(\mathrm{~d}, J=8.7 \mathrm{~Hz}, 20 \mathrm{H}, H_{2}\right), 6.36(\mathrm{~d}, J=$ $\left.8.6 \mathrm{~Hz}, 20 \mathrm{H}, H_{3}\right) .{ }^{13} \mathrm{C} \mathrm{NMR}\left(126 \mathrm{MHz}, 298 \mathrm{~K}, \mathrm{CD}_{3} \mathrm{CN}\right): \delta=159.1$ (imine), 150.1, 146.5, 144.1, 141.0, $140.9,140.8,139.6,139.2,134.4,133.8,132.6,132.5,131.0,130.8,128.2,127.9,127.6$ (two overlapping signals), $123.9,120.8\left(\mathrm{q},{ }^{1} J_{\mathrm{CF}}=320.8 \mathrm{~Hz},\left(\mathrm{CF}_{3} \mathrm{SO}_{2}\right)_{2} \mathrm{~N}^{-}\right)$. ESI-MS: $\mathrm{m} / z=396.1[3]^{10+}, 471.2$ $\left[3\left(\mathrm{NTf}_{2}^{-}\right)\right]^{9+}, 565.2\left[3\left(\mathrm{NTf}_{2}^{-}\right)_{2}\right]^{8+}, 686.0\left[3\left(\mathrm{NTf}_{2}^{-}\right)_{3}\right]^{7+}, 846.9\left[3\left(\mathrm{NTf}_{2}^{-}\right)_{4}\right]^{6+}, 1072.5\left[3\left(\mathrm{NTf}_{2}^{-}\right)_{5}\right]^{5+}, 1410.3$ $\left[3\left(\mathrm{NTf}_{2}{ }^{-}\right)_{6}\right]^{4+}$.

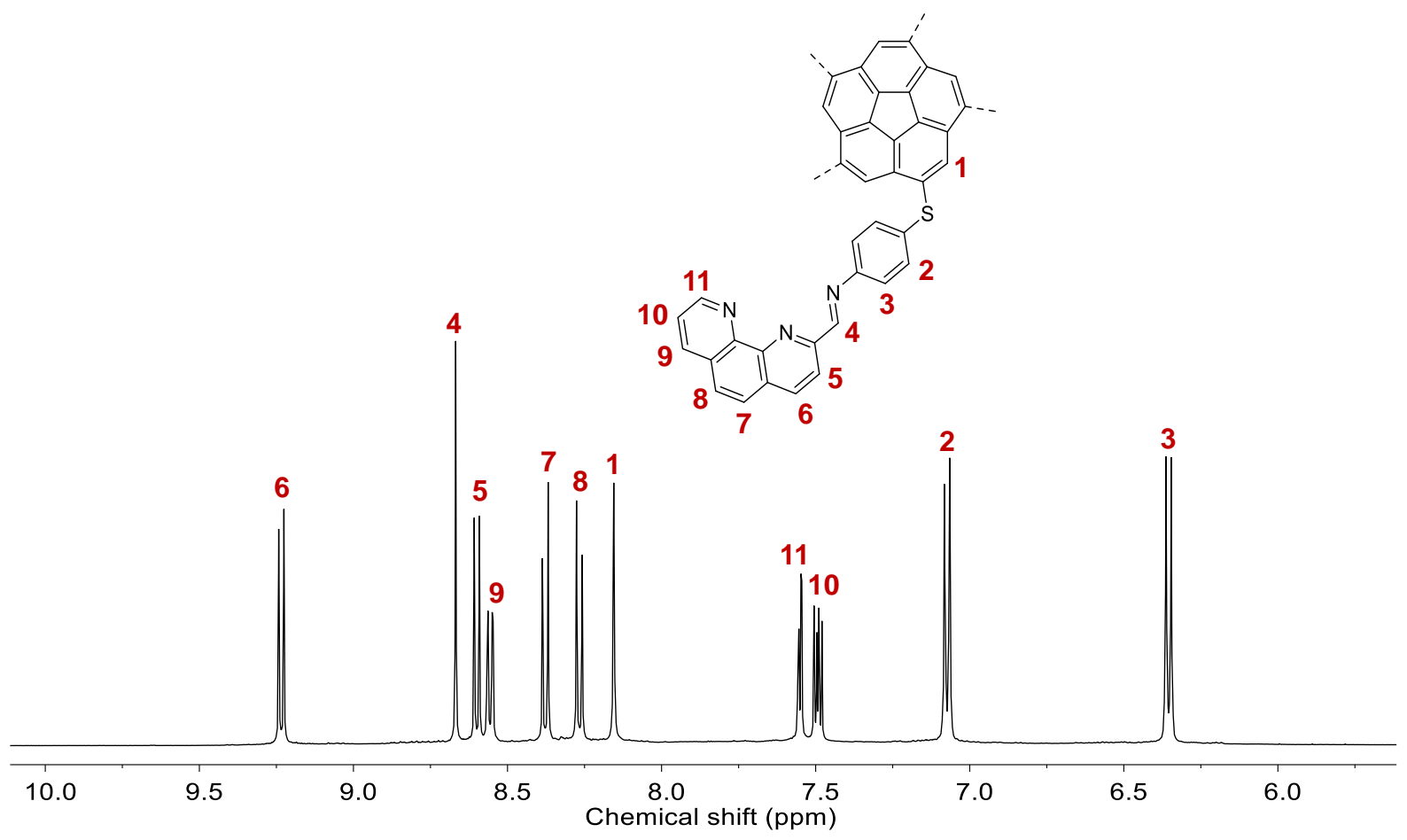

Figure S19: Aromatic region of the ${ }^{1} \mathrm{H}$ NMR spectrum (500 MHz, $298 \mathrm{~K}, \mathrm{CD}_{3} \mathrm{CN}$ ) of $\mathbf{3} \cdot 10 \mathrm{NTf}_{2}$ 


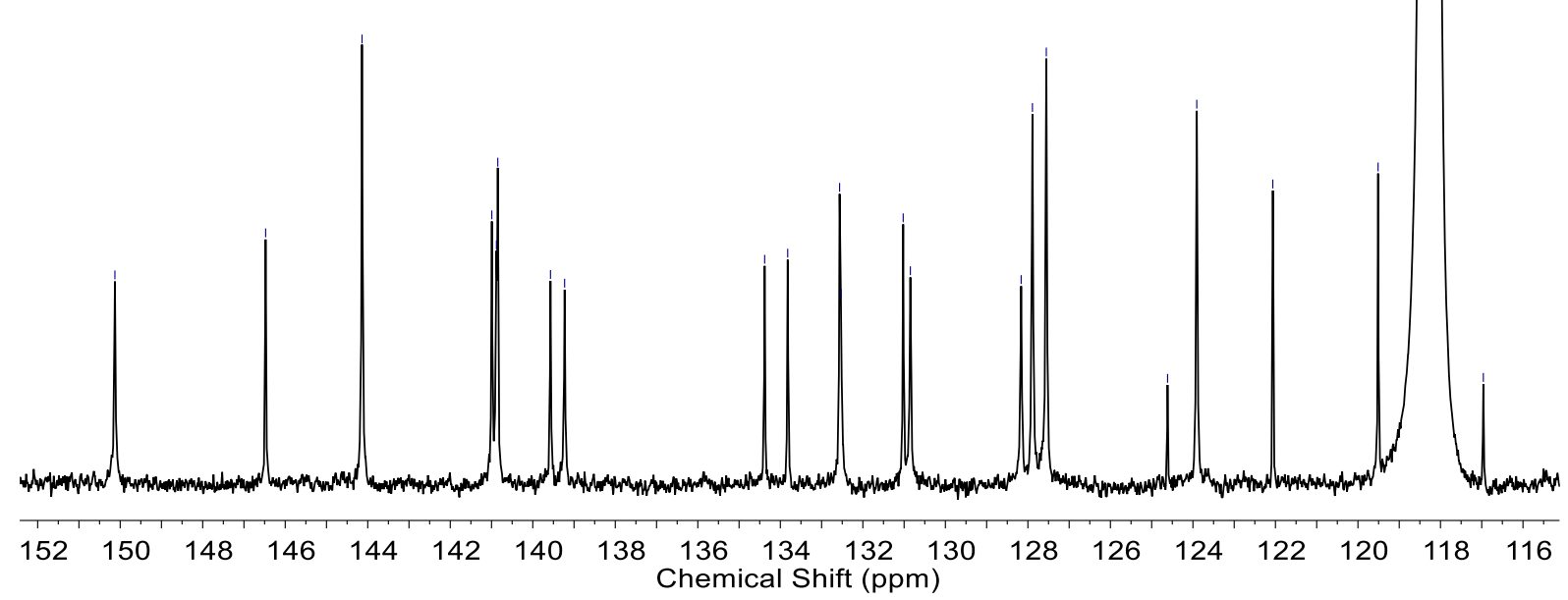

Figure S20: Aromatic region of the ${ }^{13} \mathrm{C}$ NMR spectrum $\left(126 \mathrm{MHz}, 298 \mathrm{~K}, \mathrm{CD}_{3} \mathrm{CN}\right)$ of 3.10NTf 2 .

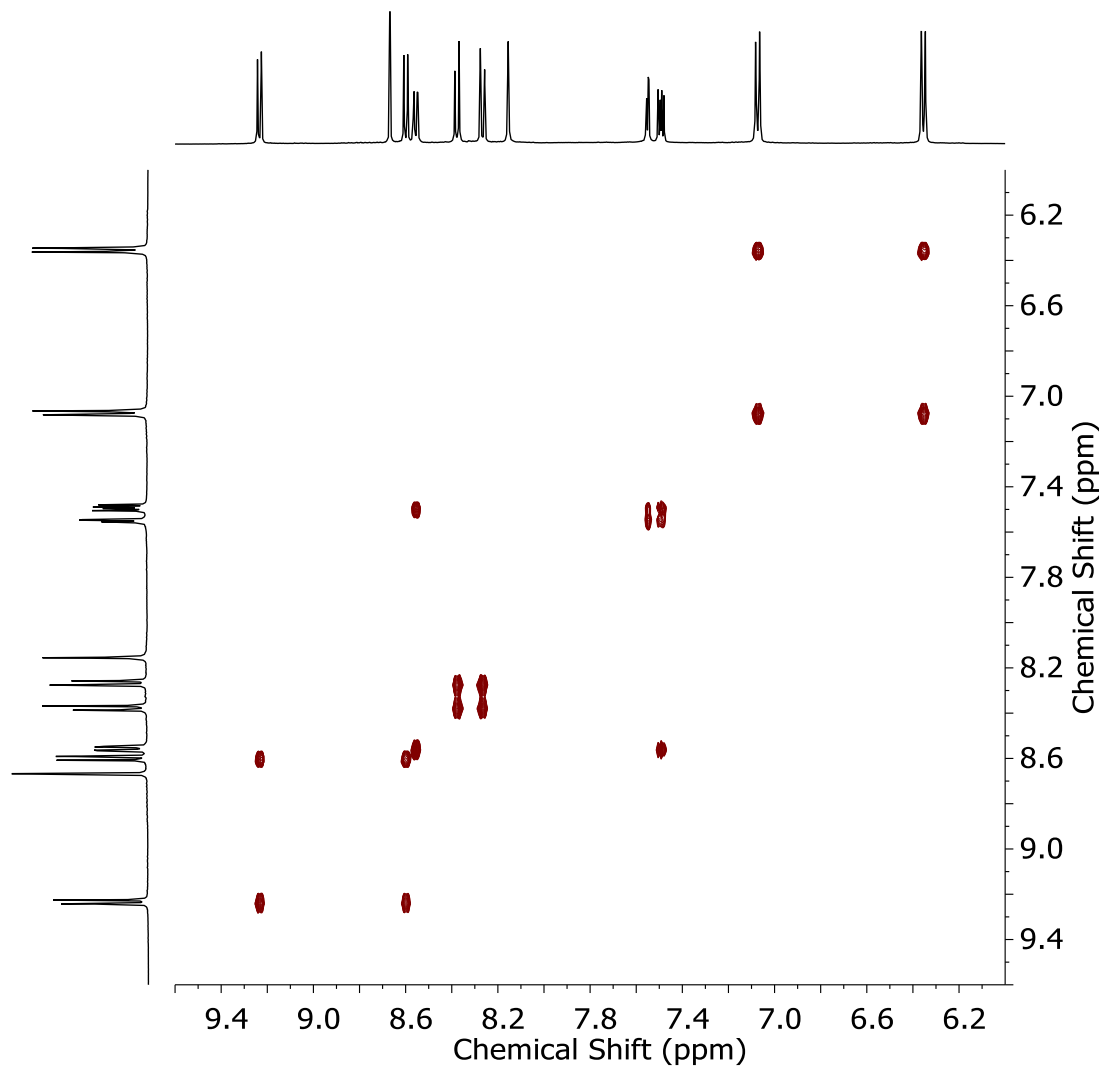

Figure S21: Aromatic region of the ${ }^{1} \mathrm{H}-{ }^{1} \mathrm{H}$ COSY spectrum $\left(500 \mathrm{MHz}, 298 \mathrm{~K}, \mathrm{CD}_{3} \mathrm{CN}\right)$ of 3.10NTf 2 . 


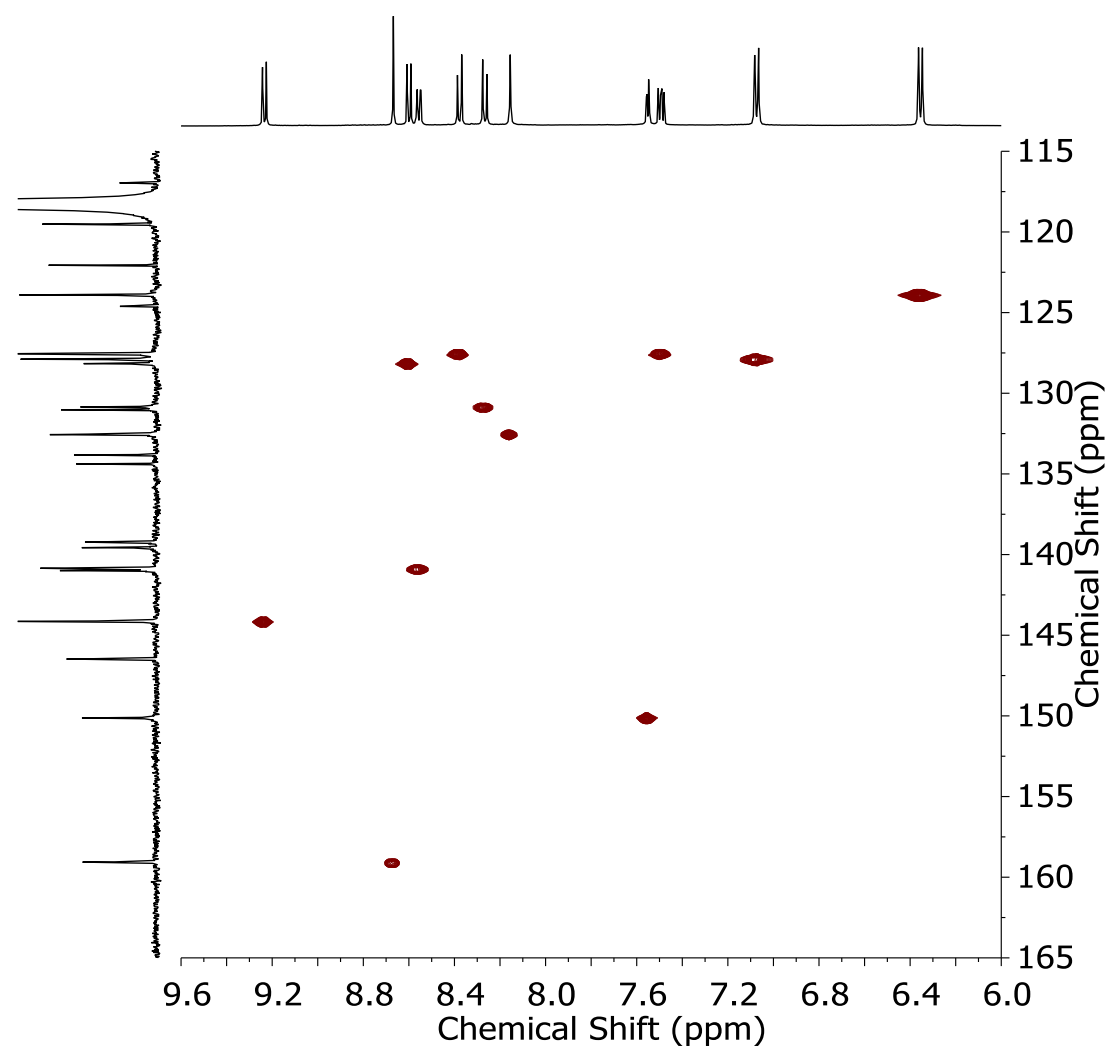

Figure S22: Aromatic region of the ${ }^{1} \mathrm{H}^{-13} \mathrm{C}$ HSQC spectrum $\left(500 \mathrm{MHz}, 298 \mathrm{~K}, \mathrm{CD}_{3} \mathrm{CN}\right)$ of $\mathbf{3} \cdot 10 \mathrm{NTf}_{2}$.

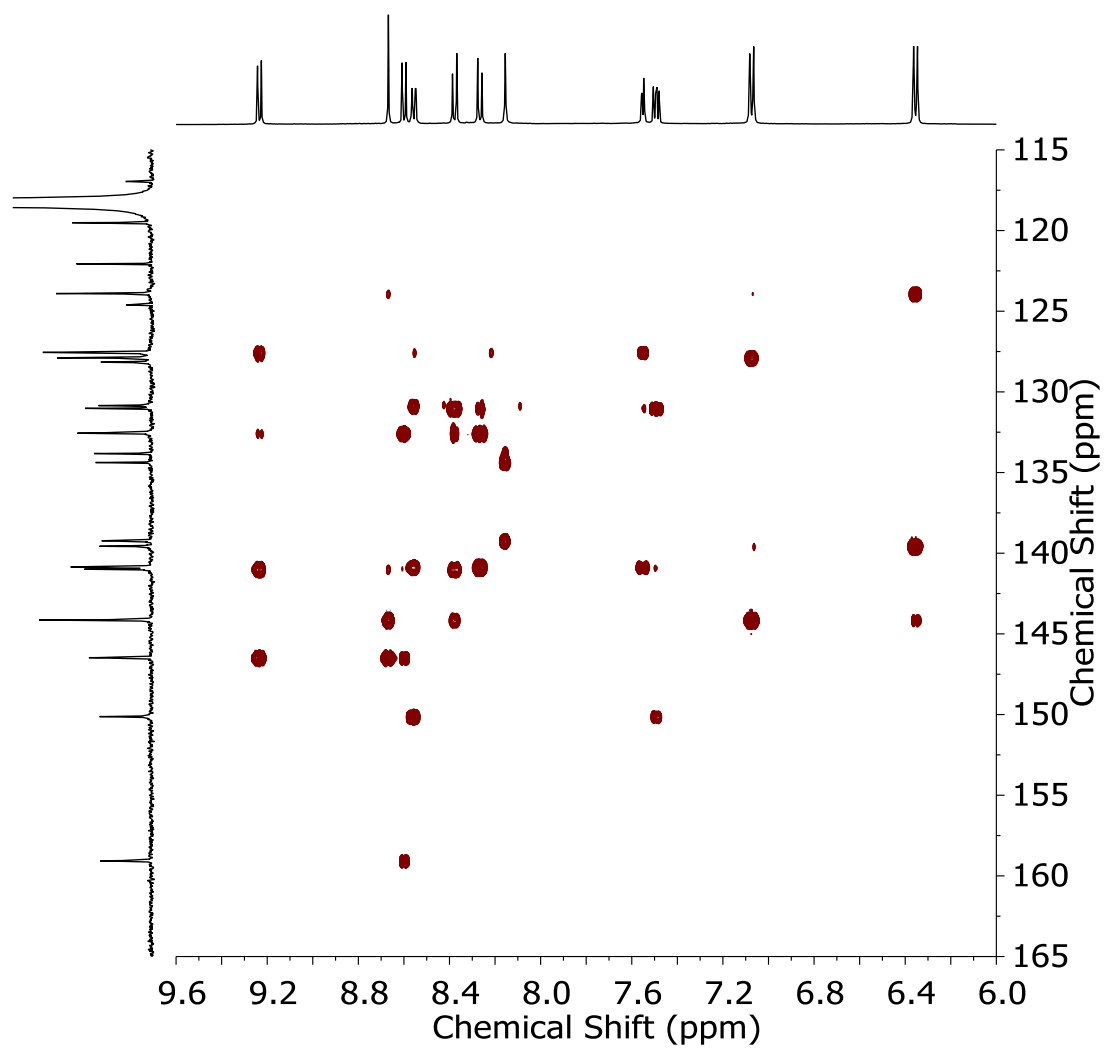

Figure S23: Aromatic region of the ${ }^{1} \mathrm{H}^{13} \mathrm{C}$ HMBC spectrum $\left(500 \mathrm{MHz}, 298 \mathrm{~K}, \mathrm{CD}_{3} \mathrm{CN}\right)$ of 3.10NTf 2 . 


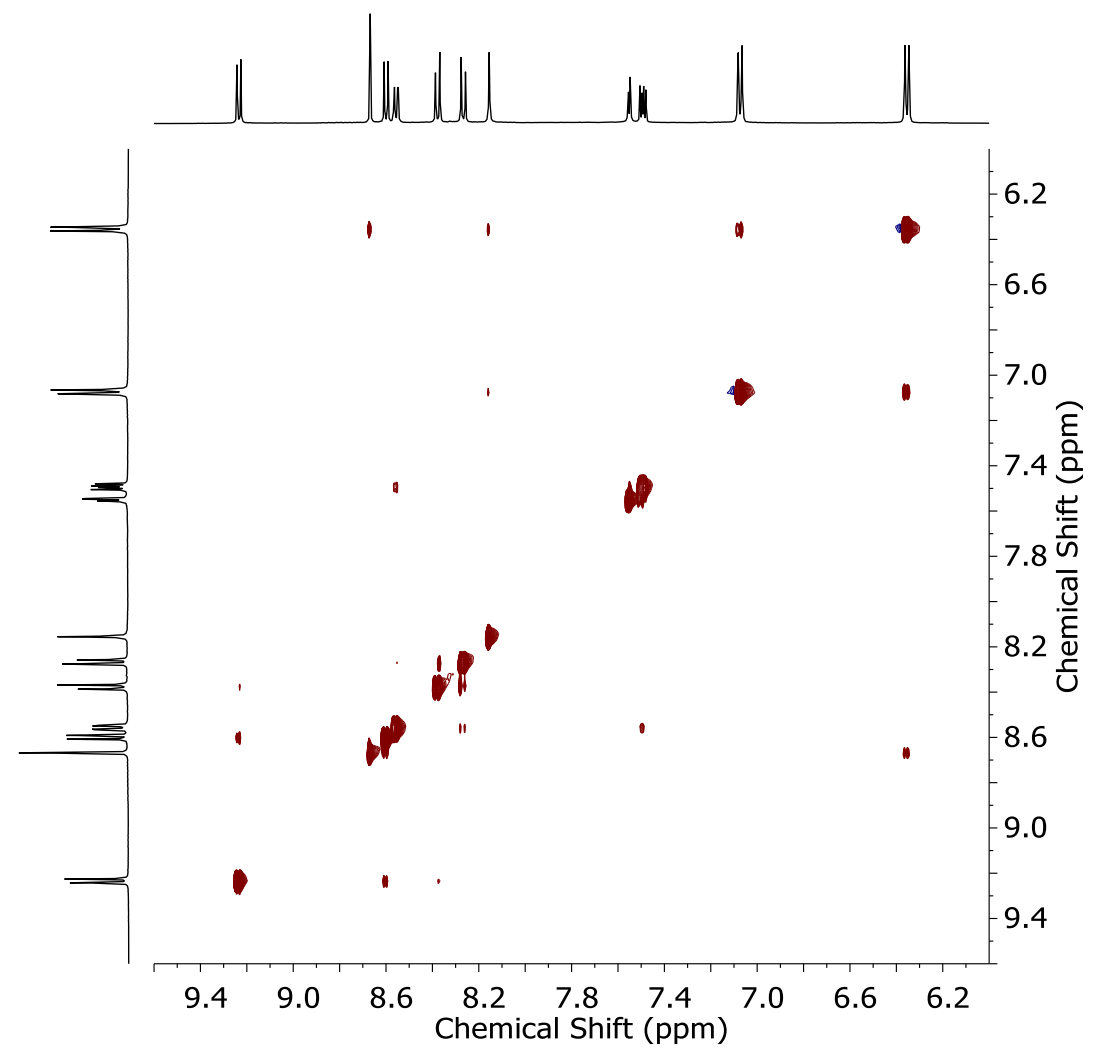

Figure S24: Aromatic region of the ${ }^{1} \mathrm{H}-{ }^{1} \mathrm{H}$ NOESY spectrum $\left(500 \mathrm{MHz}, 298 \mathrm{~K}, \mathrm{CD}_{3} \mathrm{CN}\right)$ of $\mathbf{3} \cdot 10 \mathrm{NTf}_{2}$.

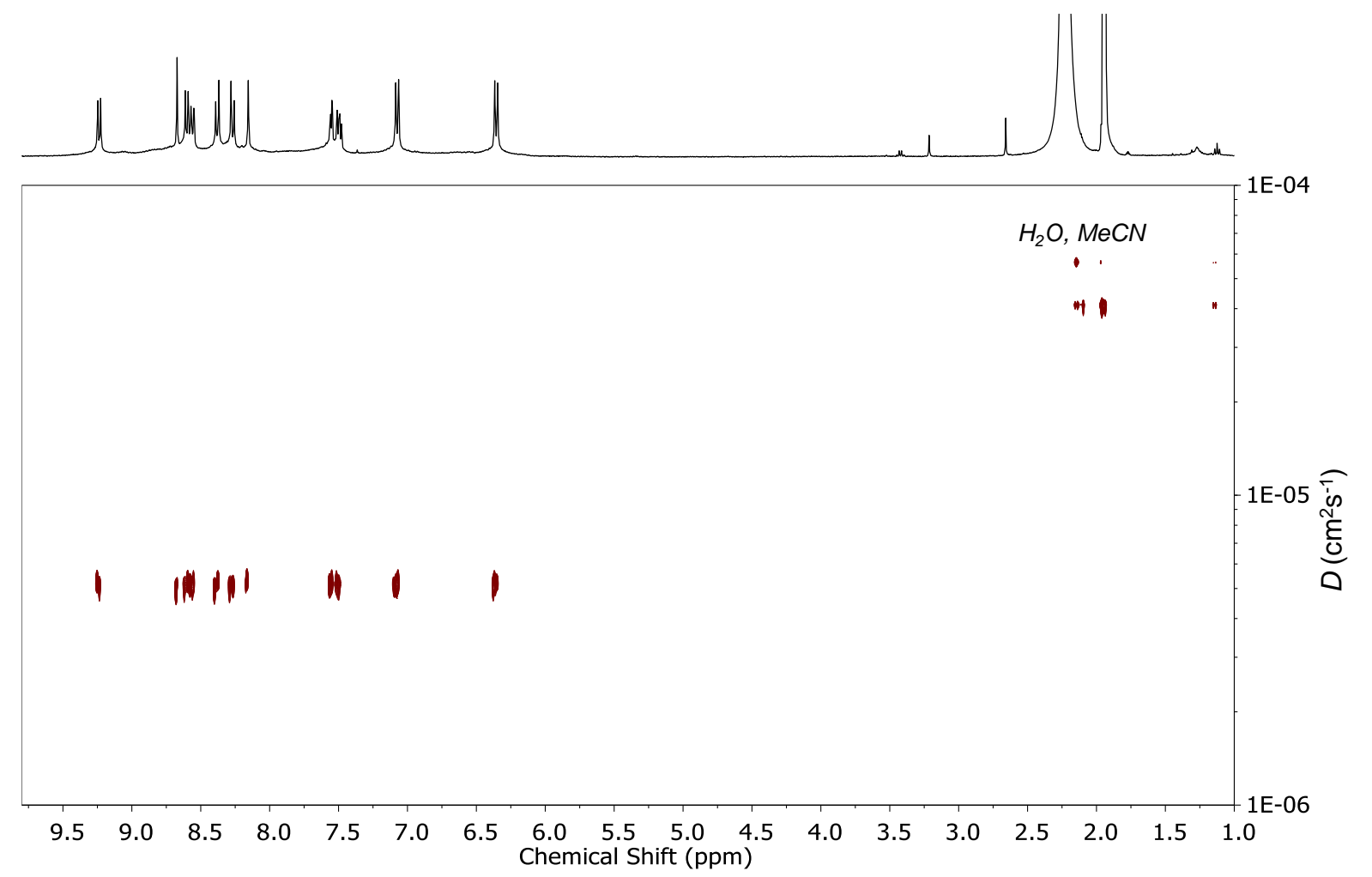

Figure S25: ${ }^{1} \mathrm{H}$ DOSY spectrum $\left(400 \mathrm{MHz}, 298 \mathrm{~K}, \mathrm{CD}_{3} \mathrm{CN}\right)$ of 3.10NTf 2 . The diffusion coefficient for 3 in $\mathrm{CD}_{3} \mathrm{CN}$ was measured to be $5.20 \times 10^{-6} \mathrm{~cm}^{2} \mathrm{~s}^{-1}$. 


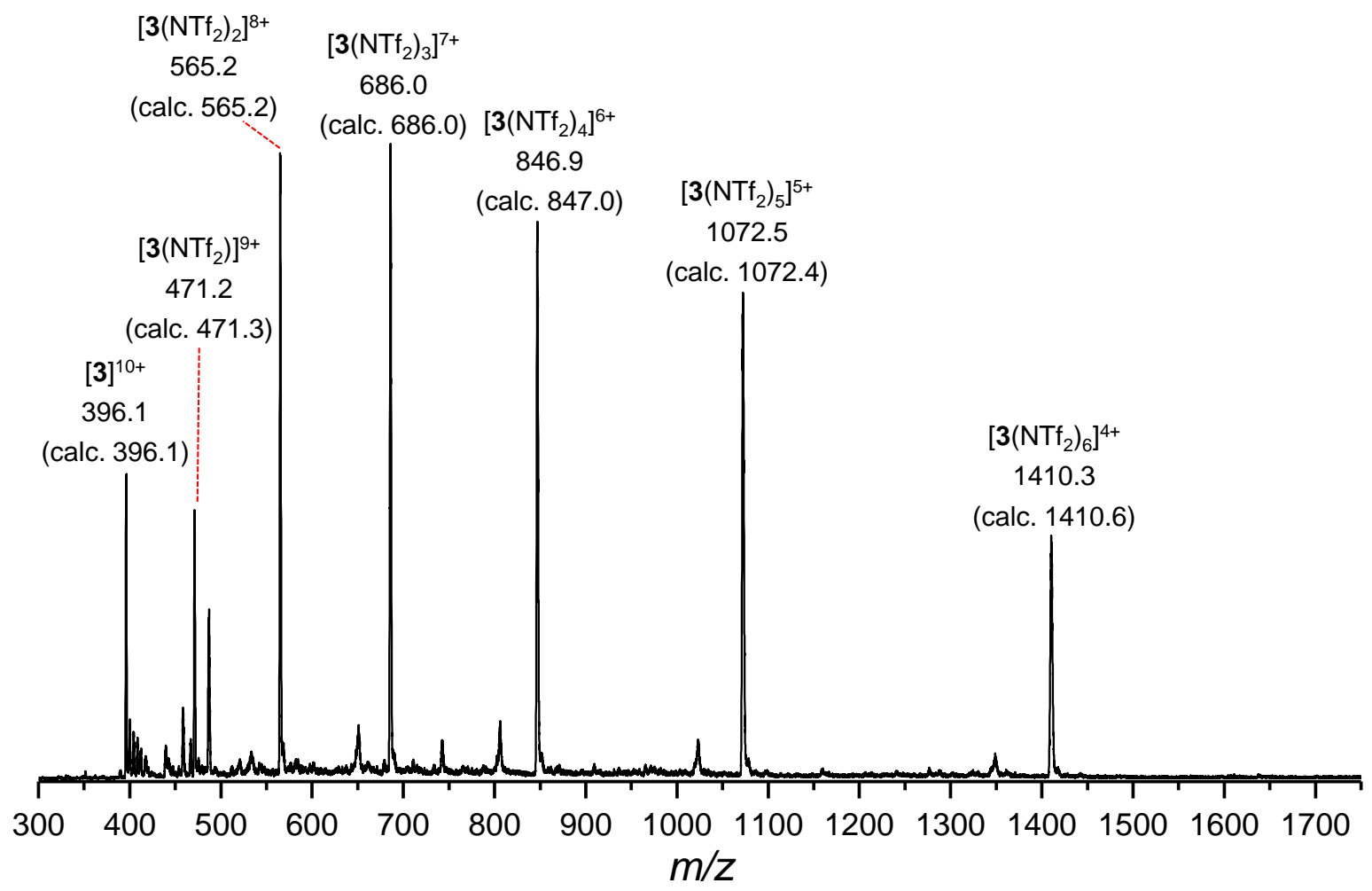

Figure S26: Low-resolution ESI-mass spectrum of 3·10NTf $\mathrm{N}_{2}$. 

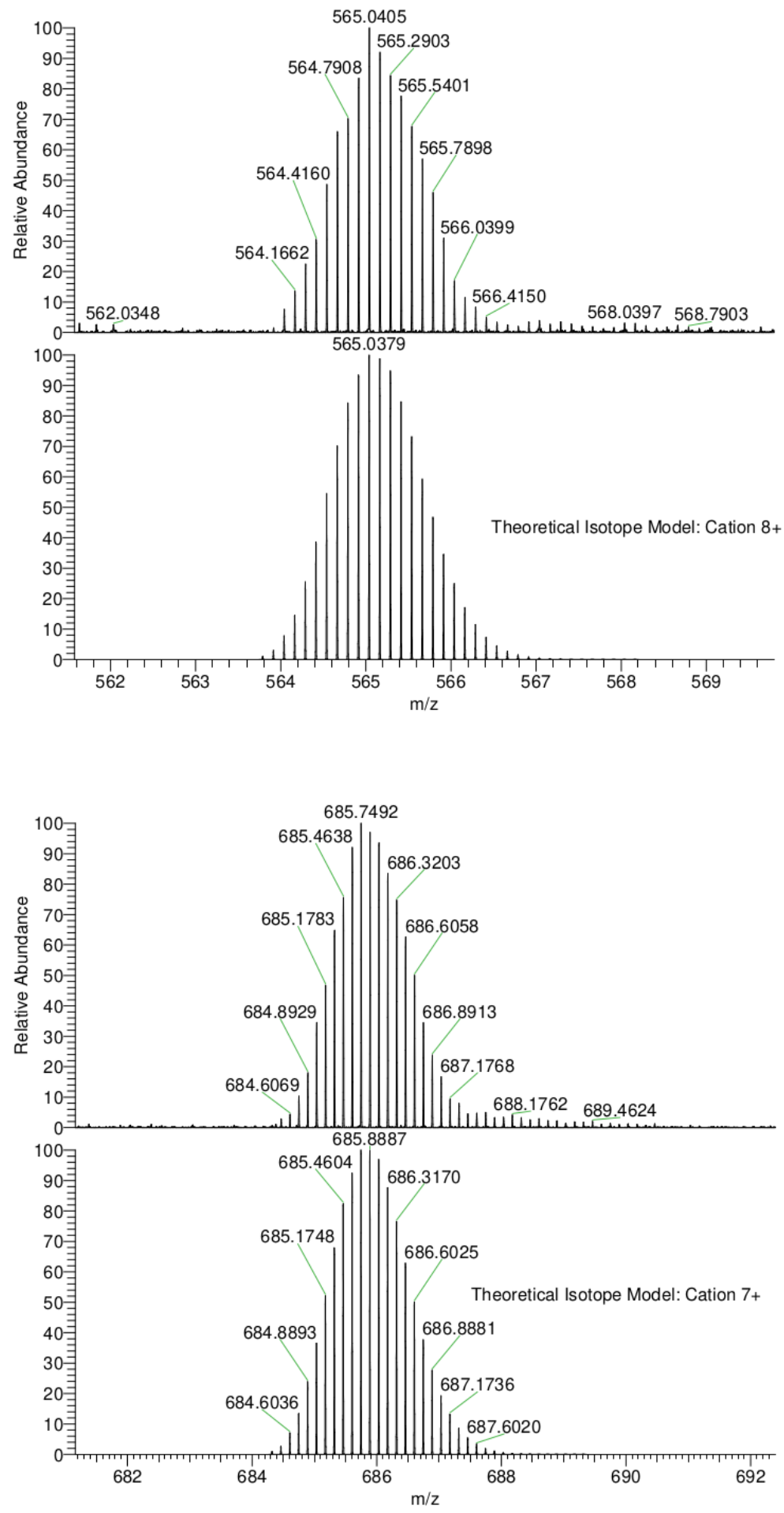

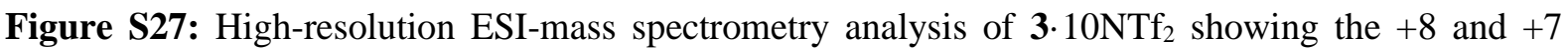
peaks. 


\subsection{Synthesis and characterization of $\left[\mathrm{Zn}_{5} \mathrm{~L}_{2}\right]\left(\mathrm{BF}_{4}\right)_{10}\left(3 \cdot 10 \mathrm{BF}_{4}\right)$}

To a small test tube was added 2-formyl-1,10-phenanthroline ( $4.8 \mathrm{mg}, 23 \mu \mathrm{mol}, 10$ equiv.), zinc tetrafluoroborate hydrate $\left(4.0 \mathrm{mg}, 11.5 \mu \mathrm{mol}, 5\right.$ equiv.) and $\mathrm{CD}_{3} \mathrm{CN}(0.5 \mathrm{~mL})$ and the mixture was stirred at room temperature for $5 \mathrm{~min}$. Sym-pentakis(4-aminothiophenyl)corannulene $(4.0 \mathrm{mg}, 4.6$ $\mu$ mol, 2 equiv.) was then added as a solution in $\mathrm{CD}_{3} \mathrm{CN}(0.4 \mathrm{~mL})$ and the mixture was degassed by bubbling with nitrogen for $15 \mathrm{~min}$ and then stirred at $353 \mathrm{~K}$ for 2 days. Formation of $\mathbf{3} \cdot 10 \mathrm{BF}_{4}$ was confirmed by ${ }^{1} \mathrm{H}$ NMR. The solution was then filtered and diethyl ether (ca. $5 \mathrm{~mL}$ ) was added. The light orange solid was isolated through centrifugation and washed a further two times with diethyl ether to give $3 \cdot 10 \mathrm{BF}_{4}$ as a light orange powder. Yield $9.7 \mathrm{mg}, 86 \%$. All NMR data closely matched those of the triflimide salt. ${ }^{~} \mathrm{H}$ NMR (400 MHz; $298 \mathrm{~K} ; \mathrm{CD}_{3} \mathrm{CN}$ ): $\delta 9.25$ (d, $\left.J=8.3 \mathrm{~Hz}, 10 \mathrm{H}, H_{6}\right), 8.70\left(\mathrm{~s}, 10 \mathrm{H}, H_{4}\right)$, $8.63\left(\mathrm{~d}, J=8.4 \mathrm{~Hz}, 10 \mathrm{H}, H_{5}\right), 8.56\left(\mathrm{dd}, J=8.2,1.5 \mathrm{~Hz}, 10 \mathrm{H}, H_{9}\right), 8.39\left(\mathrm{~d}, J=9.2 \mathrm{~Hz}, 10 \mathrm{H}, H_{7}\right), 8.27$ $\left(\mathrm{d}, J=9.2 \mathrm{~Hz}, 10 \mathrm{H}, H_{8}\right), 8.15\left(\mathrm{~s}, 10 \mathrm{H}, H_{l}\right), 7.56\left(\mathrm{dd}, J=4.8,1.5 \mathrm{~Hz}, 10 \mathrm{H}, H_{l 1}\right), 7.50(\mathrm{dd}, J=8.1,4.8$ $\left.\mathrm{Hz}, 10 \mathrm{H}, H_{10}\right), 7.08\left(\mathrm{~d}, J=8.6 \mathrm{~Hz}, 20 \mathrm{H}, H_{2}\right), 6.36\left(\mathrm{~d}, J=8.6 \mathrm{~Hz}, 20 \mathrm{H}, H_{3}\right)$. ESI-MS: $m / z=449.7$ $\left[2\left(\mathrm{BF}_{4}^{-}\right)\right]^{9+}, 516.8\left[2\left(\mathrm{BF}_{4}^{-}\right)_{2}\right]^{8+}, 603.0\left[2\left(\mathrm{BF}_{4}^{-}\right)_{3}\right]^{7+}, 718.2\left[2\left(\mathrm{BF}_{4}^{-}\right)_{4}\right]^{6+}, 879.0\left[2\left(\mathrm{BF}_{4}^{-}\right)_{5}\right]^{5+}, 1120.5$ $\left[2\left(\mathrm{BF}_{4}^{-}\right)_{6}\right]^{4+}, 1522.5\left[2\left(\mathrm{BF}_{4}^{-}\right)_{7}\right]^{3+}$.

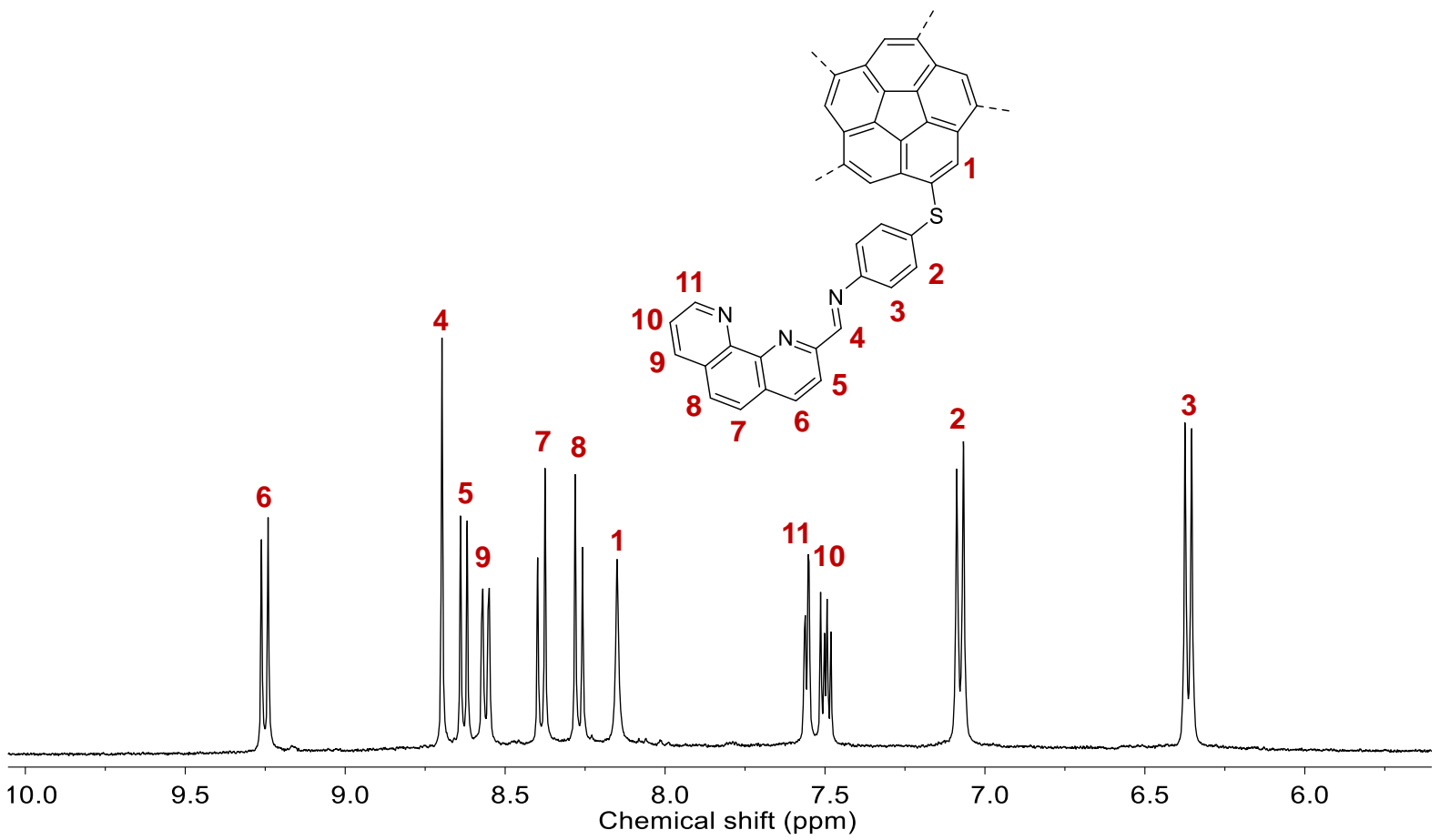

Figure S28: Aromatic region of the ${ }^{1} \mathrm{H}$ NMR spectrum $\left(400 \mathrm{MHz}, 298 \mathrm{~K}, \mathrm{CD}_{3} \mathrm{CN}\right)$ of $\mathbf{3} \cdot 10 \mathrm{BF}_{4}$. 


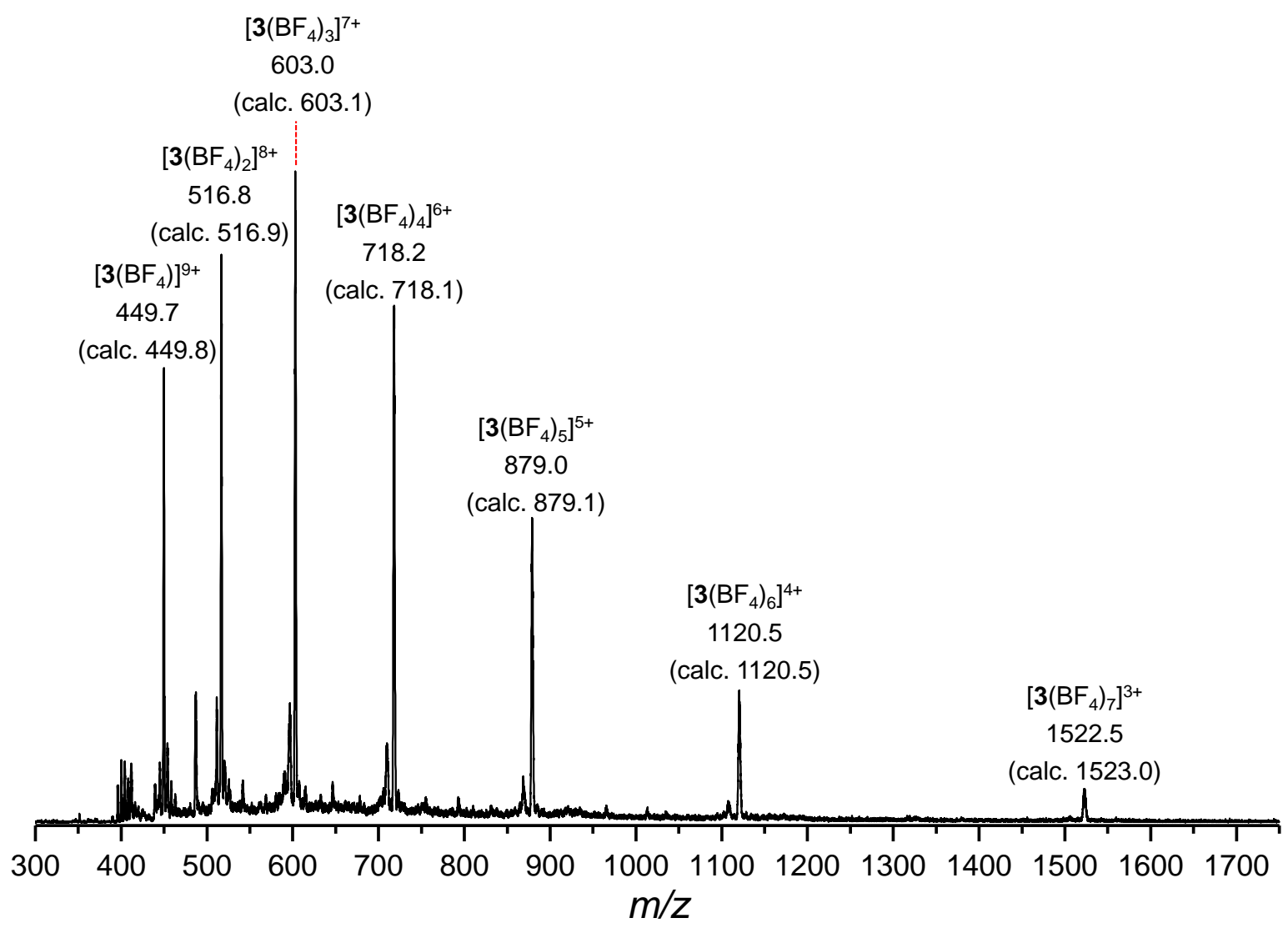

Figure S29: Low-resolution ESI-mass spectrum of a mixture of 3.10BF 4 . 

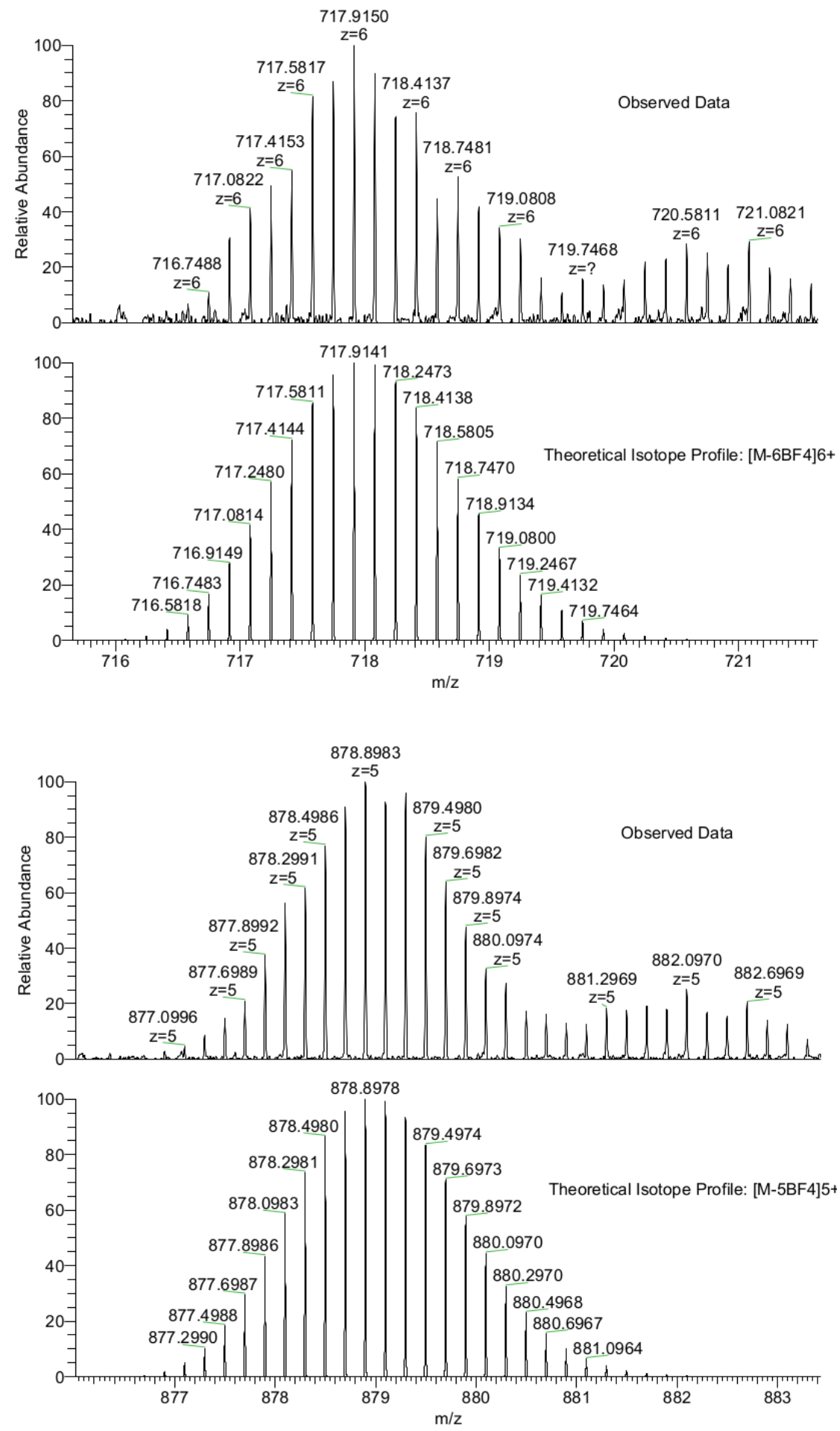

Figure S30: High-resolution ESI-mass spectrometry analysis of $3 \cdot 10 \mathrm{BF}_{4}$ showing the +6 and +5 peaks. 


\subsection{Structural transformation of 1 into 2}

A sample of $1 \cdot 10 \mathrm{BF}_{4}$ was initially prepared according to the method described in Section 1.3, starting from $2.5 \mathrm{mg}(2.9 \mu \mathrm{mol})$ of subcomponent $\mathbf{A}$. Assembly $1 \cdot 10 \mathrm{BF}_{4}$ was combined with 2 -formyl-1,10phenanthroline ( $3.0 \mathrm{mg}, 14 \mu \mathrm{mol}, 20$ equiv. per assembly, assuming quantitative formation of $\mathbf{1} \cdot 10 \mathrm{BF}_{4}$ in the first step) and $\mathrm{Co}\left(\mathrm{BF}_{4}\right)_{2} \cdot 6 \mathrm{H}_{2} \mathrm{O}\left(2.5 \mathrm{mg}, 7.3 \mu \mathrm{mol}, 10.2\right.$ equiv. per assembly) in $\mathrm{CD}_{3} \mathrm{CN}(0.65 \mathrm{~mL})$ and the mixture degassed by bubbling with nitrogen for $15 \mathrm{~min}$. The mixture was stirred at $333 \mathrm{~K}$ for $24 \mathrm{~h}$ and then at $353 \mathrm{~K}$ for $72 \mathrm{~h}$. The ${ }^{1} \mathrm{H}$ NMR (Figure S31) and ESI mass (Figure S32) spectra of the resulting mixture were consistent with the formation of $\mathbf{2} \cdot 10 \mathrm{BF}_{4}$ as the major product in solution.

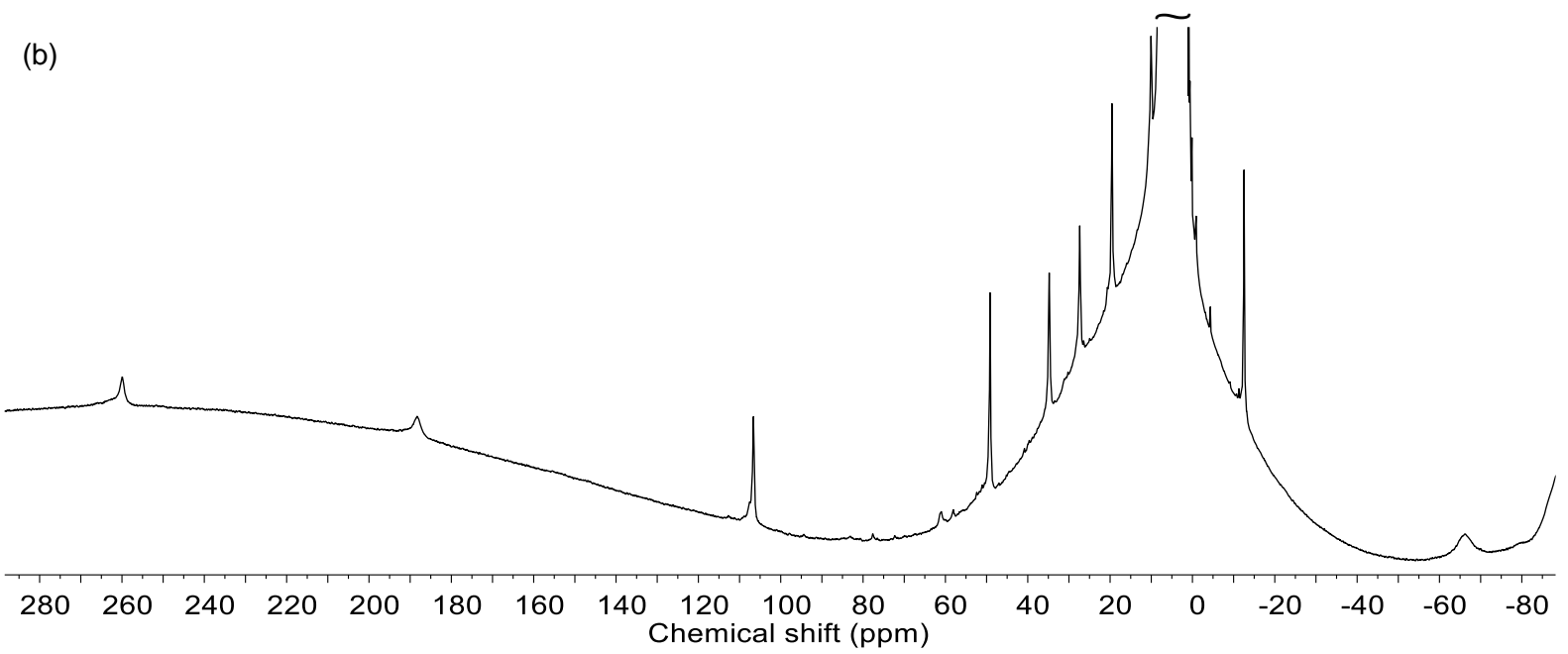

(a)

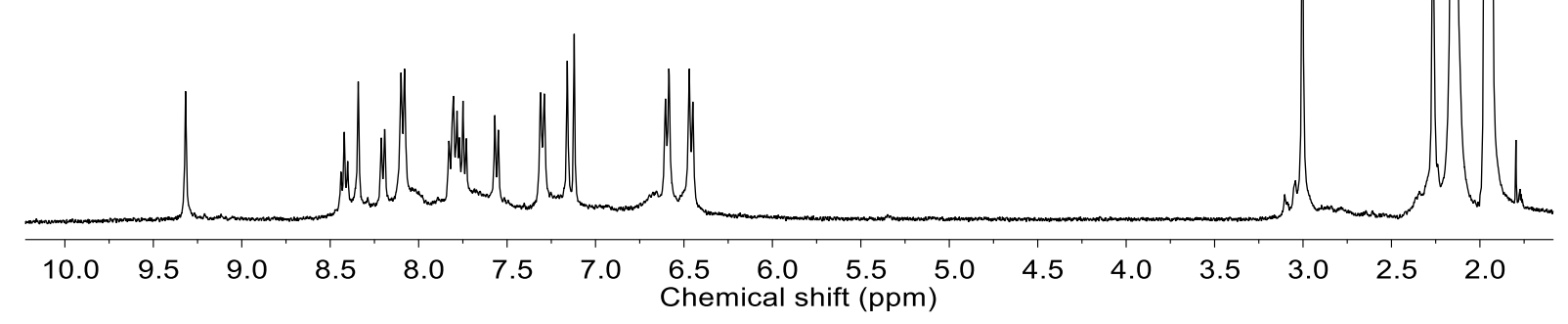

Figure S31: ${ }^{1} \mathrm{H}$ NMR spectra $\left(400 \mathrm{MHz}, 298 \mathrm{~K}, \mathrm{CD}_{3} \mathrm{CN}\right.$ ) of (a) the initial sample of $\mathbf{1} \cdot 10 \mathrm{BF}_{4}$ and (b) the sample of $2 \cdot 10 \mathrm{BF}_{4}$ obtained following the structural transformation. 


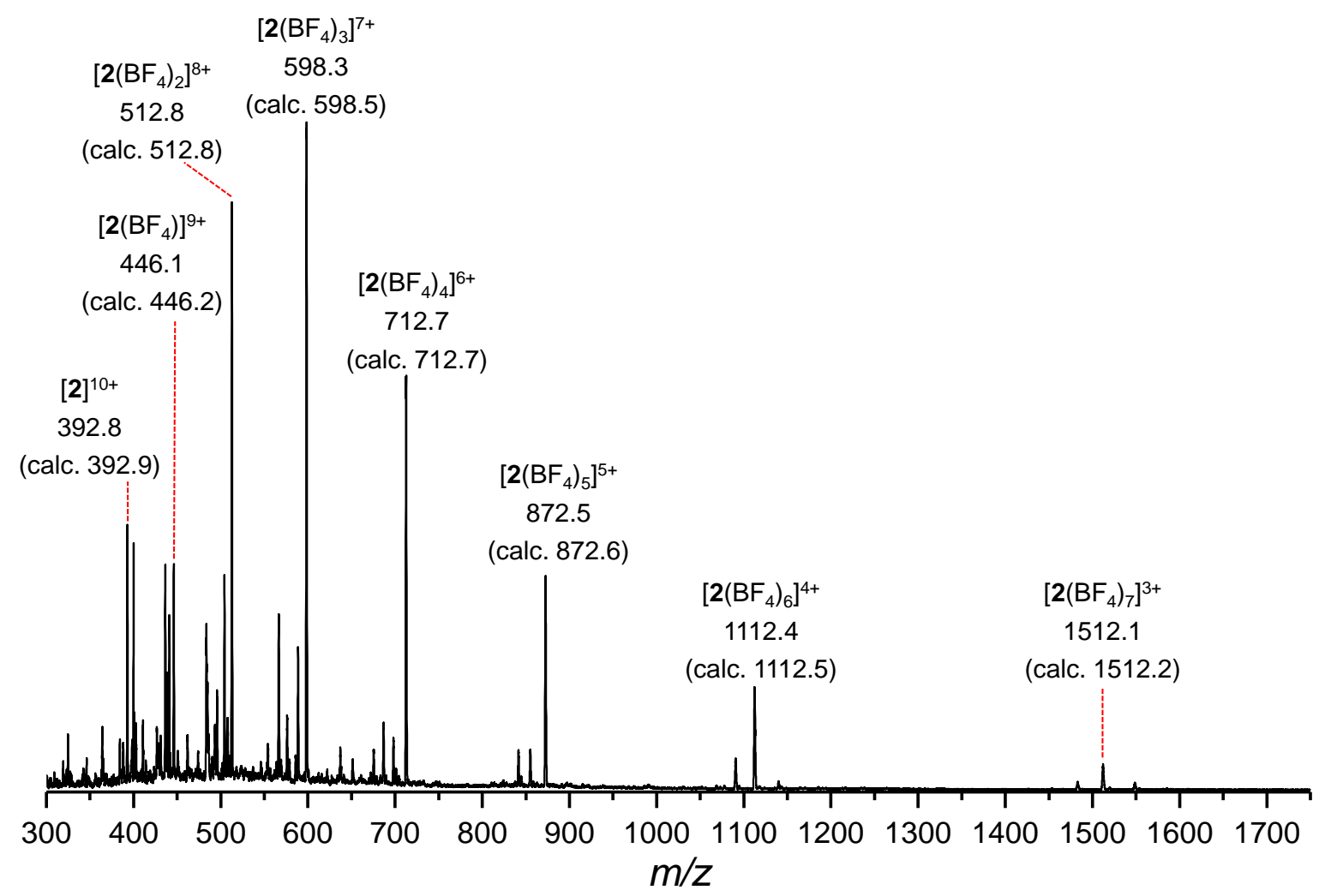

Figure S32: Low-resolution ESI-mass spectrum of the reaction mixture from the structural transformation of $\mathbf{1} \cdot 10 \mathrm{BF}_{4}$ into $2 \cdot 10 \mathrm{BF}_{4}$. 


\section{Host-guest studies}

\subsection{General procedure}

The host-guest chemistry of the diamagnetic assemblies $\mathbf{1}$ and $\mathbf{3}$ was investigated with the prospective guests shown in Figure S33. Host-guest complexes were prepared on an NMR scale and characterized by ${ }^{1} \mathrm{H}$ NMR spectroscopy. A solution of $\mathbf{1}$ or $\mathbf{3}$ in $\mathrm{CD}_{3} \mathrm{CN}(1.0-3.0 \mathrm{mM})$ was transferred to an NMR tube and the prospective guest molecule (typically 5-10 equiv) was added as a solid. The mixtures were sonicated for 10 minutes and allowed to equilibrate for at least 24 hours at $298 \mathrm{~K}$ prior to measurement of the ${ }^{1} \mathrm{H}$ NMR spectrum. In the case of $\mathbf{3}$, the mixtures were subsequently heated at $353 \mathrm{~K}$ for $24 \mathrm{hr}$ and the ${ }^{1} \mathrm{H}$ NMR spectra measured again.

In both cases a fast-exchange binding interaction was inferred to have occurred with corannulene as indicated by the observation of clear shifts in both the host and guest signals. Characterization of the resulting host-guest complexes is given below.

In all other cases no binding was inferred to have taken place, as the signals for the host appeared at the same chemical shifts as in the absence of the guest and the signals for the guest were identical to those in the absence of host for guests that were soluble in $\mathrm{CD}_{3} \mathrm{CN}$. In general small shifts of $<0.05 \mathrm{ppm}$ were attributed to weak non-specific $\pi$-stacking interactions while guest binding was inferred by more significant shifts of $>0.05 \mathrm{ppm}$. Attempts were also made to synthesise $\mathbf{1}$ and $\mathbf{3}$ in the presence of $\mathrm{C}_{60}$ and coronene resulting in ${ }^{1} \mathrm{H}$ NMR spectra identical to those obtained in the absence of guest.

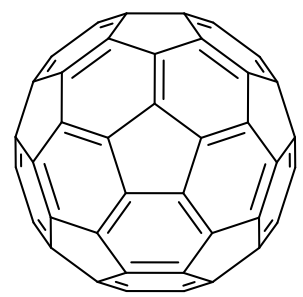

$C_{60}$

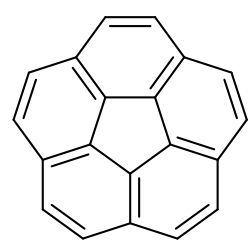

corannulene<smiles>c1cc2ccc3ccc4ccc5ccc6ccc1c1c2c3c4c5c61</smiles>

coronene

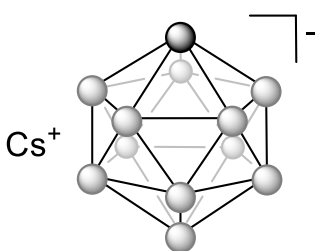

$\mathrm{CsCB}_{11} \mathrm{H}_{12}$

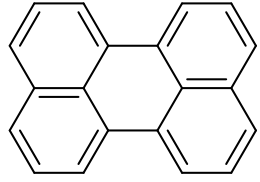

perylene

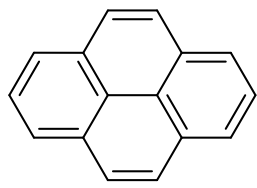

pyrene<smiles>c1ccc2c(c1)c1ccccc1c1ccccc21</smiles>

triphenylene<smiles>O=C1OC(=O)c2ccc3c4c(ccc1c24)C(=O)OC3=O</smiles>

1,4,5,8-naphthalenetetracarboxylic dianhydride

Figure S33: Overview of prospective guests used in this study. Only corannulene was observed to interact with $\mathbf{1}$ and $\mathbf{3}$. 


\subsection{Host-guest interaction of corannulene with 1}

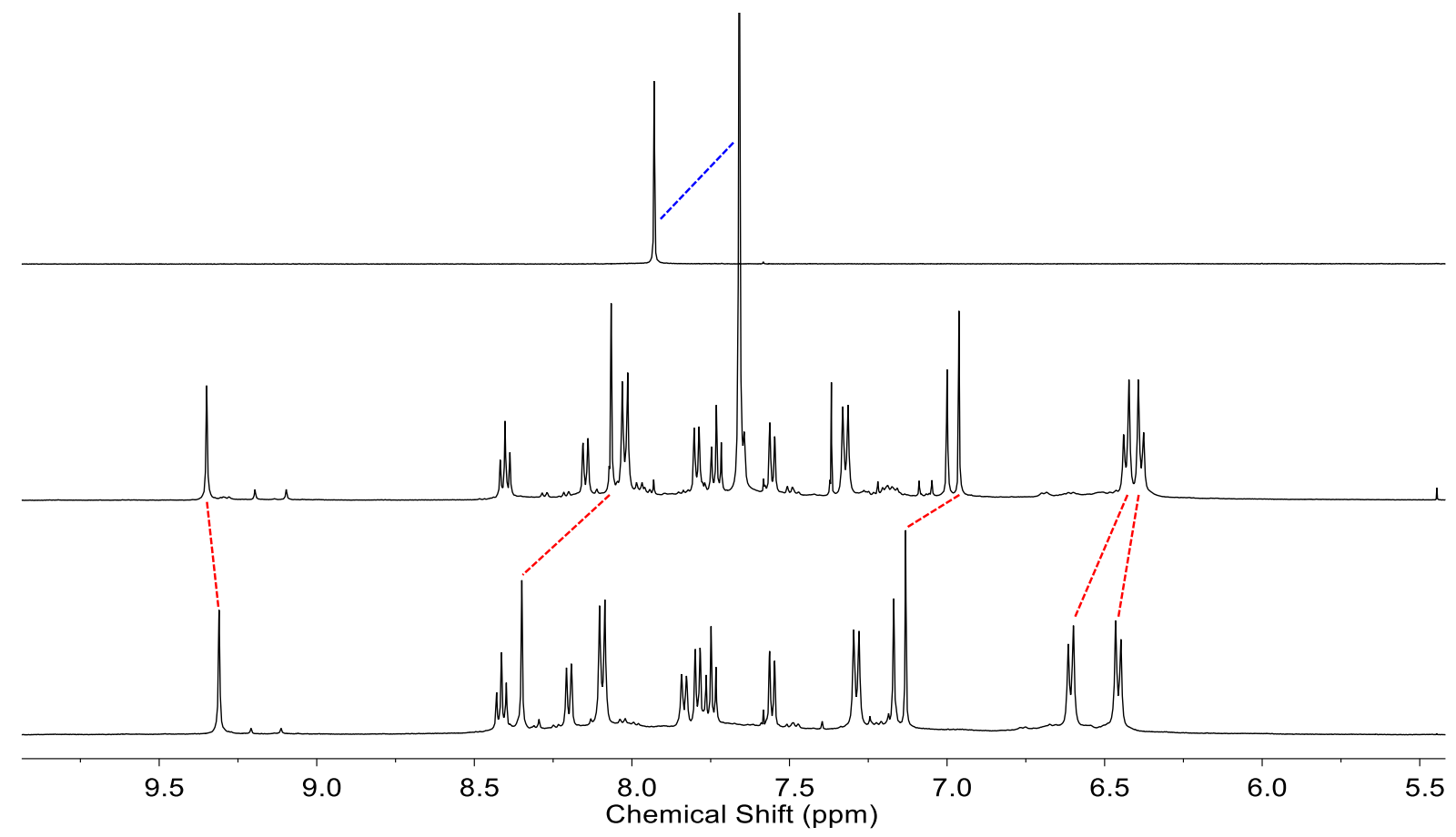

Figure S34: Aromatic region of the ${ }^{1} \mathrm{H}$ NMR spectrum $\left(500 \mathrm{MHz}, 298 \mathrm{~K}, \mathrm{CD}_{3} \mathrm{CN}\right.$ ) of corannulene (top), $\mathbf{1}$ (bottom) and a mixture of $\mathbf{1}$ and ca. 10 equiv. corannulene (middle). Shifts in the signals of $\mathbf{1}$ are marked with red dashed lines and the shift in the corannulene signal is marked with a blue dashed line. 


\subsection{Host-guest interaction of corannulene with 3}

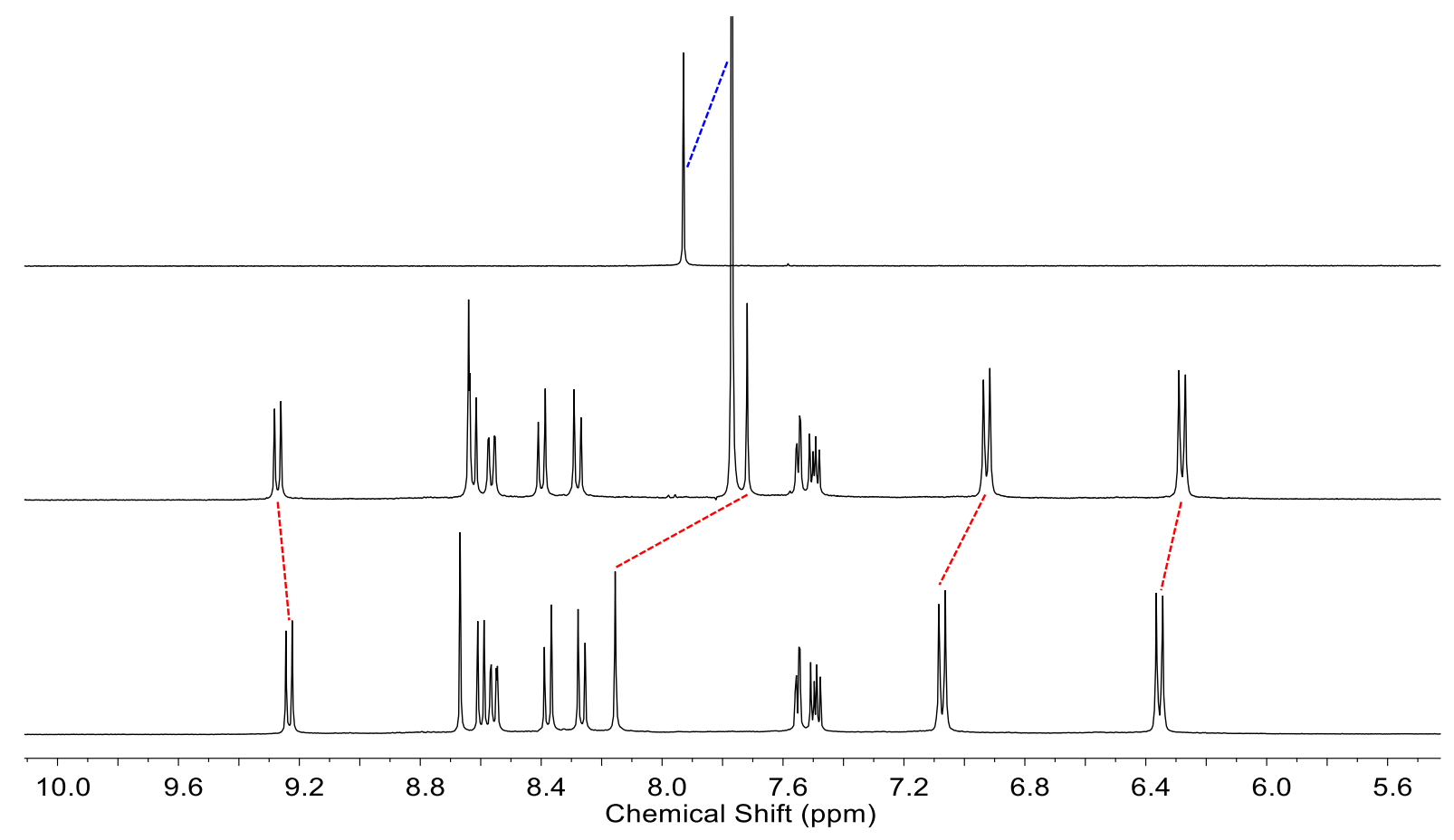

Figure S35: Aromatic region of the ${ }^{1} \mathrm{H}$ NMR spectrum $\left(500 \mathrm{MHz}, 298 \mathrm{~K}, \mathrm{CD}_{3} \mathrm{CN}\right.$ ) of corannulene (top), $\mathbf{3}$ (bottom) and a mixture of $\mathbf{3}$ and ca. 10 equiv. corannulene (middle). Shifts in the signals of $\mathbf{3}$ are marked with red dashed lines and the shift on the corannulene signal is marked with a blue dashed line. 


\section{X-ray crystallography}

Data were collected at Beamline I19 of Diamond Light Source employing silicon double crystal monochromated synchrotron radiation $(0.6889 \AA)$ with $\omega$ and $\psi$ scans at $100(2) K^{3}{ }^{3}$ Data integration and reduction were undertaken with Xia2. ${ }^{4}$ Subsequent computations were carried out using the WinGX-32 graphical user interface. ${ }^{5}$ Multi-scan empirical absorption corrections were applied to the data using the AIMLESS ${ }^{6}$ tool in the CCP4 suite. ${ }^{7}$ The structures were solved by direct methods using SHELXT $^{8}$ then refined and extended with SHELXL. ${ }^{9}$ In general, non-hydrogen atoms with occupancies greater than 0.5 were refined anisotropically. Carbon-bound hydrogen atoms were included in idealised positions and refined using a riding model. Disorder was modelled using standard crystallographic methods including constraints, restraints and rigid bodies where necessary. Crystallographic data along with specific details pertaining to the refinement follow.

In all cases no restraints were applied to the corannulene moieties within the structures. Distances between corannulene moieties in the structures were calculated as the average perpendicular distance of the atoms of the central pentagon of one corannulene to the least-squares plane of the atoms of the central pentagon of the other corannulene (and vice versa to give a total of 10 measurements). The bowl depths of corannulenes in the structures were calculated as the average perpendicular distance between the rim carbon atoms and the least-squares plane of the central pentagon. The standard deviations of all measurements are derived from the standard deviation of the measured distances and all calculated distances are given as the average across all crystallographically independent measurements in the structures.

Crystallographic data have been deposited with the CCDC (CCDC 1913638-1913643 and 1913646).

\section{$1 \cdot 10 \mathrm{BF}_{4} \cdot 16.25 \mathrm{MeCN} \cdot 2.5 \mathrm{C}_{4} \mathrm{H}_{10} \mathrm{O}[+$ solvent $]$}

Formula $\mathrm{C}_{382.50} \mathrm{H}_{313.75} \mathrm{~B}_{10} \mathrm{Cu}_{10} \mathrm{~F}_{40} \mathrm{~N}_{56.25} \mathrm{O}_{2.50} \mathrm{~S}_{20}, M$ 7882.83, Monoclinic, space group P 21/c (\#14), a 33.308(7), $b$ 28.413(6), c 44.063(9) $\AA, \beta 110.98(3), V 38935(15) \AA^{3}, D_{\mathrm{c}} 1.345 \mathrm{~g} \mathrm{~cm}^{-3}, Z 4$, crystal size 0.100 by 0.050 by $0.040 \mathrm{~mm}$, colour brown, habit block, temperature 100(2) Kelvin, $\lambda$ (Synchrotron) $0.6889 \AA, \mu$ (Synchrotron) $0.662 \mathrm{~mm}^{-1}, T$ (Analytical) $\min , \max 0.960773912838,1.0$, $2 \theta_{\text {max }} 45.00, h k l$ range $-3336,-3131,-4846, N 243326, N_{\text {ind }} 55303\left(R_{\text {merge }} 0.0340\right), N_{\text {obs }} 37740(\mathrm{I}$ $>2 \sigma(\mathrm{I})), N_{\text {var }} 4999$, residuals ${ }^{*} R 1(F) 0.0870, w R 2\left(F^{2}\right) 0.2851, \operatorname{GoF}($ all $) 1.010, \Delta \rho_{\text {min }, \text { max }}-0.924$, $1.216 \mathrm{e}^{-} \AA^{-3}$.

${ }^{*} R 1=\Sigma\left\|F_{\mathrm{o}}|-| F_{\mathrm{c}}\right\| / \Sigma\left|F_{\mathrm{o}}\right|$ for $F_{\mathrm{o}}>2 \sigma\left(F_{\mathrm{o}}\right) ; w R 2=\left(\Sigma \mathrm{w}\left(F_{\mathrm{o}}{ }^{2}-F_{\mathrm{c}}{ }^{2}\right)^{2} / \Sigma\left(\mathrm{w} F_{\mathrm{c}}{ }^{2}\right)^{2}\right)^{1 / 2}$ all reflections S32 
$\mathrm{w}=1 /\left[\sigma^{2}\left(F_{\mathrm{o}}{ }^{2}\right)+(0.2000 \mathrm{P})^{2}+25.0000 \mathrm{P}\right]$ where $\mathrm{P}=\left(F_{\mathrm{o}}{ }^{2}+2 F_{\mathrm{c}}{ }^{2}\right) / 3$

\section{Specific refinement details:}

Crystals of $1 \cdot 10 \mathrm{BF}_{4} \cdot 16.25 \mathrm{MeCN} \cdot 2.5 \mathrm{C}_{4} \mathrm{H}_{10} \mathrm{O}$ were grown by diffusion of diethyl ether into an acetonitrile solution of $\mathbf{1} \cdot 10 \mathrm{BF}_{4}$. The crystals employed immediately lost solvent after removal from the mother liquor and rapid handling prior to flash cooling in the cryostream was required to collect data. Despite these measures and the use of synchrotron radiation few reflections at greater than $0.9 \AA$ resolution were observed. The asymmetric unit was found to contain two crystallographically unique $\mathrm{Cu}_{5} \mathrm{~L}_{2}$ assemblies and associated counterions and solvent molecules; each $\mathrm{Cu}_{5} \mathrm{~L}_{2}$ assembly forms a $\mathrm{Cu}_{10} \mathrm{~L}_{4}$ [2]catenane with its enantiomer. Thermal parameter restraints (SIMU, RIGU) were applied to all atoms except for copper in order to facilitate anisotropic refinement and bond lengths and angles within pairs of chemically identical ligands arms were restrained to be similar to each other. No restraints were applied to the corannulene portion of the organic ligands. The acetonitrile and diethyl ether solvent molecules show evidence of substantial disorder. Many of these solvent molecules were modelled over multiple locations with some lattice sites modelled as a mixture of acetonitrile and diethyl ether. The disordered atoms were modelled with isotropic thermal parameters and bond length and thermal parameter restraints were applied to facilitate a reasonable refinement. The hydrogen atoms of some disordered acetonitrile molecules could not be located in the electron density map and were not included in the model.

The anions within the structure show evidence of substantial disorder. The $10 \mathrm{BF}_{4}^{-}$anions were modelled as disordered over 11 lattice sites; five of these lattice sites were further modelled as disordered over two locations. Some disordered atoms were modelled with isotropic thermal parameters and bond length and thermal parameter restraints were applied to facilitate a reasonable refinement.

Further reflecting the solvent loss and poor diffraction properties there is a small amount of void volume in the lattice containing smeared electron density from disordered solvent. Consequently the SQUEEZE $^{10}$ function of PLATON ${ }^{11}$ was employed to remove the contribution of the electron density associated with this highly disordered solvent which gave a potential solvent accessible void of $684 \AA^{3}$ per unit cell (a total of approximately 185 electrons). Since the diffuse solvent molecules could not be assigned conclusively to acetonitrile or diethyl ether they were not included in the formula. Consequently, the molecular weight and density given above are likely to be slightly underestimated.

CheckCIF gives $12 \mathrm{~B}$ level alerts. These alerts all result from the limited data resolution and thermal motion and/or unresolved disorder of some anions and solvent molecules as described above. 

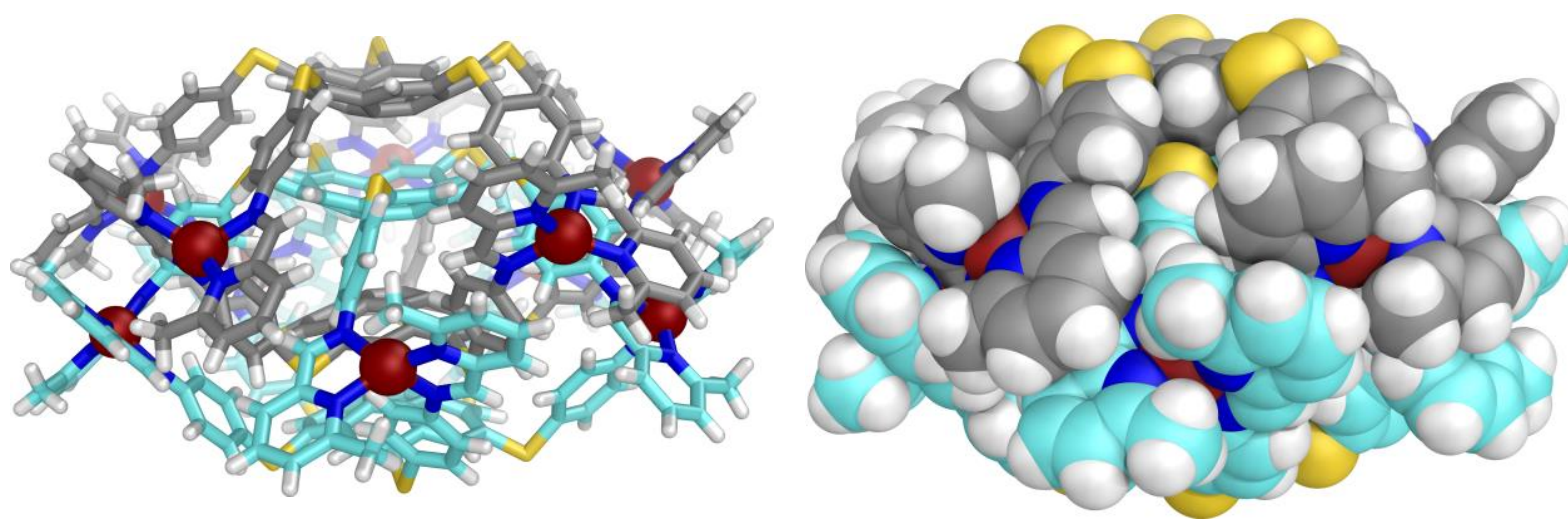

Figure S36: Side-on views of $\mathbf{1}$ from the crystal structure of $\mathbf{1} \cdot 10 \mathrm{BF}_{4} \cdot 16.25 \mathrm{MeCN} \cdot 2.5 \mathrm{C}_{4} \mathrm{H}_{10} \mathrm{O}$ in stick and space-filling representations. Counterions, solvents and disorder are omitted for clarity. The carbon atoms of the two interlocked $\left[\mathrm{Cu}_{5}^{\mathrm{I}} \mathrm{L}_{2}\right]^{5+}$ cages are colored differently and only one of the two crystallographically unique assemblies is shown.
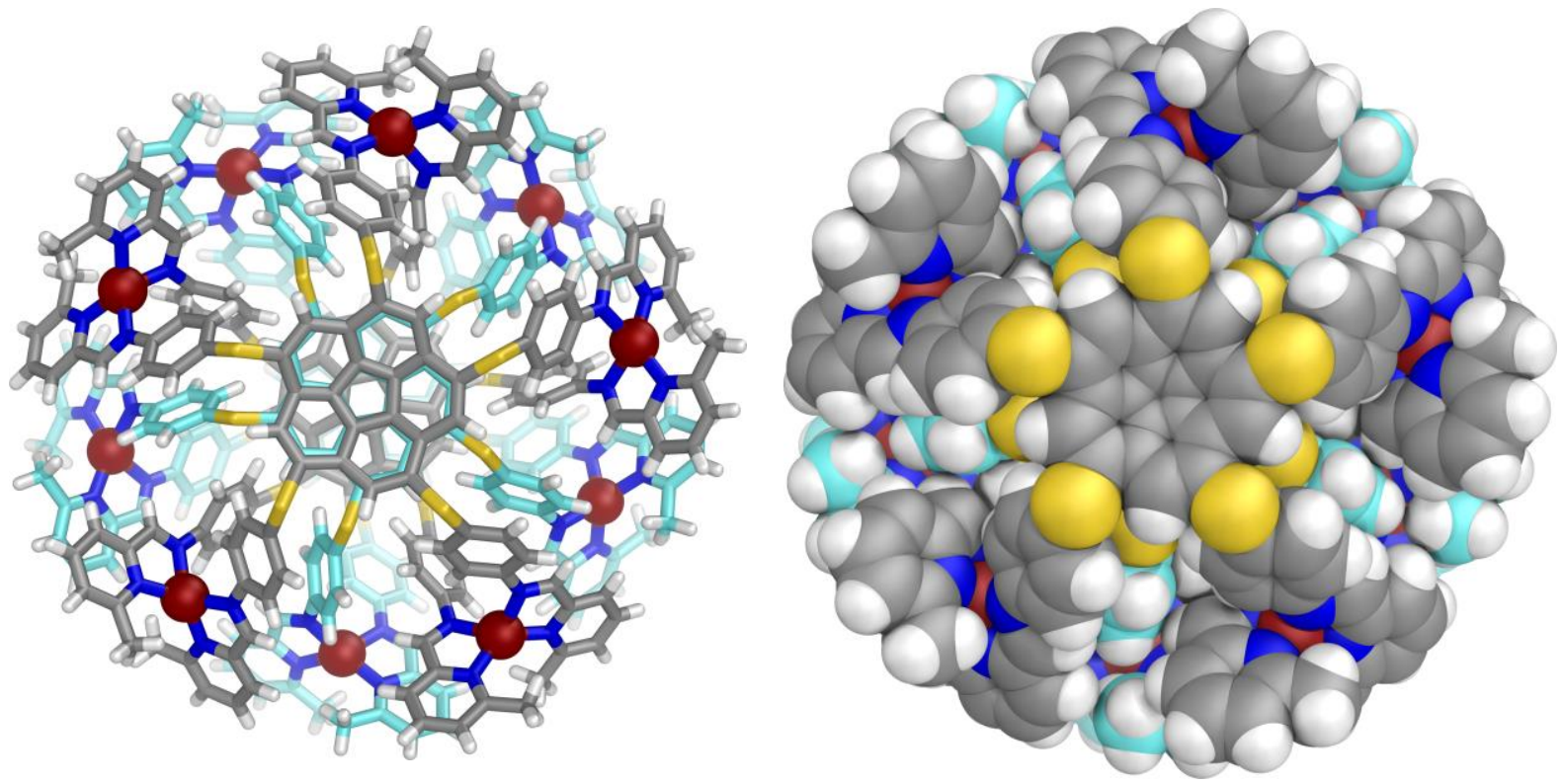

Figure S37: Top views of 1 from the crystal structure of $1 \cdot 10 \mathrm{BF}_{4} \cdot 16.25 \mathrm{MeCN} \cdot 2.5 \mathrm{C}_{4} \mathrm{H}_{10} \mathrm{O}$ in stick and space-filling representations, highlighting the $S_{10}$ symmetry of the assembly. Counterions, solvents and disorder are omitted for clarity. The carbon atoms of the two interlocked $\left[\mathrm{Cu}_{5} \mathrm{~L}_{2}\right]^{5+}$ cages are colored differently and only one of the two crystallographically unique assemblies is shown. 


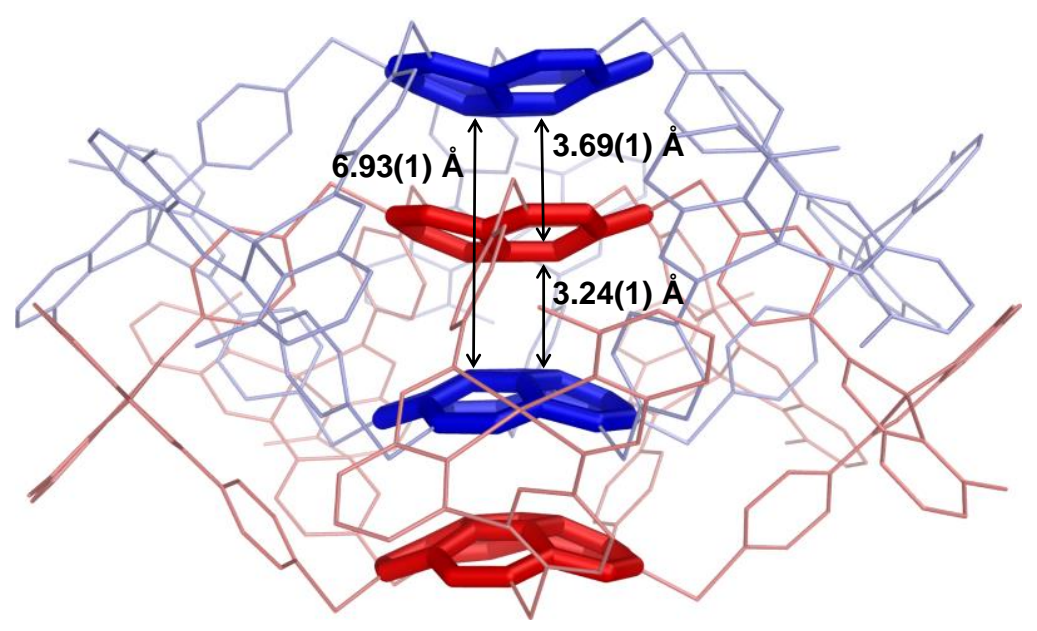

Figure S38: Structure of $\mathbf{1}$ from the crystal structure of $1 \cdot 10 \mathrm{BF}_{4} \cdot 16.25 \mathrm{MeCN} \cdot 2.5 \mathrm{C}_{4} \mathrm{H}_{10} \mathrm{O}$ highlighting the stacking arrangement between corannulenes. Counterions, solvents and disorder are omitted for clarity. The two interlocked $\left[\mathrm{Cu}_{5}^{\mathrm{I}} \mathrm{L}_{2}\right]^{5+}$ cages are colored differently and only one of the two crystallographically unique assemblies is shown. Key distances between corannulenes, given as the average between those of the two crystallographically unique assemblies, are marked.

\section{(corannulene $)_{2} \cdot 1 \cdot 10 \mathrm{BF}_{4} \cdot 4.5 \mathrm{C}_{4} \mathrm{H}_{10} \mathrm{O}[+$ solvent $]$}

Formula $\mathrm{C}_{398} \mathrm{H}_{305} \mathrm{~B}_{10} \mathrm{Cu}_{10} \mathrm{~F}_{40} \mathrm{~N}_{40} \mathrm{O}_{4.50} \mathrm{~S}_{20}, M 7864.50$, Orthorhombic, space group P c c n (\#56), $a$ 35.35960(10), b 34.5841(2), c 34.61900(10) $\AA, V$ 42334.9(3) $\AA^{3}, D_{\mathrm{c}} 1.234 \mathrm{~g} \mathrm{~cm}^{-3}, Z$ 4, crystal size 0.040 by 0.020 by $0.020 \mathrm{~mm}$, colour brown, habit block, temperature 100(2) Kelvin, $\lambda$ (Synchrotron) $0.6889 \AA$, $\mu$ (Synchrotron) $0.608 \mathrm{~mm}^{-1}, T$ (Analytical) $\min$,max $0.95366992765,1.0,2 \theta_{\max } 48.42, h k l$ range -39 42, -36 40, -40 41, $N 285360, N_{\text {ind }} 37285\left(R_{\text {merge }} 0.0414\right), N_{\text {obs }} 24921(\mathrm{I}>2 \sigma(\mathrm{I})), N_{\text {var }}$ 3215 , residuals $^{*} R 1(F) 0.0949, w R 2\left(F^{2}\right) 0.3188, \operatorname{GoF}($ all $) 1.087, \Delta \rho_{\min , \max }-0.742,0.889 \mathrm{e}^{-} \AA^{-3}$.

${ }^{*} R 1=\Sigma\left\|F_{\mathrm{o}}|-| F_{\mathrm{c}}\right\| / \Sigma\left|F_{\mathrm{o}}\right|$ for $F_{\mathrm{O}}>2 \sigma\left(F_{\mathrm{o}}\right) ; w R 2=\left(\sum \mathrm{w}\left(F_{\mathrm{o}}{ }^{2}-F_{\mathrm{c}}{ }^{2}\right)^{2} / \Sigma\left(\mathrm{w} F_{\mathrm{c}}{ }^{2}\right)^{2}\right)^{1 / 2}$ all reflections, $\mathrm{w}=1 /\left[\sigma^{2}\left(F_{\mathrm{o}}{ }^{2}\right)+(0.2000 \mathrm{P})^{2}+30.0000 \mathrm{P}\right]$ where $\mathrm{P}=\left(F_{\mathrm{o}}{ }^{2}+2 F_{\mathrm{c}}{ }^{2}\right) / 3$

\section{Specific refinement details:}

Crystals of (corannulene) $)_{2} \cdot 1 \cdot 10 \mathrm{BF}_{4} \cdot 4.5 \mathrm{C}_{4} \mathrm{H}_{10} \mathrm{O}$ were grown by diffusion of diethyl ether into an acetonitrile solution of $\mathbf{1} \cdot 10 \mathrm{BF}_{4}$ containing a large excess of corannulene. The crystals employed immediately lost solvent after removal from the mother liquor and rapid handling prior to flash cooling in the cryostream was required to collect data. Even so data were obtained to $0.84 \AA$ resolution by employing synchrotron radiation. The asymmetric unit was found to contain one $\mathrm{Cu}_{5} \mathrm{~L}_{2}$ assembly, one S35 
corannulene molecule and associated counterions and solvent molecules. The $\mathrm{Cu}_{5} \mathrm{~L}_{2}$ assembly forms a $\mathrm{Cu}_{10} \mathrm{~L}_{4}$ [2]catenane with its enantiomer. Thermal parameter restraints (SIMU, RIGU) were applied to all atoms except for copper in order to facilitate anisotropic refinement.

The structure shows evidence of substantial disorder. The main $\mathrm{Cu}_{5} \mathrm{~L}_{2}$ residue was found to exhibit whole molecule disorder with a refined occupancy of $0.8085(10)$ for the major occupancy part. Bond lengths and angles within the two chemically identical ligands (excluding the corannulene portion of the organic ligands to which no restraints were applied) of the major occupancy assembly were restrained to be similar to each other. In order to obtain a reasonable model for the minor occupancy part the GRADE program ${ }^{12}$ was employed using the GRADE Web Server ${ }^{13}$ to generate a full set of bond distance and angle restraints (DFIX, DANG, FLAT) for the organic ligands. The minor occupancy part was modelled with isotropic thermal parameters. The stacked corannulene molecule shows evidence of thermal motion or dynamic disorder which could not be adequately modelled with discrete atom positions. Consequently the thermal parameters of this residue are larger than the main $\mathrm{Cu}_{5} \mathrm{~L}_{2}$ residue. The occupancy of this corannulene was initially refined but a value close to unity was obtained hence it was fixed at full occupancy.

The diethyl ether solvent molecules also show evidence of disorder. Two of these solvent molecules were modelled as disordered over two locations. The disordered atoms were modelled with isotropic thermal parameters and bond length and thermal parameter restraints were applied to facilitate a reasonable refinement. The anions within the structure also show evidence of substantial disorder. Four of the $\mathrm{BF}_{4}^{-}$anions were modelled as disordered over two locations. Some disordered atoms were modelled with isotropic thermal parameters and bond length and thermal parameter restraints were applied to facilitate a reasonable refinement.

Further reflecting the solvent loss and poor diffraction properties there is a small amount of void volume in the lattice containing smeared electron density from 0.5 unresolved anions per $\mathrm{Cu}_{5} \mathrm{~L}_{2}$ assembly (assigned as $\mathrm{BF}_{4}^{-}$in the formula) and further highly disordered solvent. Consequently the SQUEEZE ${ }^{10}$ function of PLATON ${ }^{11}$ was employed to remove the contribution of the electron density associated with the highly disordered anion and solvent molecules which gave a potential solvent accessible void of $7354 \AA^{3}$ per unit cell (a total of approximately 2152 electrons). Since the diffuse solvent molecules could not be assigned conclusively to acetonitrile or diethyl ether they were not included in the formula. Consequently, the molecular weight and density given above are likely to be slightly underestimated.

CheckCIF gives 2 B level alerts. These alerts both result from thermal motion and/or unresolved disorder of some anions and solvent molecules as described above. 


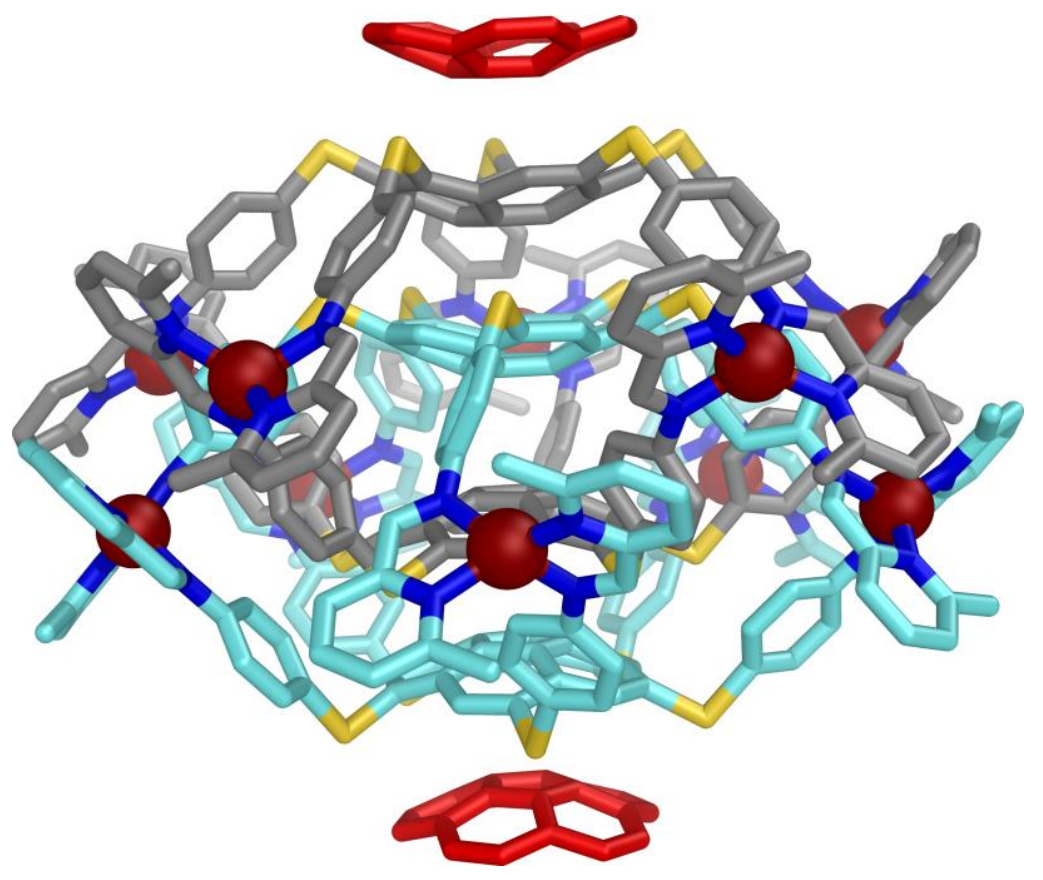

Figure S39: Side-on view of (corannulene) $)_{2} \cdot \mathbf{1}$ from the crystal structure of (corannulene) $)_{2} \cdot 1 \cdot 10 \mathrm{BF}_{4} \cdot 4.5 \mathrm{C}_{4} \mathrm{H}_{10} \mathrm{O}$ in stick representation. Counterions, solvents, hydrogen atoms and disorder are omitted for clarity. The carbon atoms of the two interlocked $\left[\mathrm{Cu}_{5} \mathrm{I}_{2}\right]^{5+}$ cages are colored differently and the carbon atoms of the stacked corannulenes are colored red.
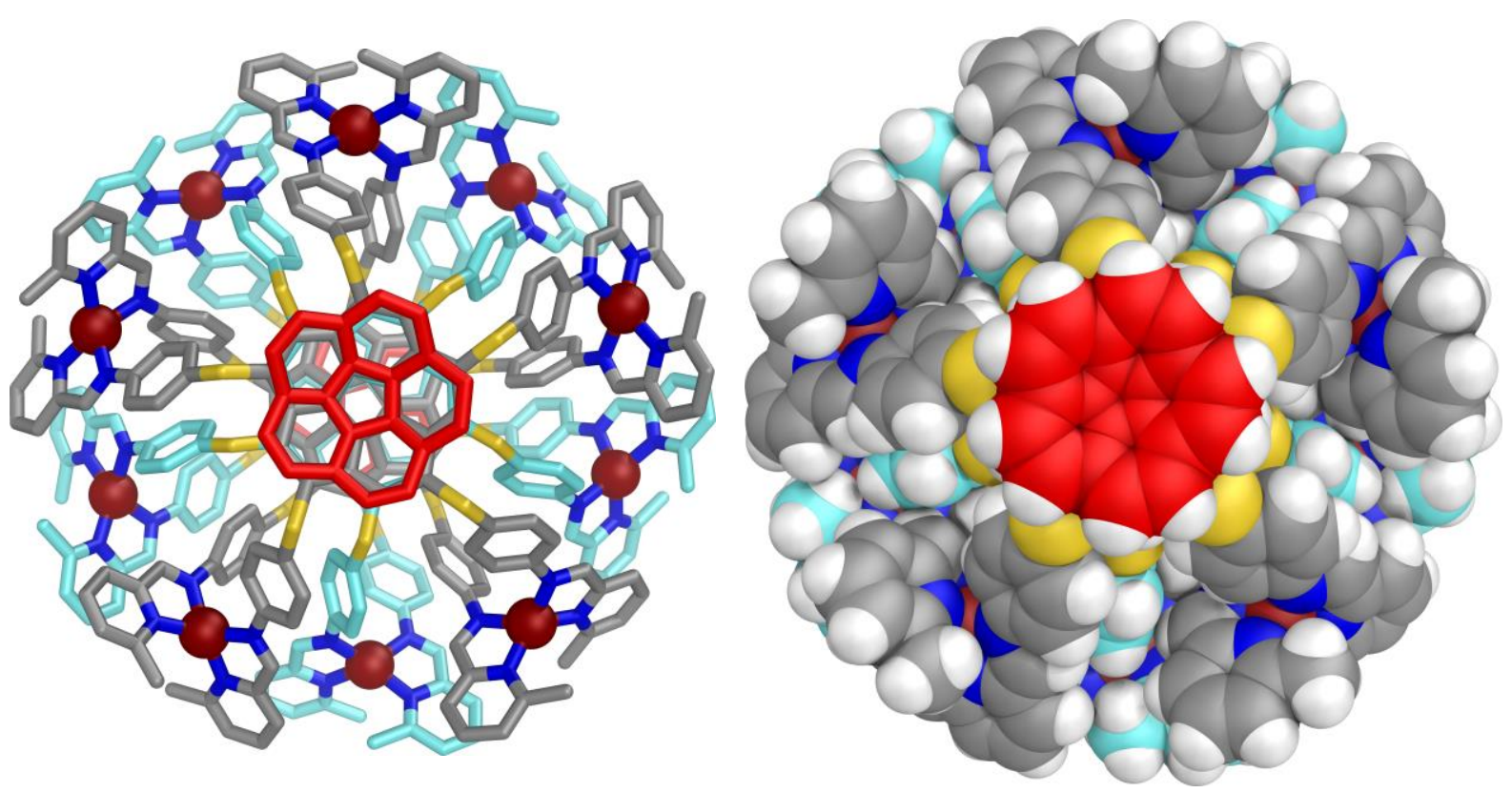

Figure S40: Top views of (corannulene $)_{2} \cdot \mathbf{1}$ from the crystal structure of (corannulene) $)_{2} \cdot 1 \cdot 10 \mathrm{BF}_{4} \cdot 4.5 \mathrm{C}_{4} \mathrm{H}_{10} \mathrm{O}$ in stick and space-filling representations. Counterions, solvents and disorder are omitted for clarity. Hydrogen atoms are also removed in the stick view. The carbon atoms of the two interlocked $\left[\mathrm{Cu}_{5}^{\mathrm{I}} \mathrm{L}_{2}\right]^{5+}$ cages are colored differently and the carbon atoms of the stacked corannulenes are colored red. 


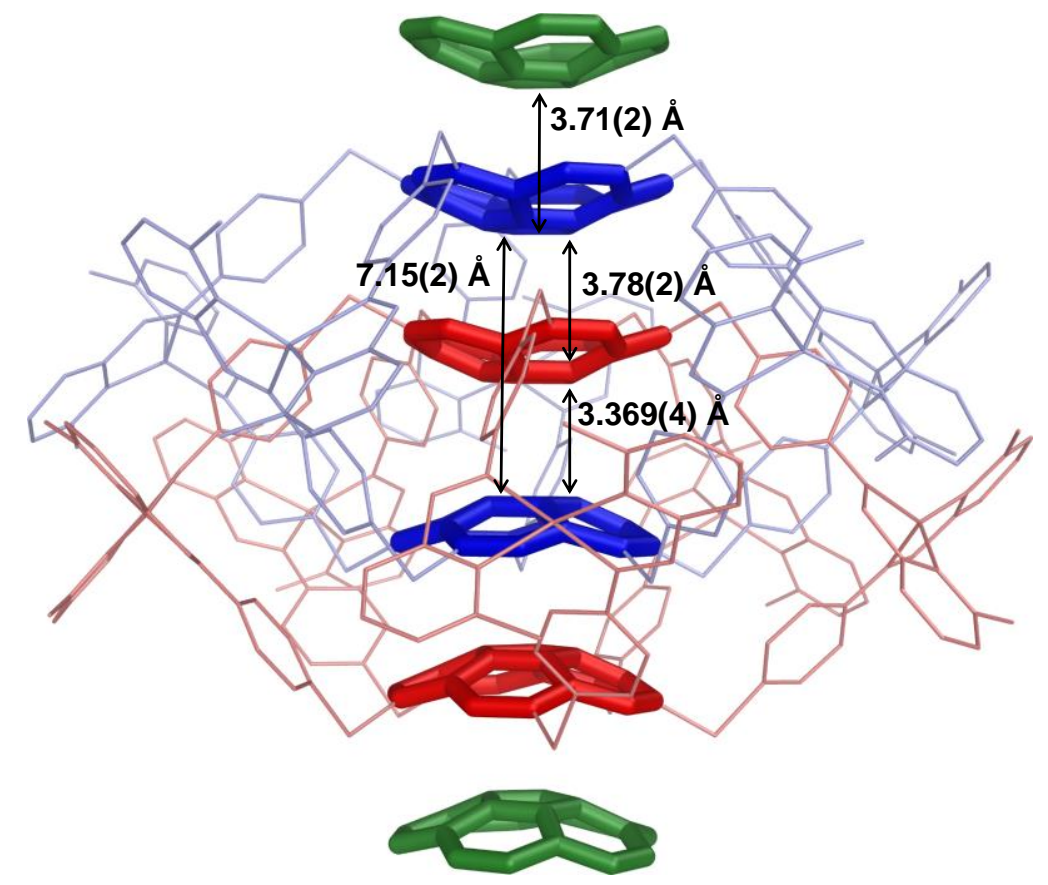

Figure S41: Structure of (corannulene) $)_{2} \cdot 1$ from the crystal structure of (corannulene) $)_{2} \cdot 1 \cdot 10 \mathrm{BF}_{4} \cdot 4.5 \mathrm{C}_{4} \mathrm{H}_{10} \mathrm{O}$ highlighting the stacking arrangement between corannulenes. Counterions, solvents and disorder are omitted for clarity. The two interlocked $\left[\mathrm{Cu}_{5}^{\mathrm{I}} \mathrm{L}_{2}\right]^{5+}$ cages and stacked corannulenes are colored differently. Key distances between corannulenes are marked.

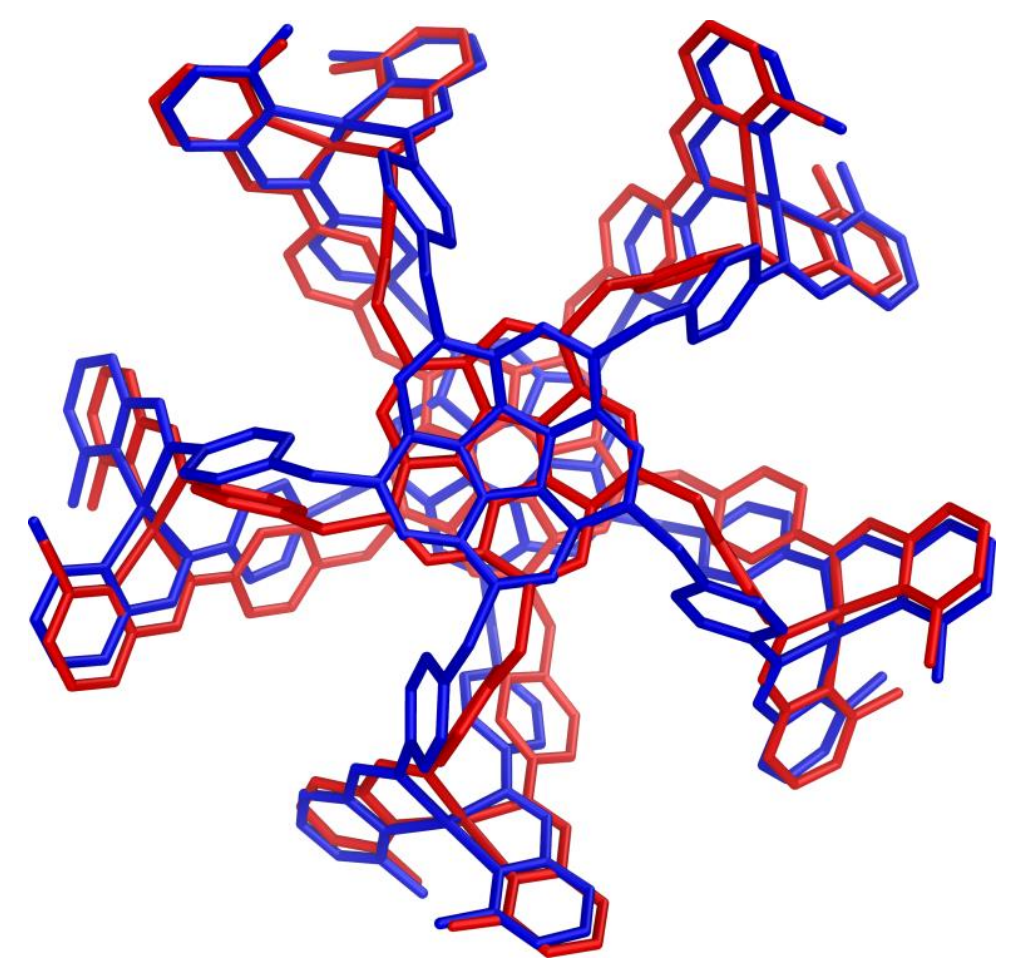

Figure S42: Whole molecule disorder of 1 in the crystal structure of (corannulene) $)_{2} \cdot 1 \cdot 10 \mathrm{BF}_{4} \cdot 4.5 \mathrm{C}_{4} \mathrm{H}_{10} \mathrm{O}$. The major occupancy part $(81 \%)$ is colored blue and the minor occupancy part $(19 \%)$ is colored red. Only the $\left[\mathrm{Cu}_{5}^{\mathrm{I}} \mathrm{L}_{2}\right]^{5+}$ cage comprising the asymmetric unit is shown. Each cage interlocks with its enantiomer (generated through inversion) to form the complete $\left[\mathrm{Cu}_{10}^{\mathrm{I}} \mathrm{L}_{4}\right]^{10+}$ assembly. Hydrogen atoms are omitted for clarity. 


\section{$2 \cdot$ coronene $\cdot 10 \mathrm{BF}_{4} \cdot 20.5 \mathrm{MeCN} \cdot \mathrm{iPr}_{2} \mathrm{O}[+$ solvent $]$}

Formula $\mathrm{C}_{301} \mathrm{H}_{217.50} \mathrm{~B}_{10} \mathrm{Co}_{5} \mathrm{~F}_{40} \mathrm{~N}_{50.50} \mathrm{OS}_{10}, M 6041.09$, Triclinic, space group P -1 (\#2), $a$ 27.3964(8), b 27.5891(11), c 27.8154(8) ̊̊, $\alpha$ 90.192(3), $\beta$ 118.294(2), $\gamma 116.730(3)^{\circ}, V 15894.8(10)$ $\AA^{3}, D_{\mathrm{c}} 1.262 \mathrm{~g} \mathrm{~cm}^{-3}, Z 2$, crystal size 0.030 by 0.020 by $0.015 \mathrm{~mm}$, colour orange, habit block, temperature $100(2) \quad$ Kelvin, $\lambda$ (Synchrotron) $0.6889 \AA \AA \quad \mu$ (Synchrotron) $0.369 \mathrm{~mm}^{-1}$, $T$ (Analytical) $\min , \max 0.972075869384,1.0,2 \theta_{\max } 48.42, h k l$ range $-3232,-3232,-3333, N 190480$, $N_{\text {ind }} 55574\left(R_{\text {merge }} 0.0601\right), N_{\text {obs }} 29848(\mathrm{I}>2 \sigma(\mathrm{I})), N_{\text {var }} 4135$, residuals $^{*} R 1(F) 0.1092, w R 2\left(F^{2}\right)$ 0.3466, GoF(all) 1.099, $\Delta \rho_{\min , \max }-0.612,1.368 \mathrm{e}^{-} \AA^{-3}$.

${ }^{*} R 1=\Sigma\left\|F_{\mathrm{o}}|-| F_{\mathrm{c}}\right\| / \Sigma\left|F_{\mathrm{o}}\right|$ for $F_{\mathrm{o}}>2 \sigma\left(F_{\mathrm{o}}\right) ; w R 2=\left(\Sigma \mathrm{w}\left(F_{\mathrm{o}}{ }^{2}-F_{\mathrm{c}}{ }^{2}\right)^{2} / \Sigma\left(\mathrm{w} F_{\mathrm{c}}{ }^{2}\right)^{2}\right)^{1 / 2}$ all reflections, $\mathrm{w}=1 /\left[\sigma^{2}\left(F_{\mathrm{o}}{ }^{2}\right)+(0.2000 \mathrm{P})^{2}+4.0000 \mathrm{P}\right]$ where $\mathrm{P}=\left(F_{\mathrm{o}}{ }^{2}+2 F_{\mathrm{c}}{ }^{2}\right) / 3$

\section{Specific refinement details:}

The crystals of $\mathbf{2} \cdot$ coronene $\cdot 10 \mathrm{BF}_{4} \cdot 20.5 \mathrm{MeCN} \cdot \mathrm{Pr}_{2} \mathrm{O}$ [+ solvent] were grown by diffusion of diisopropyl ether into an acetonitrile solution of $\mathbf{2} \cdot 10 \mathrm{BF}_{4}$ containing excess coronene. The crystals employed immediately lost solvent after removal from the mother liquor and rapid handling prior to flash cooling in the cryostream was required to collect data. Even so data were obtained to $0.84 \AA$ A resolution by employing synchrotron radiation. The asymmetric unit was found to contain one complete $\mathrm{Co}_{5} \mathrm{~L}_{2}$ assembly, half of two separate coronene molecules (located over special positions) and associated counterions and solvent molecules.

Bond lengths and angles within pairs of chemically identical organic ligand arms were restrained to be similar to each other as were the two coronene molecules. No restraints were applied to the corannulene portion of the organic ligands. Thermal parameter restraints (SIMU, RIGU) were applied to all atoms except for cobalt to facilitate anisotropic stable refinement. One of the coronene molecules shows evidence of thermal motion or minor unresolved disorder resulting in a large average Ueq value for that residue.

The anions within the structure show evidence of substantial disorder. The $10 \mathrm{BF}_{4}^{-}$anions were modelled as disordered over 12 lattice sites; eight of these lattice sites were further modelled as disordered over two locations. Some disordered atoms were modelled with isotropic thermal parameters and bond length and thermal parameter restraints were applied to facilitate a reasonable refinement. Many acetonitrile solvent molecules were also modelled as disordered over multiple locations and/or 
with partial occupancy. The hydrogen atoms of some of the disordered solvent molecules could not be located in the electron density map and were not included in the model.

Further reflecting the solvent loss there is a small amount of void volume in the lattice containing smeared electron density from disordered solvent. Consequently the SQUEEZE ${ }^{10}$ function of PLATON ${ }^{11}$ was employed to remove the contribution of the electron density associated with this highly disordered solvent which gave a potential solvent accessible void of $874 \AA^{3}$ per unit cell (a total of approximately 210 electrons). Since the diffuse solvent molecules could not be assigned conclusively to acetonitrile or diisopropyl ether they were not included in the formula. Consequently, the molecular weight and density given above are likely to be slightly underestimated.

CheckCIF gives $3 \mathrm{~A}$ and $47 \mathrm{~B}$ level alerts. These alerts (both A and B level) all result from solvent molecules for which the hydrogen atoms were not modelled (singly bonded carbons) and thermal motion and/or unresolved disorder of some anions, solvent molecules and one of the coronenes as described above.

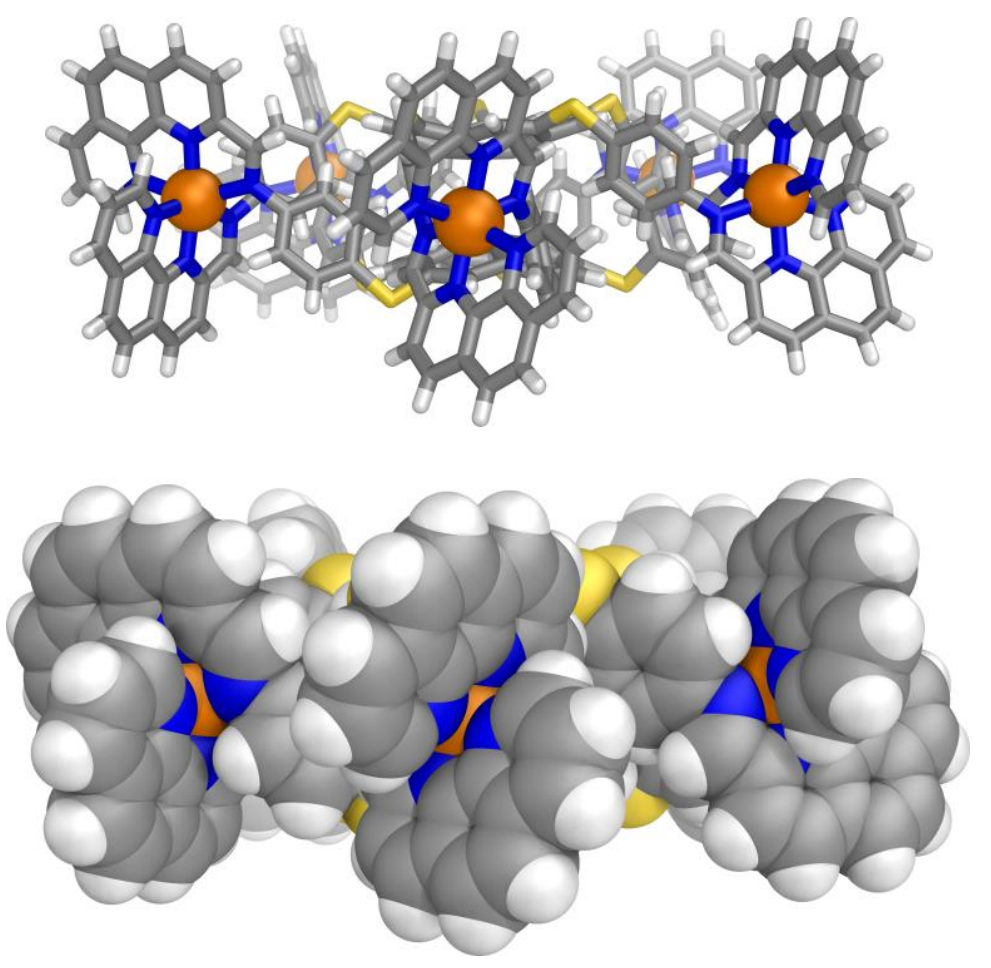

Figure S43: Side-on views of 2 from the crystal structure of $2 \cdot$ coronene $\cdot 10 \mathrm{BF}_{4} \cdot 20.5 \mathrm{MeCN} \cdot \mathrm{iPr}_{2} \mathrm{O}$ in stick and space-filling representations. Counterions, solvents and disorder are omitted for clarity. The structure is similar to that of $\mathbf{2}$ in the structures of $\mathbf{2} \cdot 10 \mathrm{ClO}_{4} \cdot 3 \mathrm{MeCN}$ (Figure S49) and $\mathbf{2} \cdot 10 \mathrm{BF}_{4} \cdot 11 \mathrm{MeCN}$ (Figure S48). 

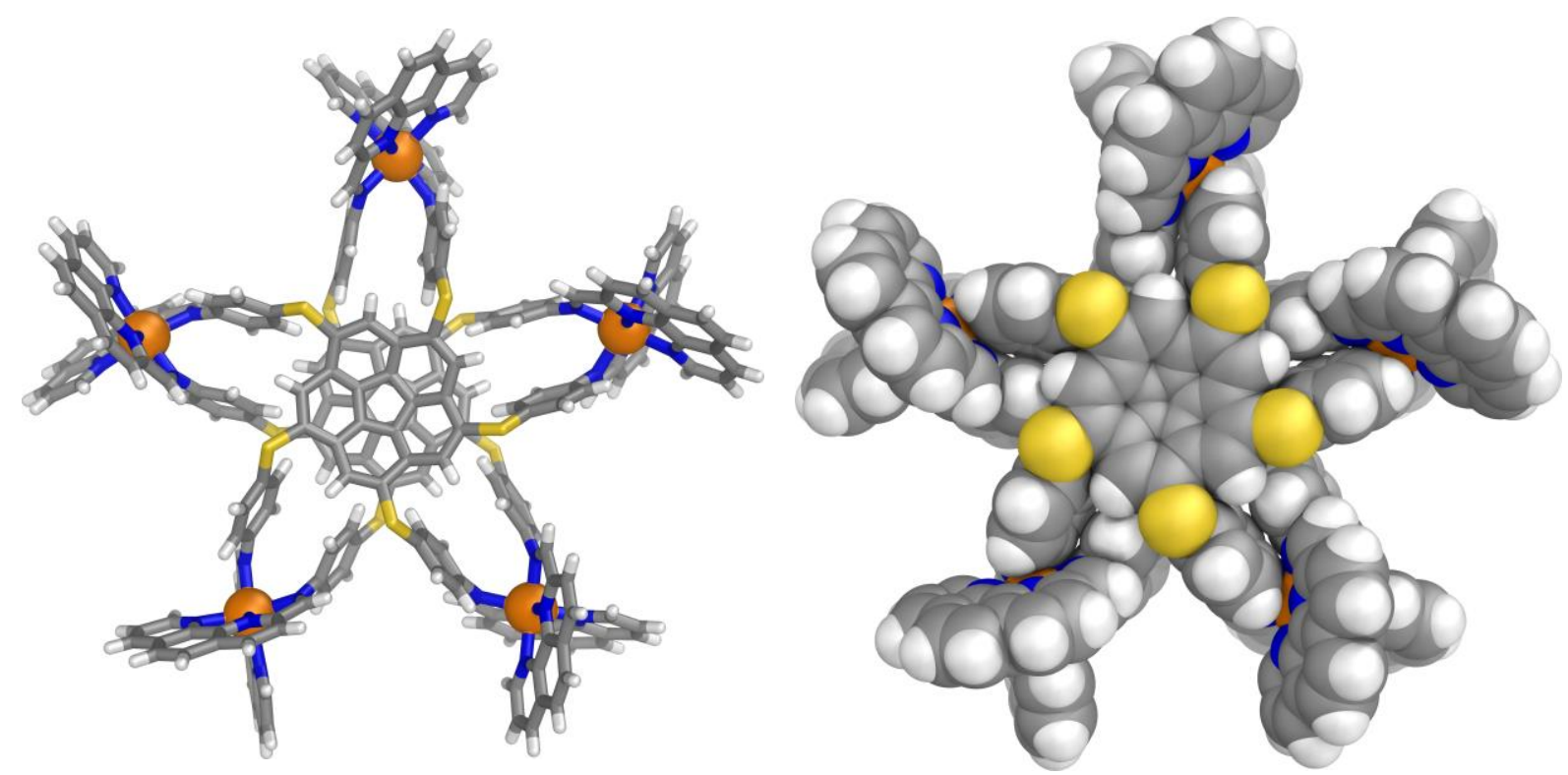

Figure S44: Top views of 2 from the crystal structure of $\mathbf{2} \cdot$ coronene $10 \mathrm{BF}_{4} \cdot 20.5 \mathrm{MeCN} \cdot \mathrm{iPr}_{2} \mathrm{O}$ in stick and space-filling representations. Counterions, solvents and disorder are omitted for clarity. The structure is similar to that of $\mathbf{2}$ in the structures of $\mathbf{2} \cdot 10 \mathrm{ClO}_{4} \cdot 3 \mathrm{MeCN}$ (Figure S49) and $\mathbf{2} \cdot 10 \mathrm{BF}_{4} \cdot 11 \mathrm{MeCN}$ (Figure S48).

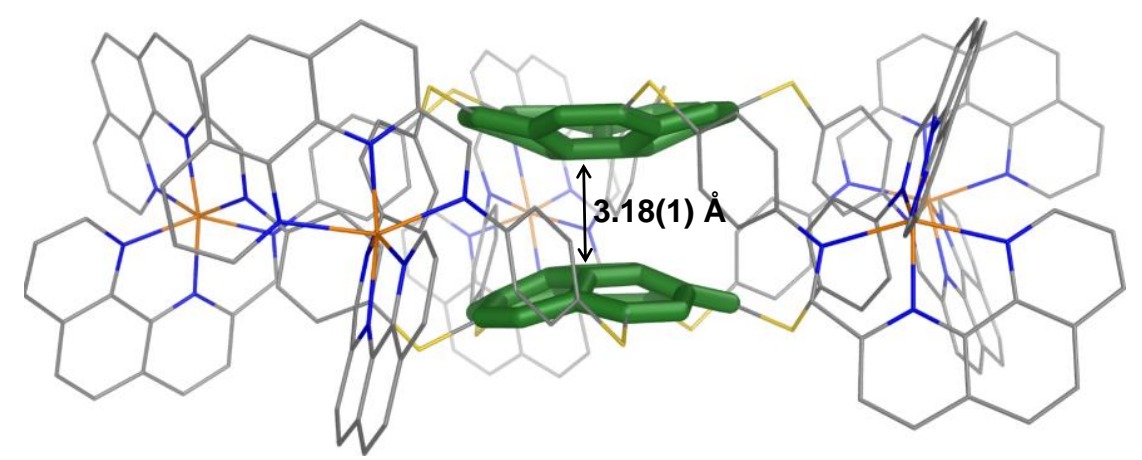

Figure S45: The structure of 2 from the crystal structure of $\mathbf{2} \cdot$ coronene $\cdot 10 \mathrm{BF}_{4} \cdot 20.5 \mathrm{MeCN} \cdot \mathrm{Pr}_{2} \mathrm{O}$ highlighting the arrangement of corannulenes. Counterions, solvents and disorder are omitted for clarity. The distance between the corannulenes is marked, highlighting the absence of a cavity in the solid state. Similar distances were obtained for the structures $2 \cdot 10 \mathrm{ClO}_{4} \cdot 3 \mathrm{MeCN}(3.23(3) \AA$ ) and $2 \cdot 10 \mathrm{BF}_{4} \cdot 11 \mathrm{MeCN}(3.28(3) \AA)$. 


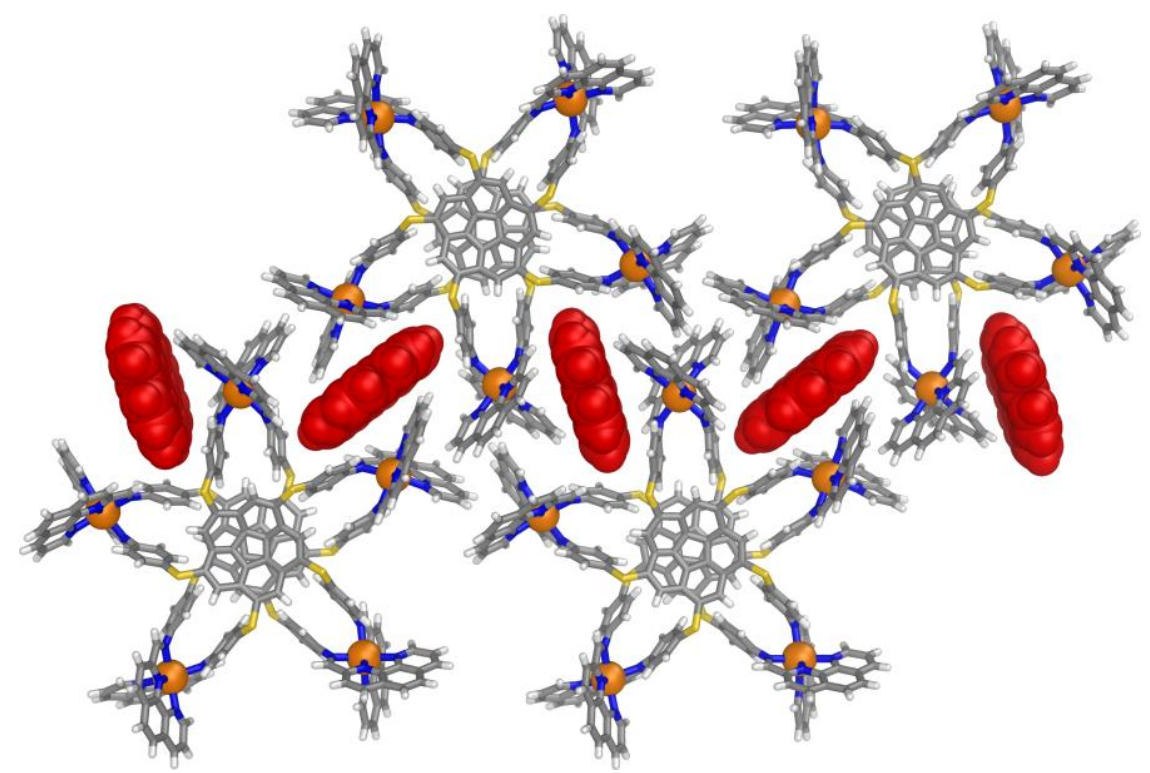

Figure S46: Crystal packing within the crystal structure of $2 \cdot$ coronene $\cdot 10 \mathrm{BF}_{4} \cdot 20.5 \mathrm{MeCN} \cdot \mathrm{Pr}_{2} \mathrm{O}$ showing the arrangement of the co-crystallized coronene (shown in red) which intercalates between molecules of 2 forming a 1D tape. Counterions, solvents and disorder are omitted for clarity.

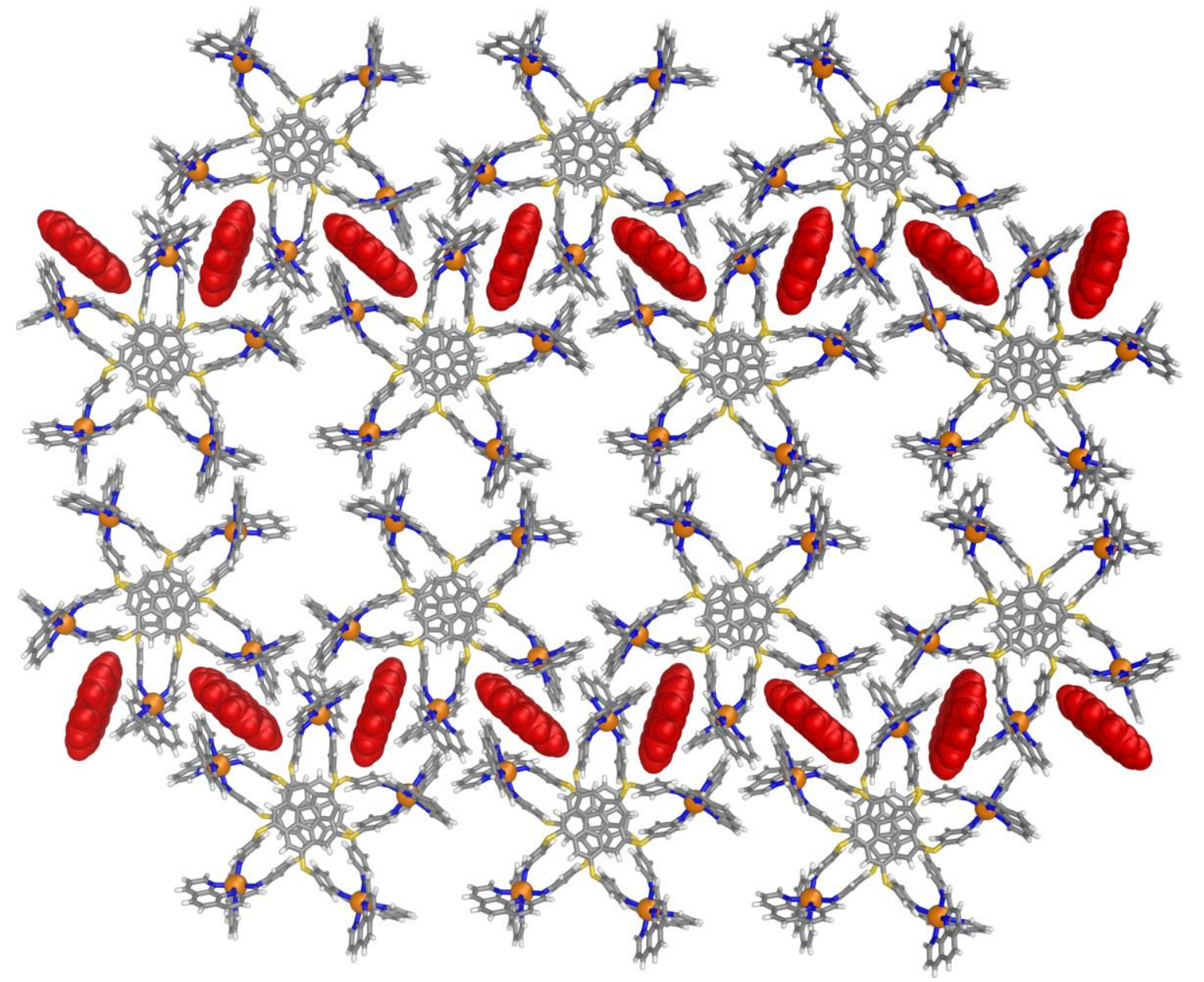

Figure S47: Crystal packing within the crystal structure of $\mathbf{2} \cdot$ coronene $\cdot 10 \mathrm{BF}_{4} \cdot 20.5 \mathrm{MeCN} \cdot \mathrm{Pr}_{2} \mathrm{O}$ showing the packing of the co-crystallized coronene (shown in red) and $\mathbf{2}$ into $2 \mathrm{D}$ sheets. The counterions and solvents which occupy the remaining voids in the structure are omitted for clarity. 


\section{$2 \cdot 10 \mathrm{BF}_{4} \cdot 11 \mathrm{MeCN}[+$ solvent $]$}

Formula $\mathrm{C}_{252} \mathrm{H}_{163} \mathrm{~B}_{10} \mathrm{Co}_{5} \mathrm{~F}_{40} \mathrm{~N}_{41} \mathrm{~S}_{10}, M$ 5248.57, Monoclinic, space group $\mathrm{C} 2 / \mathrm{c}$ (\#15), $a$ 12.7122(3), b 60.0379(11), c 36.2181(5) $\AA, \beta 98.238(2), V 27356.9(9) \AA^{3}, D_{\mathrm{c}} 1.274 \mathrm{~g} \mathrm{~cm}^{-3}, Z 4$, crystal size 0.004 by 0.003 by $0.003 \mathrm{~mm}$, colour orange, habit block, temperature 100(2) Kelvin, $\lambda$ (Synchrotron) $0.6889 \AA$ А $\mu$ (Synchrotron) $0.417 \mathrm{~mm}^{-1}, T$ (Analytical) $\min , \max 0.973424816736,1.0$, $2 \theta_{\max } 36.50, h k l$ range $-1111,-5454,-3231, N 33477, N_{\text {ind }} 10555\left(R_{\text {merge }} 0.0607\right), N_{\text {obs }} 6151(\mathrm{I}>$ $2 \sigma(\mathrm{I})), N_{\text {var }} 1575$, residuals $^{*} R 1(F) 0.1131, w R 2\left(F^{2}\right) 0.3460, \mathrm{GoF}($ all $) 1.081, \Delta \rho_{\text {min, } \max }-0.360,0.831$ $\mathrm{e}^{-} \AA^{-3}$.

${ }^{*} R 1=\Sigma\left\|F_{\mathrm{o}}|-| F_{\mathrm{c}}\right\| / \Sigma\left|F_{\mathrm{o}}\right|$ for $F_{\mathrm{O}}>2 \sigma\left(F_{\mathrm{o}}\right) ; w R 2=\left(\Sigma \mathrm{w}\left(F_{\mathrm{o}}{ }^{2}-F_{\mathrm{c}}{ }^{2}\right)^{2} / \Sigma\left(\mathrm{w} F_{\mathrm{c}}{ }^{2}\right)^{2}\right)^{1 / 2}$ all reflections, $\mathrm{w}=1 /\left[\sigma^{2}\left(F_{\mathrm{o}}{ }^{2}\right)+(0.2000 \mathrm{P})^{2}+80.0000 \mathrm{P}\right]$ where $\mathrm{P}=\left(F_{\mathrm{o}}{ }^{2}+2 F_{\mathrm{c}}{ }^{2}\right) / 3$

\section{Specific refinement details:}

The crystals of $2 \cdot 10 \mathrm{BF}_{4} \cdot 11 \mathrm{MeCN}$ [+ solvent] were grown by diffusion of diethyl ether into an acetonitrile solution of the complex. The crystals employed immediately lost solvent after removal from the mother liquor and rapid handling prior to flash cooling in the cryostream was required to collect data. Despite these measures and the use of synchrotron radiation few reflections at greater than $1.1 \AA$ resolution were observed and the data were trimmed accordingly. Nevertheless, the quality of the data is far more than sufficient to establish the connectivity of the structure. The asymmetric unit was found to contain one half of a $\mathrm{Co}_{5} \mathrm{~L}_{2}$ assembly and associated counterions and solvent molecules.

Due to the limited resolution, bond lengths and angles within pairs of chemically identical organic ligand arms were restrained to be similar to each other. No restraints were applied to the corannulene portion of the organic ligands. Two of the five ligand arms show evidence of substantial thermal motion or dynamic disorder which could not be adequately modelled with discrete atom positions. In order to obtain a reasonable model for these ligand arms the GRADE program ${ }^{12}$ was employed using the GRADE Web Server ${ }^{13}$ to generate a full set of bond distance and angle restraints (DFIX, DANG, FLAT) for these residues. Thermal parameter restraints (SIMU, RIGU) were applied to all atoms except for cobalt to facilitate anisotropic stable refinement. Even with these restraints some thermal parameters remain larger than ideal as a consequence of the high level of thermal motion or minor unresolved disorder present throughout the structure resulting in a large average Ueq value.

The anions within the structure also show evidence of disorder. One $\mathrm{BF}_{4}{ }^{-}$anion was modelled as disordered over two locations and several more were modelled with partial occupancy. Some disordered 
atoms were modelled with isotropic thermal parameters and bond length and thermal parameter restraints were applied to facilitate a reasonable refinement. Some acetonitrile solvent molecules were also modelled as disordered over multiple locations and/or with partial occupancy. The hydrogen atoms of some disordered acetonitrile molecules could not be located in the electron density map and were not included in the model.

A further two anions per $\operatorname{Co}_{5} \mathrm{~L}_{2}$ assembly remain unaccounted for and no satisfactory model for these anions could be obtained despite numerous attempts at modelling, including with rigid bodies. Therefore the SQUEEZE ${ }^{10}$ function of PLATON ${ }^{11}$ was employed to account for the highly disordered anions and further disordered solvent molecules, which gave a potential solvent accessible void of 4517 $\AA^{3}$ per unit cell (a total of approximately 1008 electrons). These anions are included as $\mathrm{BF}_{4}^{-}$in the formula given above. Since the diffuse solvent molecules could not be assigned conclusively to acetonitrile or diethyl ether they were not included in the formula. Consequently, the molecular weight and density given above are likely to be underestimated.

CheckCIF gives one A and sixteen B level alerts. These alerts (both A and B level) all result from the limited data resolution, solvent molecules for which the hydrogen atoms were not modelled, thermal motion and/or unresolved disorder of some anions and solvent molecules and the generally high level of thermal motion present throughout the structure as described above. 

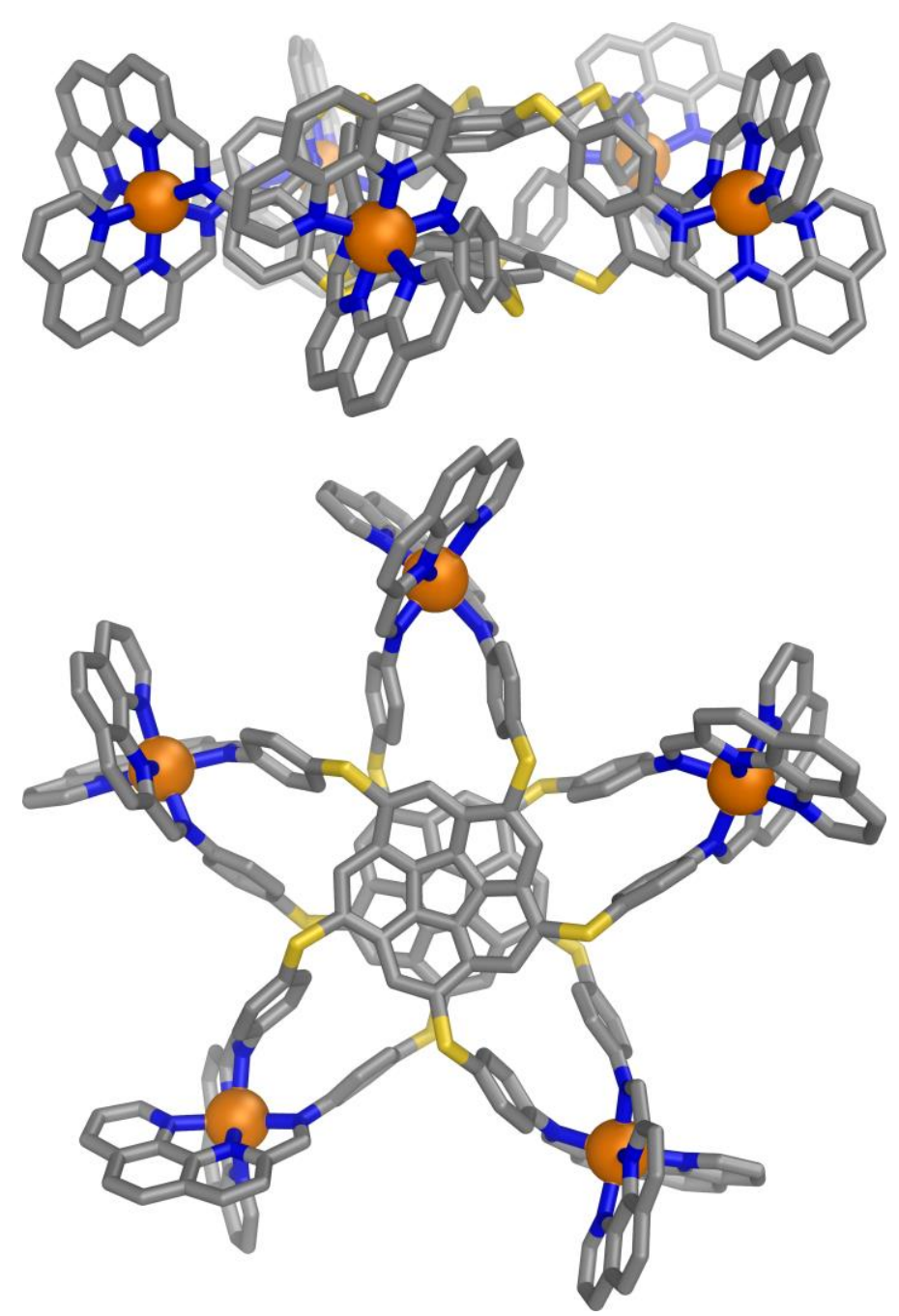

Figure S48: Two views of the structure of $\mathbf{2}$ from the crystal structure of $\mathbf{2} \cdot 10 \mathrm{BF}_{4} \cdot 11 \mathrm{MeCN}$. Counterions, solvents, hydrogen atoms and disorder are omitted for clarity. The structure is similar to that of $\mathbf{2}$ in the structures of $\mathbf{2} \cdot 10 \mathrm{ClO}_{4} \cdot 3 \mathrm{MeCN}$ (Figure S49) and $\mathbf{2} \cdot$ coronene $\cdot 10 \mathrm{BF}_{4} \cdot 20.5 \mathrm{MeCN} \cdot \mathrm{iPr}_{2} \mathrm{O}$ (Figure 1 in the main text, Figures S43-S45).

\section{$2 \cdot 10 \mathrm{ClO}_{4} \cdot 3 \mathrm{MeCN}[+$ solvent $]$}

Formula $\mathrm{C}_{236} \mathrm{H}_{139} \mathrm{Cl}_{10} \mathrm{Co}_{5} \mathrm{~N}_{33} \mathrm{O}_{40} \mathrm{~S}_{10}, M$ 5046.54, Monoclinic, space group $\mathrm{C} 2 / \mathrm{c}$ (\#15), $a$ 12.80850(10), $b$ 60.9472(10), c 36.1921(3) $\AA, \beta 98.5390(10), V 27939.9(6) \AA^{3}, D_{\mathrm{c}} 1.200 \mathrm{~g} \mathrm{~cm}^{-3}, Z 4$, crystal size 0.020 by 0.020 by $0.020 \mathrm{~mm}$, colour orange, habit block, temperature 100(2) Kelvin, $\lambda$ (Synchrotron) $0.6889 \AA, \mu$ (Synchrotron) $0.481 \mathrm{~mm}^{-1}, T$ (Analytical) $\min , \max 0.979027237085,1.0$, $2 \theta_{\text {max }} 48.42, h k l$ range $-1415,-7272,-4340, N 133938, N_{\text {ind }} 24616\left(R_{\text {merge }} 0.0355\right), N_{\text {obs }} 11504(\mathrm{I}$ 
$>2 \sigma(\mathrm{I})), N_{\text {var }} 1558$, residuals ${ }^{*} R 1(F) 0.0909, w R 2\left(F^{2}\right) 0.3339, \operatorname{GoF}($ all $) 1.083, \Delta \rho_{\text {min }, \max }-0.793$, $0.885 \mathrm{e}^{-} \AA^{-3}$.

${ }^{*} R 1=\Sigma\left\|F_{\mathrm{o}}|-| F_{\mathrm{c}}\right\| / \Sigma\left|F_{\mathrm{o}}\right|$ for $F_{\mathrm{o}}>2 \sigma\left(F_{\mathrm{o}}\right) ; w R 2=\left(\Sigma \mathrm{w}\left(F_{\mathrm{o}}{ }^{2}-F_{\mathrm{c}}{ }^{2}\right)^{2} / \Sigma\left(\mathrm{w} F_{\mathrm{c}}{ }^{2}\right)^{2}\right)^{1 / 2}$ all reflections, $\mathrm{w}=1 /\left[\sigma^{2}\left(F_{\mathrm{o}}{ }^{2}\right)+(0.2000 \mathrm{P})^{2}\right]$ where $\mathrm{P}=\left(F_{\mathrm{o}}{ }^{2}+2 F_{\mathrm{c}}{ }^{2}\right) / 3$

\section{Specific refinement details:}

The crystals of $\mathbf{2} \cdot 10 \mathrm{ClO}_{4} \cdot 3 \mathrm{MeCN}$ [+ solvent] were grown by diffusion of diethyl ether into an acetonitrile solution of $\mathbf{2} \cdot 10 \mathrm{NTf}_{2}$ containing excess $\mathrm{TBAClO}_{4}$. The crystals employed immediately lost solvent after removal from the mother liquor and rapid handling prior to flash cooling in the cryostream was required to collect data. Even so data were obtained to $0.84 \AA$ A resolution by employing synchrotron radiation. The asymmetric unit was found to contain one half of a $\operatorname{Co}_{5} \mathrm{~L}_{2}$ assembly and associated counterions and solvent molecules.

Bond lengths and angles within pairs of chemically identical organic ligand arms were restrained to be similar to each other. No restraints were applied to the corannulene portion of the organic ligands. One of the five ligand arms was modelled as disordered over two locations with a refined occupancy of 0.723(5) for the major part. In order to obtain a reasonable model for the lower occupancy part of the disordered ligand arm the GRADE program ${ }^{12}$ was employed using the GRADE Web Server ${ }^{13}$ to generate a full set of bond distance and angle restraints (DFIX, DANG, FLAT) for these residues. Thermal parameter restraints (SIMU, RIGU) were applied to all atoms except for cobalt to facilitate anisotropic stable refinement. Even with these restraints some thermal parameters remain larger than ideal as a consequence of the high level of thermal motion or minor unresolved disorder present throughout the structure resulting in a large average Ueq value.

The anions within the structure also show evidence of disorder. One $\mathrm{ClO}_{4}{ }^{-}$anion was modelled as disordered over two locations and several more were modelled with partial occupancy. Some disordered atoms were modelled with isotropic thermal parameters and bond length and thermal parameter restraints were applied to facilitate a reasonable refinement. Some acetonitrile solvent molecules were also modelled as disordered over multiple locations and/or with partial occupancy. The hydrogen atoms of some disordered acetonitrile molecules could not be located in the electron density map and were not included in the model.

A further three anions per $\mathrm{Co}_{5} \mathrm{~L}_{2}$ assembly remain unaccounted for and no satisfactory model for these anions could be obtained despite numerous attempts at modelling, including with rigid bodies. Therefore the SQUEEZE ${ }^{10}$ function of PLATON ${ }^{11}$ was employed to account for the highly disordered anions and further disordered solvent molecules, which gave a potential solvent accessible void of 8373 S46 
$\AA^{3}$ per unit cell (a total of approximately 2399 electrons). These anions are included as $\mathrm{ClO}_{4}^{-}$in the formula given above. Since the diffuse solvent molecules could not be assigned conclusively to acetonitrile or diethyl ether they were not included in the formula. Consequently, the molecular weight and density given above are likely to be underestimated.

CheckCIF gives one A and seven B level alerts. These alerts (both A and B level) all result from solvent molecules for which the hydrogen atoms were not modelled, thermal motion and/or unresolved disorder of some anions and solvent molecules and the generally high level of thermal motion present throughout the structure as described above.
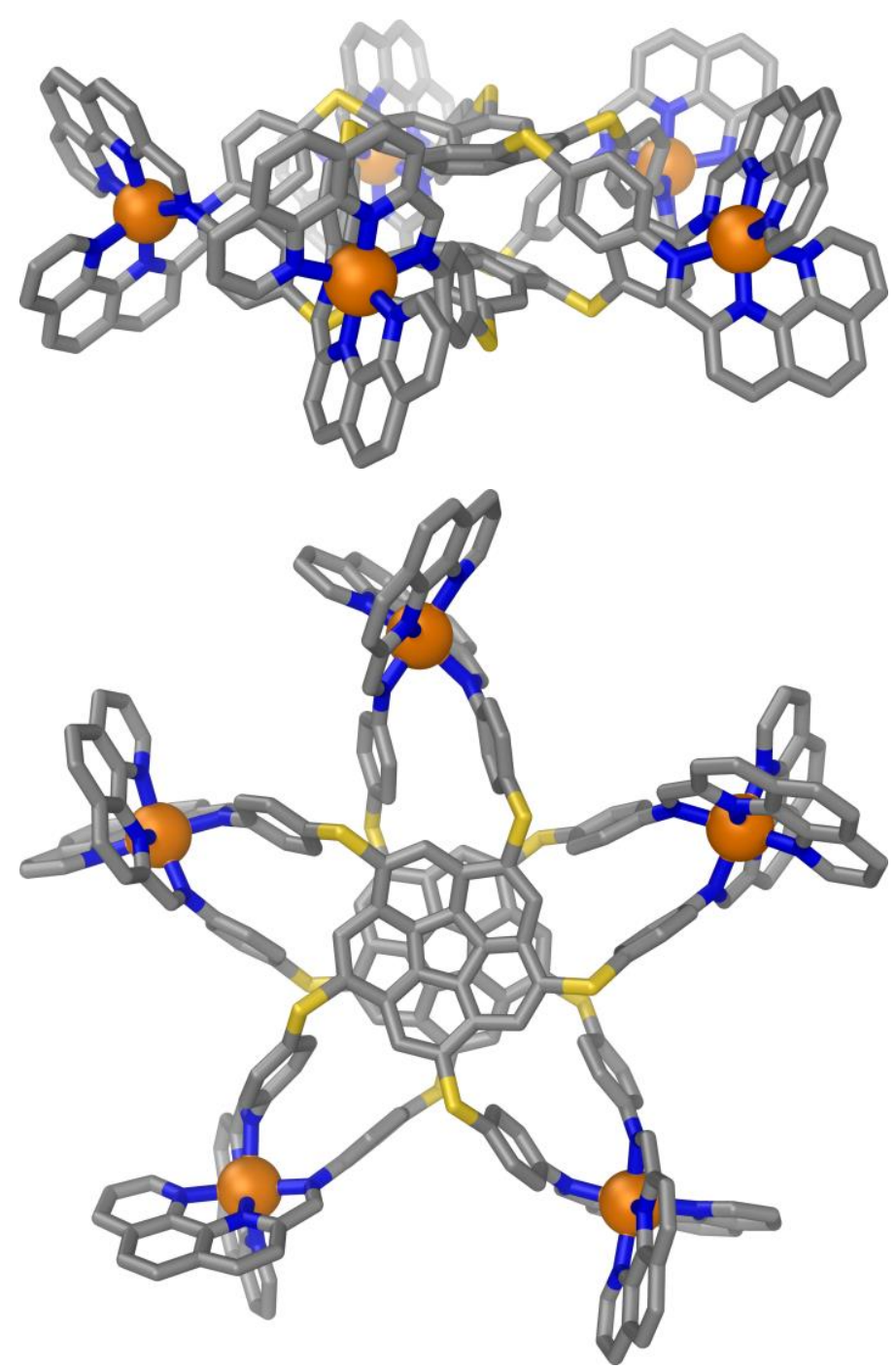

Figure S49: Two views of the structure of 2 from the crystal structure of $2 \cdot 10 \mathrm{ClO}_{4} \cdot 3 \mathrm{MeCN}$ Counterions, solvents, hydrogen atoms and disorder are omitted for clarity. The structure is similar to that of $\mathbf{2}$ in the structures of $\mathbf{2} \cdot 10 \mathrm{BF}_{4} \cdot 11 \mathrm{MeCN}$ (Figure S48) and $\mathbf{2} \cdot$ coronene $\cdot 10 \mathrm{BF}_{4} \cdot 20.5 \mathrm{MeCN} \cdot \mathrm{Pr}_{2} \mathrm{O}$ (Figure 1 in the main text, Figures S43-S45). 


\section{$(\text { corannulene })_{0.6} \cdot 2 \cdot 4 \mathrm{ReO}_{4} \cdot 6 \mathrm{NTf}_{2} \cdot 3.5 \mathrm{MeCN} \cdot 2.5 \mathrm{Et}_{2} \mathrm{O} \cdot \mathrm{H}_{2} \mathrm{O}[+$ solvent $]$}

Formula $\mathrm{C}_{271} \mathrm{H}_{173.50} \mathrm{Co}_{5} \mathrm{~F}_{36} \mathrm{~N}_{39.50} \mathrm{O}_{43.50} \mathrm{Re}_{4} \mathrm{~S}_{22}, M$ 7107.75, Triclinic, space group P -1 (\#2), $a$ $14.98310(10), b 24.4806(2), c$ 40.1002(2) $\AA, \alpha 83.3500(10), \beta 88.8670(10), \quad \gamma 85.8950(10)^{\circ}, \quad V$ $14571.15(17) \AA^{3}, D_{\mathrm{c}} 1.620 \mathrm{~g} \mathrm{~cm}^{-3}, Z 2$, crystal size 0.030 by 0.020 by $0.020 \mathrm{~mm}$, colour orange, habit block, temperature 100(2) Kelvin, $\lambda$ (Synchrotron) $0.6889 \AA$ A, $\mu$ (Synchrotron) $2.001 \mathrm{~mm}^{-1}$, $T$ (Analytical) $\min , \max 0.954206444679,1.0,2 \theta_{\max } 58.95, h k l$ range $-2121,-3434,-5757, N 247778$, $N_{\text {ind }} 87373\left(R_{\text {merge }} 0.0619\right), N_{\text {obs }} 46258(\mathrm{I}>2 \sigma(\mathrm{I})), N_{\text {var }} 4101$, residuals $^{*} R 1(F) 0.0781, w R 2\left(F^{2}\right)$ 0.2716, GoF(all) 0.984, $\Delta \rho_{\min , \max }-2.264,2.084 \mathrm{e}^{-} \AA^{-3}$.

${ }^{*} R 1=\Sigma\left\|F_{\mathrm{o}}|-| F_{\mathrm{c}}\right\| / \Sigma\left|F_{\mathrm{o}}\right|$ for $F_{\mathrm{o}}>2 \sigma\left(F_{\mathrm{o}}\right) ; w R 2=\left(\sum \mathrm{w}\left(F_{\mathrm{o}}{ }^{2}-F_{\mathrm{c}}{ }^{2}\right)^{2} / \Sigma\left(\mathrm{w} F_{\mathrm{c}}{ }^{2}\right)^{2}\right)^{1 / 2}$ all reflections, $\mathrm{w}=1 /\left[\sigma^{2}\left(F_{\mathrm{o}}{ }^{2}\right)+(0.1689 \mathrm{P})^{2}\right]$ where $\mathrm{P}=\left(F_{\mathrm{o}}{ }^{2}+2 F_{\mathrm{c}}{ }^{2}\right) / 3$

\section{Specific refinement details:}

The crystals of (corannulene) $)_{0.6} \cdot 2 \cdot 4 \mathrm{ReO}_{4} \cdot 6 \mathrm{NTf}_{2} \cdot 3.5 \mathrm{MeCN} \cdot 2.5 \mathrm{Et}_{2} \mathrm{O} \cdot \mathrm{H}_{2} \mathrm{O}$ [+ solvent] were grown by diffusion of diethyl ether into an acetonitrile solution of $\mathbf{2} \cdot 10 \mathrm{NTf}_{2}$ containing excess $\mathrm{TBAReO}_{4}$ and a large excess of corannulene. The crystals employed immediately lost solvent after removal from the mother liquor and rapid handling prior to flash cooling in the cryostream was required to collect data. Even so data were obtained to $0.7 \AA$ resolution by employing synchrotron radiation. The asymmetric unit was found to contain one complete $\mathrm{Co}_{5} \mathrm{~L}_{2}$ assembly, one partial occupancy corannulene molecule and associated counterions and solvent molecules.

Bond lengths and angles within the two chemically identical organic ligands were restrained to be similar to each other (excluding the corannulene portion of the organic ligands to which no restraints were applied). Thermal parameter restraints (SIMU, RIGU) were applied to all atoms except for cobalt and rhenium to facilitate anisotropic stable refinement. The occupancy of the stacked corannulene was initially refined and then fixed at the obtained value of ca. 0.6 (rounded to the nearest 0.1 ).

The anions within the structure show evidence of very substantial disorder. Almost all located anions were modelled as disordered over two or three locations with some lattice sites modelled as a mixture of perrhenate and triflimide. The occupancies of the disordered anions were allowed to refine freely and then fixed at the obtained values. Some additional minor occupancy positions of the anions could not be located in the electron density map and were not included in the model resulting in a discrepancy of 1.6 counterions per $\mathrm{Co}_{5} \mathrm{~L}_{2}$ assembly (included as triflimide in the formula since no large electron density S48 
peaks corresponding to rhenium remained). Some disordered atoms were modelled with isotropic thermal parameters and bond length and thermal parameter restraints were applied to facilitate a reasonable refinement. Many acetonitrile solvent molecules were also modelled as disordered over multiple locations and/or with partial occupancy. The hydrogen atoms of one disordered solvent molecule could not be located in the electron density map and were not included in the model.

Further reflecting the solvent loss there is a small amount of void volume in the lattice containing smeared electron density from disordered solvent. Consequently the SQUEEZE ${ }^{10}$ function of PLATON $^{11}$ was employed to remove the contribution of the electron density associated with this highly disordered solvent which gave a potential solvent accessible void of $978 \AA^{3}$ per unit cell (a total of approximately 314 electrons). Since the diffuse solvent molecules could not be assigned conclusively to acetonitrile or diethyl ether they were not included in the formula. Consequently, the molecular weight and density given above are likely to be slightly underestimated.

CheckCIF gives two B level alerts, both resulting from solvent molecules for which the hydrogen atoms were not modelled (singly bonded carbons).

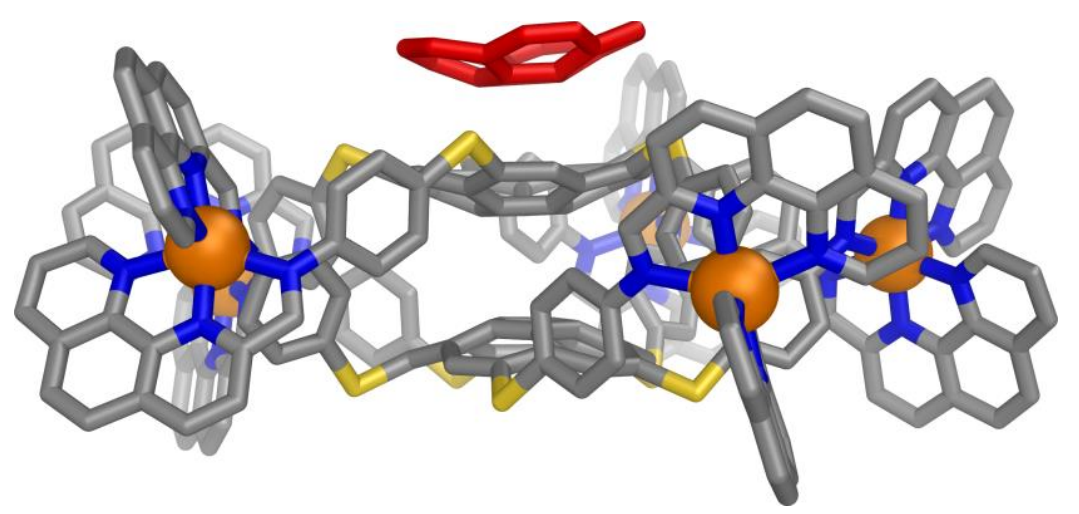

Figure S50: Side-on view of (corannulene) 2 from the crystal structure of (corannulene) $)_{0.6} \cdot 2 \cdot 4 \mathrm{ReO}_{4} \cdot 6 \mathrm{NTf}_{2} \cdot 3.5 \mathrm{MeCN} \cdot 2.5 \mathrm{Et}_{2} \mathrm{O} \cdot \mathrm{H}_{2} \mathrm{O}$ in stick representation. Counterions, solvents, hydrogen atoms and disorder are omitted for clarity. The stacked corannulene is colored red. 


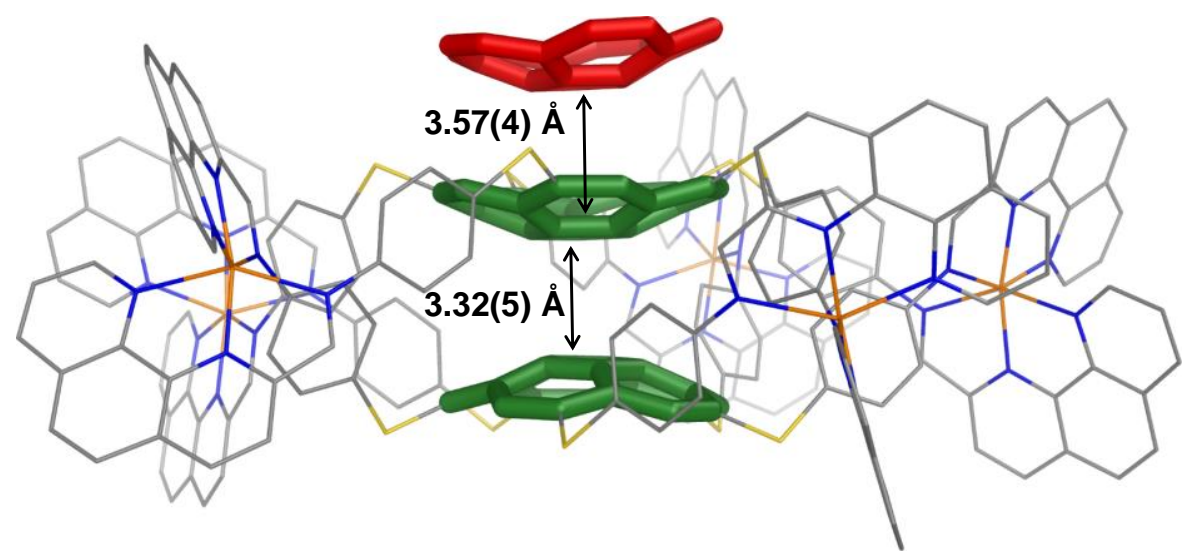

Figure S51: The structure of (corannulene) 2 from the crystal structure of (corannulene) $)_{0.6} \cdot 2 \cdot 4 \mathrm{ReO}_{4} \cdot 6 \mathrm{NTf}_{2} \cdot 3.5 \mathrm{MeCN} \cdot 2.5 \mathrm{Et}_{2} \mathrm{O} \cdot \mathrm{H}_{2} \mathrm{O}$ highlighting the arrangement of corannulenes. Counterions, solvents and disorder are omitted for clarity. Key distances between corannulenes are marked.

\section{$3 \cdot 2 \mathrm{CB}_{11} \mathrm{H}_{12} \cdot 8 \mathrm{NTf}_{2} \cdot 2.5 \mathrm{MeCN}[+$ solvent]}

Formula $\mathrm{C}_{253} \mathrm{H}_{161.50} \mathrm{~B}_{22} \mathrm{~F}_{48} \mathrm{~N}_{40.50} \mathrm{O}_{32} \mathrm{~S}_{26} \mathrm{Zn}_{5}, M$ 6590.95, Monoclinic, space group P 21/n (\#14), $a$ 24.5549(2), $b$ 26.5080(3), c 47.3015(5) ̊, $\beta$ 93.0730(10), V 30744.3(5) $\AA^{3}, D_{\mathrm{c}} 1.424 \mathrm{~g} \mathrm{~cm}^{-3}, Z 4$, crystal size 0.030 by 0.030 by $0.020 \mathrm{~mm}$, colour light orange, habit block, temperature 100(2) Kelvin, $\lambda$ (Synchrotron) $0.6889 \AA, \mu$ (Synchrotron) $0.601 \mathrm{~mm}^{-1}, T$ (Analytical) $\min , \max 0.990961230145,1.0$, $2 \theta_{\max } 34.86, h k l$ range $-2121,-2323,-4141, N 69371, N_{\text {ind }} 21123\left(R_{\text {merge }} 0.0766\right), N_{\text {obs }} 10356(\mathrm{I}$ $>2 \sigma(\mathrm{I})), N_{\text {var }} 3580$, residuals ${ }^{*} R 1(F) 0.1263, w R 2\left(F^{2}\right) 0.3866, \mathrm{GoF}($ all $) 1.121, \Delta \rho_{\text {min,max }}-0.482$, $0.783 \mathrm{e}^{-} \AA^{-3}$.

${ }^{*} R 1=\Sigma\left\|F_{\mathrm{o}}|-| F_{\mathrm{c}}\right\| / \Sigma\left|F_{\mathrm{o}}\right|$ for $F_{\mathrm{o}}>2 \sigma\left(F_{\mathrm{o}}\right) ; w R 2=\left(\Sigma \mathrm{w}\left(F_{\mathrm{o}}{ }^{2}-F_{\mathrm{c}}{ }^{2}\right)^{2} / \Sigma\left(\mathrm{w} F_{\mathrm{c}}{ }^{2}\right)^{2}\right)^{1 / 2}$ all reflections, $\mathrm{w}=1 /\left[\sigma^{2}\left(F_{\mathrm{o}}{ }^{2}\right)+(0.2000 \mathrm{P})^{2}+75.0000 \mathrm{P}\right]$ where $\mathrm{P}=\left(F_{\mathrm{o}}{ }^{2}+2 F_{\mathrm{c}}{ }^{2}\right) / 3$

\section{Specific refinement details:}

The crystals of $3 \cdot 2 \mathrm{CB}_{11} \mathrm{H}_{12} \cdot 8 \mathrm{NTf}_{2} \cdot 2.5 \mathrm{MeCN}$ [+ solvent] were grown by diffusion of diethyl ether into an acetonitrile solution of $\mathbf{3} \cdot 10 \mathrm{NTf}_{2}$ containing excess $\mathrm{CsCB}_{11} \mathrm{H}_{12}$. The crystals employed immediately lost solvent after removal from the mother liquor and rapid handling prior to flash cooling in the cryostream was required to collect data. Despite these measures and the use of synchrotron radiation few reflections at greater than 1.15 A resolution were observed and the data were trimmed accordingly. 
Nevertheless, the quality of the data is far more than sufficient to establish the connectivity of the structure. The asymmetric unit was found to contain one complete $\mathrm{Zn}_{5} \mathrm{~L}_{2}$ assembly and associated counterions and solvent molecules.

Due to the less than ideal resolution, extensive restraints were required to facilitate realistic modeling for the organic parts of the structure. The GRADE program ${ }^{12}$ was employed using the GRADE Web Server ${ }^{13}$ to generate a full set of bond distance and angle restraints (DFIX, DANG, FLAT) for the organic ligand arms (excluding the corannulene portion of the organic ligands to which no restraints were applied). Thermal parameter restraints (SIMU, RIGU) were applied to all atoms except for zinc to facilitate anisotropic stable refinement. Even with these restraints some thermal parameters remain larger than ideal as a consequence of the high level of thermal motion or minor unresolved disorder present throughout the structure resulting in a large average Ueq value for the main residue.

The anions within the structure also show evidence of disorder. Three of the triflimide anions were modelled as disordered over two locations and the other two were modelled with partial occupancy. The occupancies of the disordered anions were allowed to refine freely and then fixed at the obtained values. Some disordered atoms were modelled with isotropic thermal parameters and bond length and thermal parameter restraints were applied to facilitate a reasonable refinement. The $\mathrm{CB}_{11} \mathrm{H}_{12}{ }^{-}$anions were modelled as rigid groups; for these anions the carbon site could not be clearly discerned from the electron density map so all atoms of the $\mathrm{CB}_{11} \mathrm{H}_{12}{ }^{-}$anions were modelled as boron. Some acetonitrile solvent molecules were also modelled with partial occupancy. The hydrogen atoms of one of these acetonitrile molecules could not be located in the electron density map and were not included in the model.

A further 4.4 anions per $\mathrm{Zn}_{5} \mathrm{~L}_{2}$ assembly remain unaccounted for and no satisfactory model for these anions could be obtained despite numerous attempts at modelling, including with rigid bodies. Therefore the SQUEEZE ${ }^{10}$ function of PLATON ${ }^{11}$ was employed to account for the highly disordered anions and further disordered solvent molecules, which gave a potential solvent accessible void of 7641 $\AA^{3}$ per unit cell (a total of approximately 2217 electrons). These anions are included as triflimide in the formula given above. Since the diffuse solvent molecules could not be assigned conclusively to acetonitrile or diethyl ether they were not included in the formula. Consequently, the molecular weight and density given above are likely to be underestimated.

CheckCIF gives $8 \mathrm{~A}$ and $9 \mathrm{~B}$ level alerts. These alerts (both A and B level) all result from the limited data resolution, the solvent molecule for which the hydrogen atoms were not modelled, thermal motion and/or unresolved disorder of some anions and solvent molecules and the generally high level of thermal motion present throughout the structure as described above. 

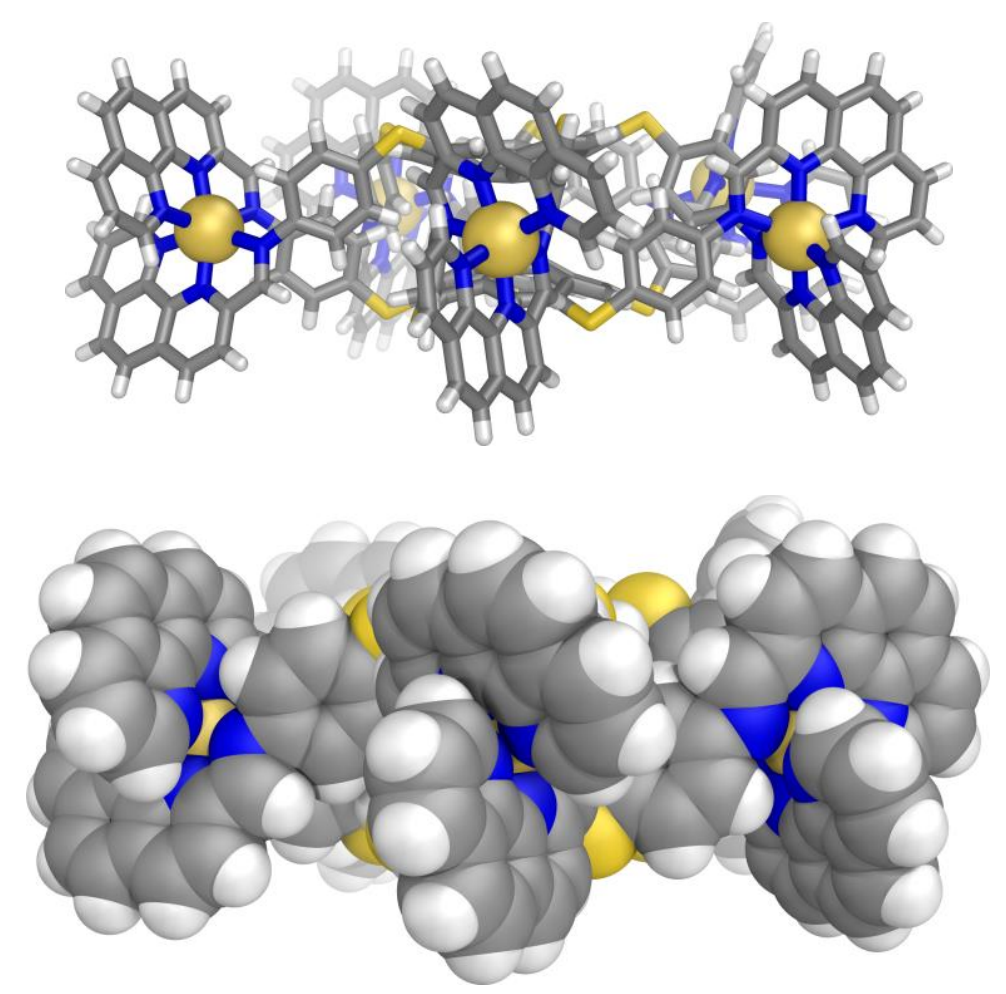

Figure S52: Side-on views of 3 from the crystal structure of $3 \cdot 2 \mathrm{CB}_{11} \mathrm{H}_{12} \cdot 8 \mathrm{NTf}_{2} \cdot 2.5 \mathrm{MeCN}$ in stick and space-filling representations. Counterions, solvents and disorder are omitted for clarity. The structure is similar to that of $\mathbf{2}$ in the structures of $\mathbf{2} \cdot$ coronene $\cdot 10 \mathrm{BF}_{4} \cdot 20.5 \mathrm{MeCN} \cdot \mathrm{Pr}_{2} \mathrm{O}$ (Figure 1 in main text, Figures S43-S45), $\mathbf{2} \cdot 10 \mathrm{ClO}_{4} \cdot 3 \mathrm{MeCN}$ (Figure S49) and $\mathbf{2} \cdot 10 \mathrm{BF}_{4} \cdot 11 \mathrm{MeCN}$ (Figure Figure S48).
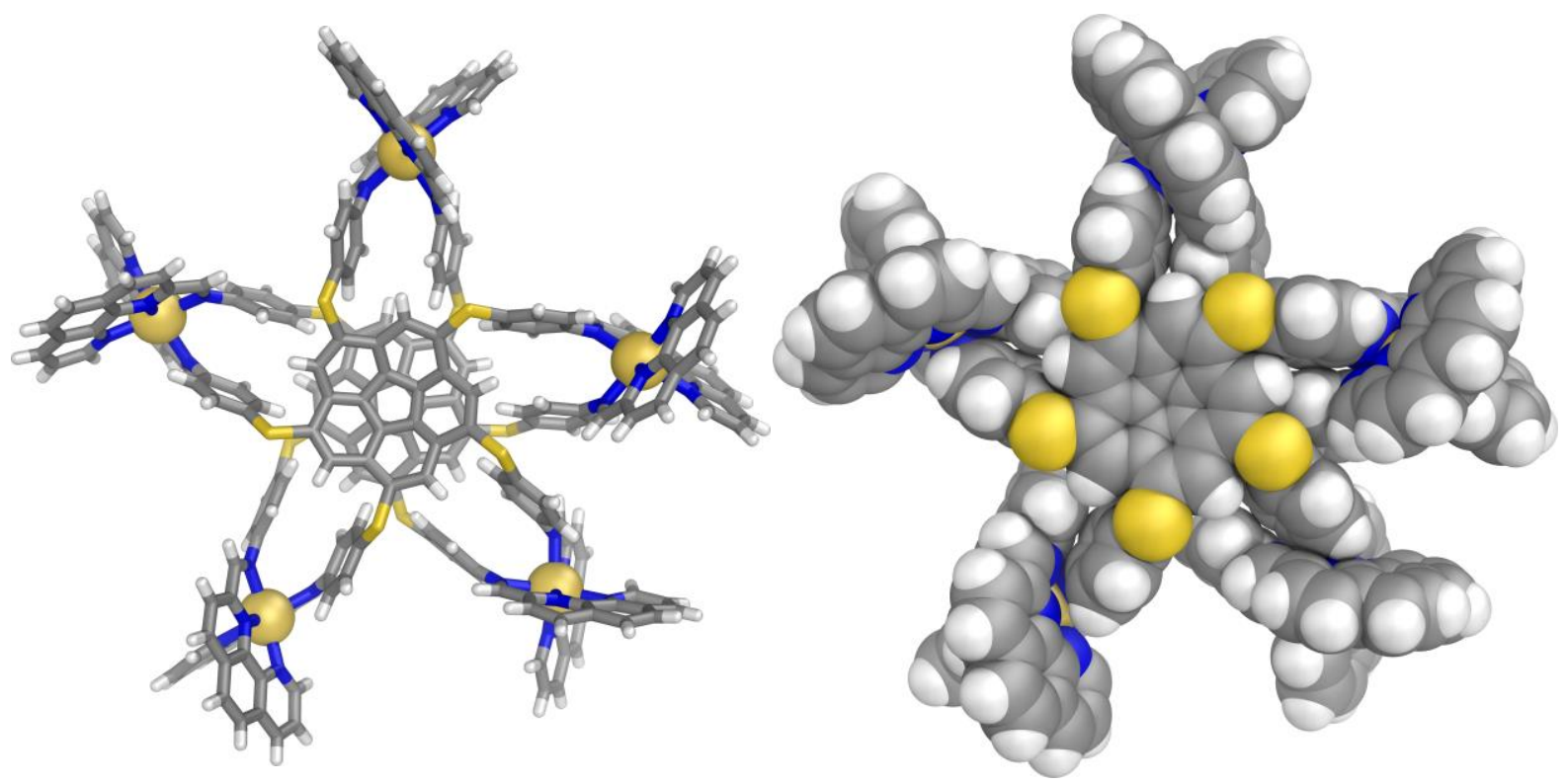

Figure S53: Top views of 3 from the crystal structure of $3 \cdot 2 \mathrm{CB}_{11} \mathrm{H}_{12} \cdot 8 \mathrm{NTf}_{2} \cdot 2.5 \mathrm{MeCN}$ in stick and space-filling representations. Counterions, solvents and disorder are omitted for clarity. The structure is similar to that of $\mathbf{2}$ in the structures of $\mathbf{2} \cdot$ coronene $10 \mathrm{BF}_{4} \cdot 20.5 \mathrm{MeCN} \cdot \mathrm{Pr}_{2} \mathrm{O}$ (Figure 1 in main text, Figures S43-S45), $\mathbf{2} \cdot 10 \mathrm{ClO}_{4} \cdot 3 \mathrm{MeCN}$ (Figure S49) and $\mathbf{2} \cdot 10 \mathrm{BF}_{4} \cdot 11 \mathrm{MeCN}$ (Figure Figure S48). 


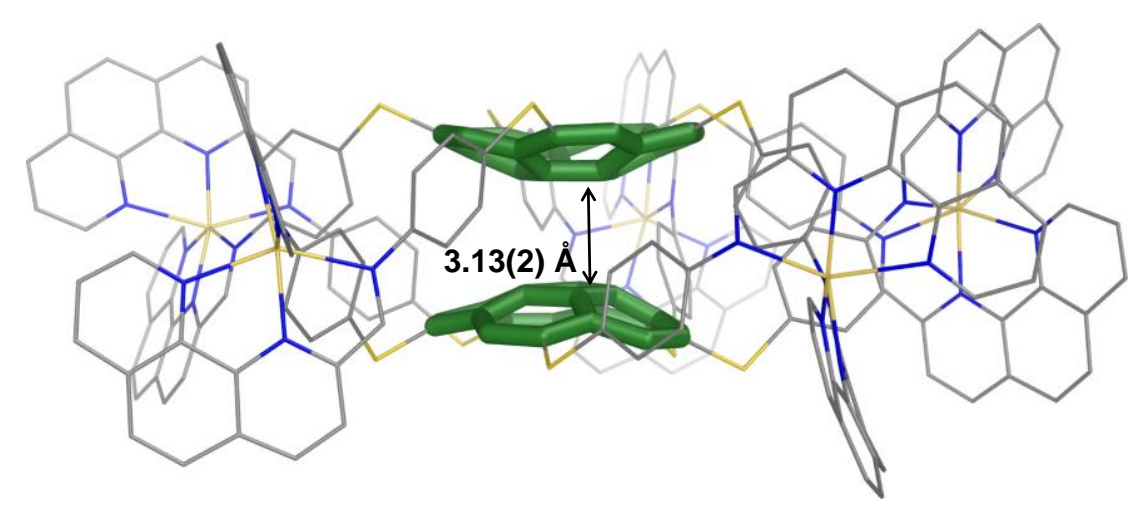

Figure S54: The structure of $\mathbf{3}$ from the crystal structure of $3 \cdot 2 \mathrm{CB}_{11} \mathrm{H}_{12} \cdot 8 \mathrm{NTf}_{2} \cdot 2.5 \mathrm{MeCN}$ highlighting the arrangement of corannulenes. Counterions, solvents and disorder are omitted for clarity. The distance between the corannulenes is marked, highlighting the absence of a cavity in the solid state.

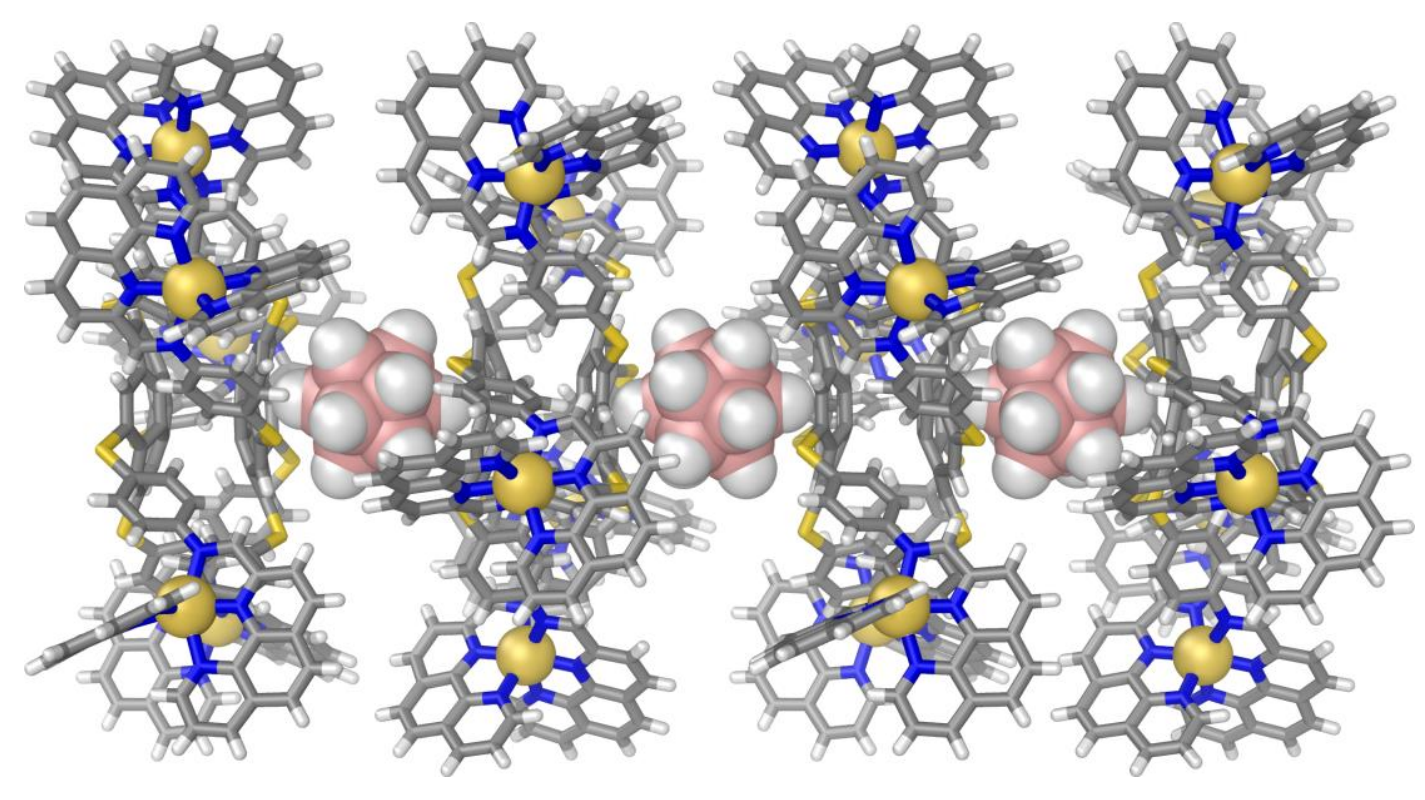

Figure S55: Crystal packing within the crystal structure of $3 \cdot 2 \mathrm{CB}_{11} \mathrm{H}_{12} \cdot 8 \mathrm{NTf}_{2} \cdot 2.5 \mathrm{MeCN}$ showing the 1D stacking of 3 with the $\mathrm{CB}_{11} \mathrm{H}_{12}{ }^{-}$counterions along the $\mathrm{b}$ axis. Other counterions, solvents and disorder are omitted for clarity. No significant interaction was observed between 3 and $\mathrm{CB}_{11} \mathrm{H}_{12}{ }^{-}$in solution by $1 \mathrm{H}$ NMR. 


\section{Computational methods}

Full geometry optimizations were performed and uniquely characterized via second derivatives (Hessian) analysis to establish stationary points. Several Density Functional types were investigated in this work, including, B3LYP,${ }^{14}$ B3LYP-D3, ${ }^{15}$ and B97-D ${ }^{16}$ together with an ultrafine grid. The 6$31 \mathrm{G}(\mathrm{d}, \mathrm{p})$ basis $\operatorname{set}^{17}$ (7640 basis functions) and TZVP ${ }^{18}$ basis set (9430 basis functions) were used for optimization and single point analysis, including effects of solvent. Effects of solvent employed the COSMO: $a b$ initio continuum method ${ }^{19}$ with the dielectric constant as in experiment. Visualization and analysis of structural and property results were obtained using GaussView ${ }^{20}$ and WebMO. ${ }^{21}$ 


\section{References}

1. Sibi, M. P.; Petrovic, G., Enantioselective radical reactions: the use of metal triflimides as Lewis acids. Tetrahedron: Asymmetry 2003, 14, 2879.

2. $\quad$ Seiders, T. J.; Baldridge, K. K.; Elliott, E. L.; Grube, G. H.; Siegel, J. S., Synthesis and Quantum Mechanical Structure of sym-Pentamethylcorannulene and Decamethylcorannulene. J. Am. Chem. Soc. 1999, $121,7439$.

3. Allan, D.; Nowell, H.; Barnett, S.; Warren, M.; Wilcox, A.; Christensen, J.; Saunders, L.; Peach, A.; Hooper, M.; Zaja, L.; Patel, S.; Cahill, L.; Marshall, R.; Trimnell, S.; Foster, A.; Bates, T.; Lay, S.; Williams, M.; Hathaway, P.; Winter, G.; Gerstel, M.; Wooley, R., A Novel Dual Air-Bearing Fixed- $\chi$ Diffractometer for Small-Molecule Single-Crystal X-ray Diffraction on Beamline I19 at Diamond Light Source. Crystals 2017, 7, 336.

4. (a) Collaborative Computational Project, N., The CCP4 suite: programs for protein crystallography. Acta Cryst. 1994, D50, 760; (b) Evans, P., Scaling and assessment of data quality. Acta Cryst. 2006, D62, 72; (c) Winter, G., xia2: an expert system for macromolecular crystallography data reduction. J. Appl. Crystallogr. 2010, 43, 186.

5. Farrugia, L., WinGX and ORTEP for Windows: an update. J. Appl. Crystallogr. 2012, 45, 849.

6. Evans, P. R.; Murshudov, G. N., How good are my data and what is the resolution? Acta Cryst. 2013, D69, 1204.

7. Winn, M. D.; Ballard, C. C.; Cowtan, K. D.; Dodson, E. J.; Emsley, P.; Evans, P. R.; Keegan, R. M.; Krissinel, E. B.; Leslie, A. G. W.; McCoy, A.; McNicholas, S. J.; Murshudov, G. N.; Pannu, N. S.; Potterton, E. A.; Powell, H. R.; Read, R. J.; Vagin, A.; Wilson, K. S., Overview of the CCP4 suite and current developments. Acta Cryst. 2011, D67, 235.

8. Sheldrick, G., SHELXT - Integrated space-group and crystal-structure determination. Acta. Cryst. 2015, A71, 3.

9. Sheldrick, G. M., Crystal structure refinement with SHELXL. Acta. Cryst. 2015, C71, 3.

10. van der Sluis, P.; Spek, A. L., BYPASS: an effective method for the refinement of crystal structures containing disordered solvent regions. Acta Cryst. 1990, A46, 194.

11. Spek, A. L., PLATON: A Multipurpose Crystallographic Tool. Utrecht University: Utrecht, The Netherlands, 2008.

12. Bricogne, G.; Blanc, E.; Brandle, M.; Flensburg, C.; Keller, P.; Paciorek, W.; Roversi, P.; Sharff, A.; Smart, O. S.; Vonrhein, C.; Womack, T. O., BUSTER. 2.11.2 ed.; Global Phasing Ltd.: Cambridge, United Kingdom, 2011.

13. Smart, O. S.; Womack, T. O., Grade Web Server. Global Phasing Ltd. : 2014.

14. Becke, A. D., Density-Functional Thermochemistry .3. the Role of Exact Exchange. J. Chem. Phys. 1993, 98, 5648.

15. Grimme, S.; Antony, J.; Ehrlich, S.; Krieg, H., A consistent and accurate ab initio parametrization of density functional dispersion correction (DFT-D) for the 94 elements H-Pu. J. Chem. Phys. 2010, 132.

16. Grimme, S., Semiempirical GGA-type density functional constructed with a long-range dispersion correction. J. Comput. Chem. 2006, 27, 1787.

17. Petersson, G. A.; Al-Laham, M. A., A complete basis set model chemistry. II. Open-shell systems and the total energies of the first-row atoms. J. Chem. Phys. 1991, 94, 6081.

18. Weigend, F.; Ahlrichs, R., Balanced basis sets of split valence, triple zeta valence and quadruple zeta valence quality for $\mathrm{H}$ to $\mathrm{Rn}$ : Design and assessment of accuracy. PCCP 2005, 7, 3297.

19. (a) Klamt, A.; Schüürmann, G., COSMO: A new approach to dielectric screening in solvents with explicit expressions for the screening energy and its gradient. J. Chem.Soc., Perkin Trans. 2 1993, 799; (b) Baldridge, K.; Klamt, A., First principles implementation of solvent effects without outlying charge error. J. Chem. Phys. 1997, 106, 6622.

20. Dennington, R.; Keith, T. A.; Millam, J. M., GaussView, Version 6. Semichem Inc.: Shawnee Mission, KS, 2016.

21. Cundari, T.; Schmidt, J. R., WEBMO: www.webmo.net. 